\title{
An Assessment of the Risk of Transporting Plutonium Dioxide by Cargo Aircraft
}

\author{
T. I. McSweeney \\ J. F. Johnson
}

June 1977

Prepared for the Energy Research and Development Administration under Contract EY-76-C-06-1830 


\title{
NOTICE
}

This report was prepared as an account of work sponsored by the United States Covernment. Neither the United States nor the Energy Research and Development Administration, nor any of their employees, nor any of their contractors, subcontractors, or their employees, makes any warranty, express or implied, or assumes any legal liability or responsibility for the accuracy, completeness or usefulness of any information, apparatus, product or process disclosed, or represents that its use would not infringe privately owned rights.

\author{
PACIFIC NORTHWEST LABORATORY \\ operated by \\ BATTELLE \\ for the \\ ENERGY RESEARCH AND DEVELOPMENT ADMINISTRATION \\ Under Contract EY-76-C-06-1830
}

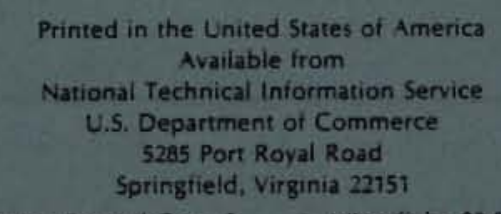

Price: Printed Copy S__; Microfiche $\$ 3.00$

$\begin{array}{cc}\text {-Pages } & \text { NTIS } \\ \text { Selling Price } \\ 001-025 & \$ 4.50 \\ 026-050 & \$ 5.00 \\ 051-075 & \$ 5.50 \\ 076-100 & \$ 6.00 \\ 101-125 & \$ 6.50 \\ 126-150 & \$ 7.00 \\ 151-175 & 57.75 \\ 176-200 & \$ 8.50 \\ 201-225 & \$ 8.75 \\ 226-250 & 59.00 \\ 251-275 & 570.00 \\ 276-300 & \$ 10.25\end{array}$


BNWL -2030

UC -71

\section{7}

AN ASSESSMENT OF THE RISK OF TRANSPORTING

PLUTONIUM DIOXIDE BY CARGO AIRCRAFT

T. I. McSweeney

J. F. Johnson

June 1977

BATTELLE

Pacific Northwest Laboratories

Richland, Washington 99352 


\section{PREFACE}

This document is the third in a series of risk assessments dealing with the shipment of potentially hazardous energy materials. Work done on the initial study, An Assessment of the Risk of Transporting Plutonium Oxide and Liquid Plutonium Nitrate by Truck, (BNWL-1846), forms the basis for the series. This study, being an extension of the first, relies heavily on that work. The authors and technical contributors of the first study, therefore, deserve credit for much of the material that was used in this risk assessment.

This study was initially issued in draft form and released on a 1 imited basis for comments. Comments received from reviewers were evaluated and wherever possible revisions were made in the draft document to increase clarity and technical credibility. Some comments were not included because it was determined that the changes suggested, although technically valid, would not significantly increase the accuracy or credibility of the results. We thank all of those who took time to review the document and respond. 
LIST OF FIGURES

i i

LIST OF TABLES

1.0 INTRODUCTION

2.0 SUMMARY

3.0 RISK ANALYSIS MODEL

3.1 RISK MODEL DESCRIPTION

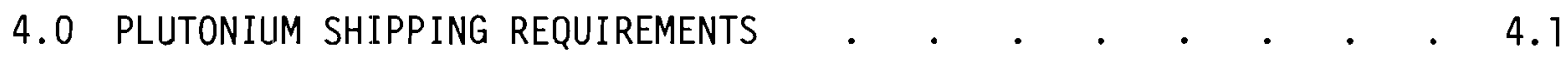

4.1 NUCLEAR INDUSTRY CHARACTERISTICS . . . . . . . . 4.1

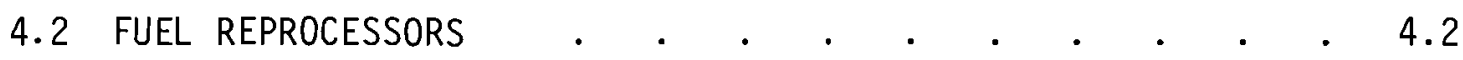

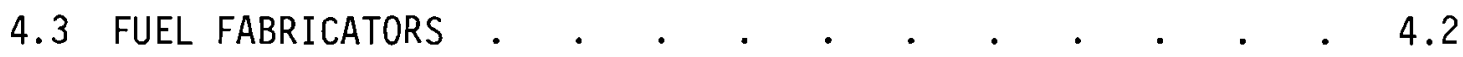

4.4 PLUTONIUM SHIPPING DISTANCES.$\quad \cdot \quad \cdot \quad \cdot \quad \cdot \quad \cdot \quad \cdot \quad \cdot 4.3$

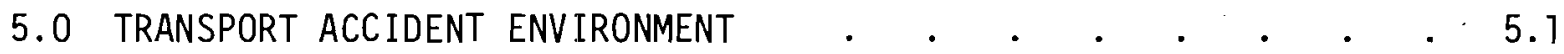

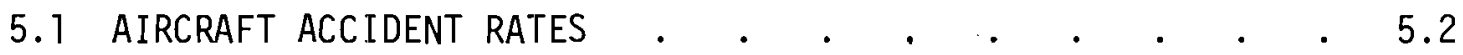

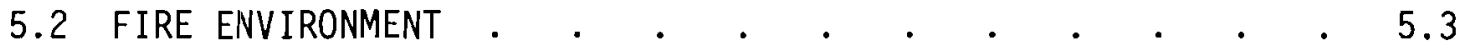

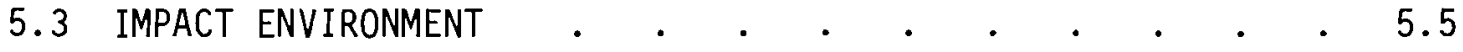

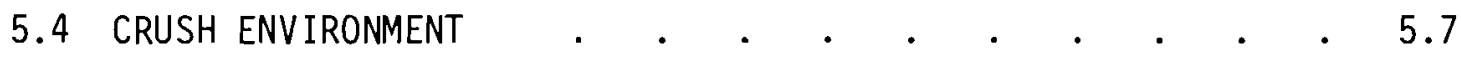

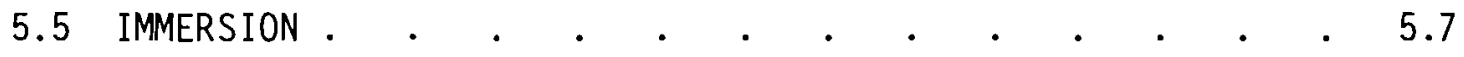

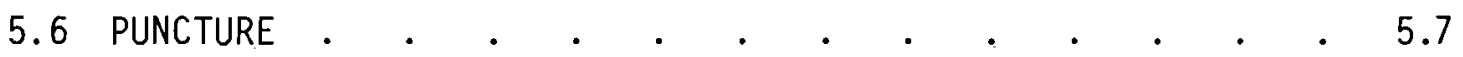

6.0 PACKAGE FAILURE THRESHOLDS . . . . . . . . . . . . . . 6.1

6.1 OUTER DRUM FAILURE THRESHOLDS . . . . . . . 6.3

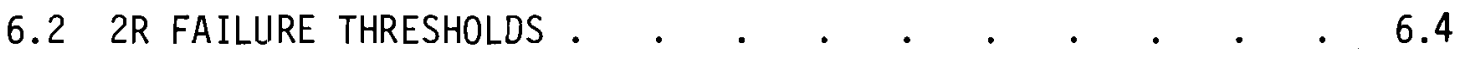

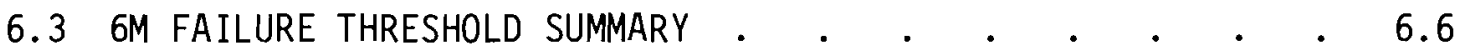

7.0 CONDITIONS OF PACKAGES DURING TRANSPORT.$\quad \cdot \quad \cdot \quad \cdot \quad \cdot \quad \cdot 7.1$

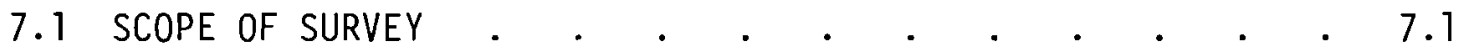

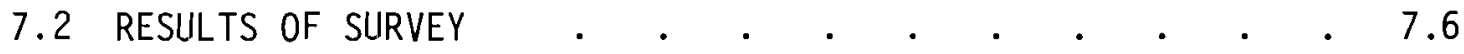

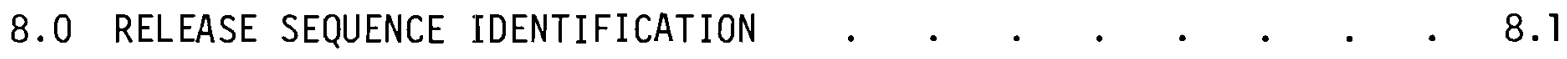

8.1 FAULT TREE CONSTRUCTION

8.2 FAULT TREES FOR SHIPMENT OF PUO ${ }_{2}$ IN $6 M$ CONTAINERS.$\quad \cdot \quad \cdot 8.2$

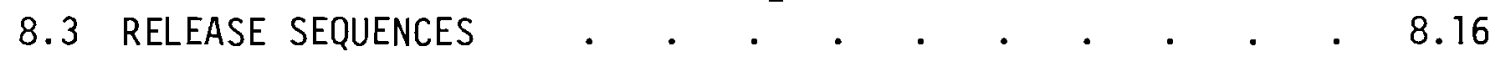

9.0 RELEASE SEQUENCE EVALUATION

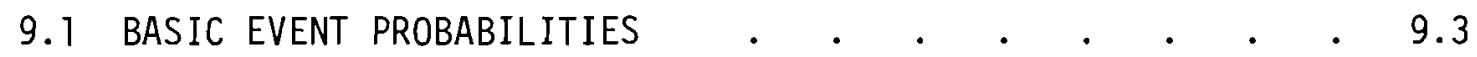

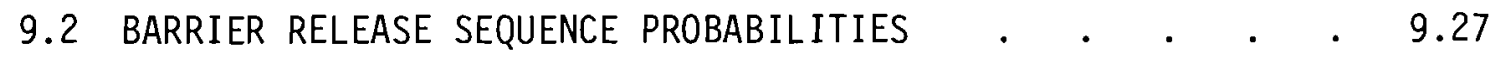




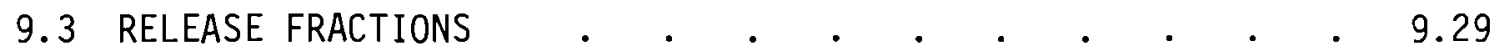

9.4 SUMMARY OF RELEASE SEQUENCE EVALUATIONS . . . . . $\quad . \quad 9.30$

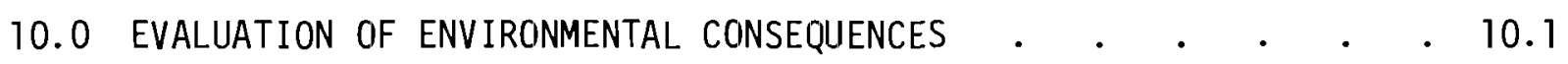

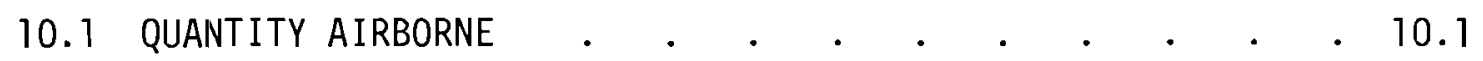

10.2 METEOROLOGY . . . . . . . . . . . . . . . 10.4

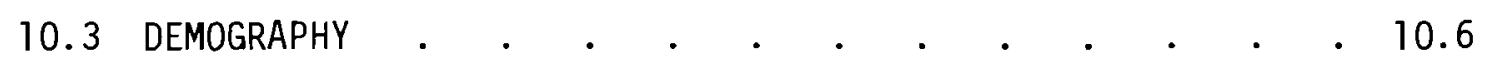

10.4 INDIVIDUAL AND POPULATION DOSE FACTORS . . . . 10.15

10.5 POPULATION HEALTH EFFECTS . . . . . . . . . . 10.24

10.6 ESTIMATED EXPOSURE FREQUENCY . . . . . . . . 10.28

11.0 THE RISK OF SHIPPING PLUTONIUM DIOXIDE BY AIR . . . . . 11.1

11.1 SYSTEM DESCRIPTION . . . . . . . . . . . . . 11.2

11.2 RISK EVALUATIONS FOR PLUTONIUM DIOXIDE SHIPMENTS BY

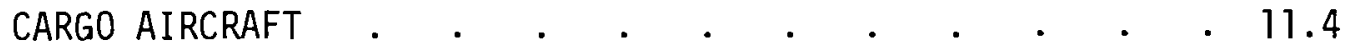

11.3 RISK CALCULATIONAL UNCERTAINTIES . . . . . . . 11.9

11.4 RISK SENSITIVITY EVALUATIONS . . . . . . . . . . . . 11.12

11.5 COMPARISON OF PLUTONIUM SHIPMENT RISKS FOR TRUCK AND CARGO AIRCRAFT .. . . . . . . . . . 11.15

APPENDIX A DESCRIPTION OF 6M PACKAGE USED TO SHIP PUO 2 - • • - A.1 $\begin{array}{lll}\text { APPENDIX B } & \begin{array}{l}\text { PHYSICAL AND CHEMICAL PROPERTIES OF } \\ \text { PLUTONIUM DIOXIDE }\end{array}\end{array}$ APPENDIX C MECHANICAL ANALYSIS OF THE 6M CONTAINER . . . . . . . C.1 


\section{LIST OF FIGURES}

2.1 Risk Spectra for Plutonium Shipments in the Early 1980s for the Entire U.S. and Other Activities . . . . . 2.3

3.1 Model to Calculate the Risk of Shipping Nuclear Material a . 3.2

3.2 Information Required to Describe Transport System $\quad . \quad$ • $\quad$ • $\quad 3.5$

5.1 Cumulative Distribution of Fire Duration for Aircraft Accidents Involving Fire . . . . . . . . . 5.4

5.2 Cumulative Distribution of Impact Forces Yielding an Environment $<\mathrm{v} \mathrm{ft} / \mathrm{sec}$ onto an Unyielding Target Given that an Airçraft Accident has Occurred . . . . . . . 5.6

5.3 Cumulative Distribution of Immersion Depth for Al1 Accident Classifications

7.1A Fault Tree for L-10 Plutonium Nitrate Solution Package Closure Analysis

7.1B Fault Tree for L-10 Plutonium Nitrate Solution Package Closure Analysis (Part 2) . . . . . . . . 7.4

7.2 Fault Tree for 6M Plutonium Dioxide Package Closure Analysis. $\quad 7.5$

8.1 Fault Tree for the Shipment of Plutonium Dioxide in the $6 \mathrm{M}$ Container . . . . . . . . . . 8.3

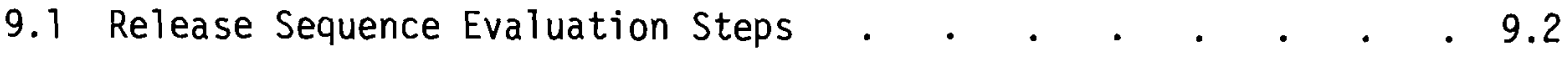

9.2 Screening Process Schematic . . . . . . . . . . . . . . 9.28

10.1 Release Sequence Evaluation Steps 10.2 . 10.2

10.2 Fuel Reprocessing Sites and Plutonium Fuel Fabrication

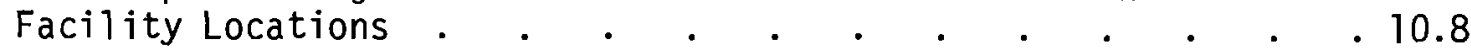

11.1 Risk Spectrum for Shipping One Metric Ton of Plutonium 1500 Miles Across the U.S. . . . . . . . 11.8

11.2 Kisk Spectrum for Plutonium Shipments in the Early 1980s for the Entire U.S. Single Container Analysis . . . . 11.10

11.3 Risk Spectrum Evaluation of Single and Multiple Container Failure from Impact Forces Imposed on the $6 \mathrm{M}$ in the Accident Environment 
11.4 Sensitivity of the Risk Spectrum Curves to Several

Parameters for Plutonium Dioxide Shipments in the

$6 \mathrm{M}$ Container

11.5 Risk Spectrum for Shipping One Metric Ton of Plutonium

Dioxide by Cargo Aircraft 1500 Miles Across the North

Central and Southeastern U.S. . . . . . . . . 11.16

11.6 Risk Spectrum for Plutonium Shipments in the Early 1980s

for the Entire U.S. . . . . . . . . . . 11.16

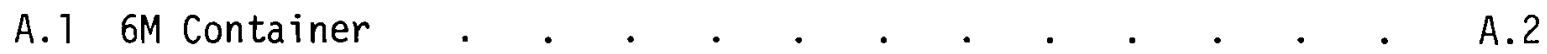

B. 1 Plutonium Dioxide Particle Size Distribution Formed

by Calcination of Plutonium 0xalate . . . . . . B.2

C.1 She 11 Deformation from Impact Versus Drop Height for the 6M Container

C.2 Deformation of Inner Vessel from Impact as a Function of Drop Height - 6M Container 


\section{$\underline{\text { LIST OF TABLES }}$}

4.1 Nuclear Industry Characteristics. . . . . . . . 4.1

4.2 Location of Plutonium Fuel Fabrication Facilities . . . 4.2

4.3 Estimated Route Distances Between Fuel Reprocessors . . . 4.4

5.1 Accident Rate by Flight Operations . . . . . . . 5.2

5.2 Fire Frequency, Given an Aircraft Accident Classification . 5.4

5.3 Frequency of Occurrence of Accident Generated

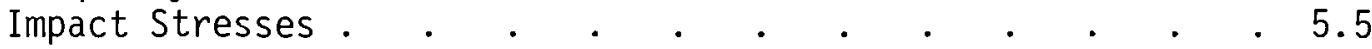

5.4 Estimated Likelihood of Impacting Various Surfaces for the Three Accident Classifications Posing an Impact Environment . 5.6

5.5 Likelihood of Irrmersion for Selected Accident

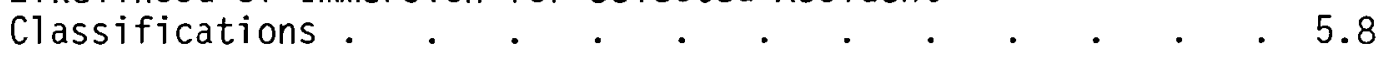

$6.16 \mathrm{M}$ Test Results. . . . . . . . . . . . . . . 6.5

6.2 LLD-1 Test Results . . . . . . . . . . . 6.5

6.3 Failure Thresholds for 15-Gal 6M Shipping Containers. . . 6.7

7.1 Fault Tree Symbolism. . . . . . . . . . . . . 7.2

7.2 Estimated Number of Shipments and Packages Included in Survey . . . . . . . . . . . . . 7.8

7.3 Data Bank - Package Closure Experience Obtained by Survey • 7.9

8.1 Listing of Basic Events for 6M Analysis. . . . . . 8.13

10.1 Average Windspeed/Stability Characteristics . . . . . 10.6

10.2 New Jersey Population Characteristics - 1960 . . . . 10.9

10.3 Massachusetts Population Characteristics - 1960 . . . . 10.9

10.4 Missouri Population Characteristics - 1960 . . . . . 10.10

10.5 Washington Population Characteristics - 1960 . . . . 10.10

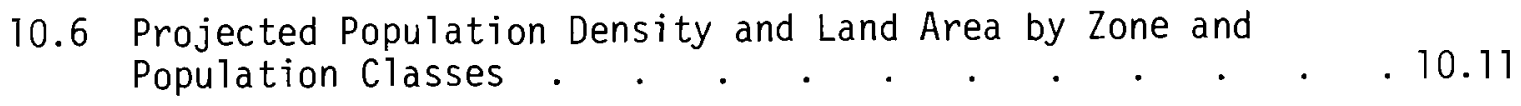

10.7 Average Population Densities by Zone . . . . . . 10.12 
10.8 Projected Land Area of Urban Areas in the Four Zones of the U.S.

10.9 Fractional Shipping Route Mileage by Population Zones . . 10.13

10.10 Distribution of Ascent, Descent, Takeoff and Landing Accidents Occurring in Selected Demographic Zones

10.11 Dose Conversion Factors for Inhalation of Plutonium and $241_{A m}$ I sotopes . . . . . . . . . . . . . 10.18

10.12 Reference Mixture of Plutonium and Americium . . . . 10.19

10.13 Dose Conversion Factors for Inhalation of Reference

10.14 Values of $\sigma_{y}$ for Pasquill Stability Categories . . . . . 10.21

10.15 Values of $\sigma_{z}$ for Pasquill Stability Categories . . . . 10.21

10.16 Land Areas Within Isopleths of a Release Plume and More
Than $100 \mathrm{~m}$ from the Release Point . . . . . . 10.23

10.17 Land Area Contaminated Within $100 \mathrm{~m}$ of Accident Scene and Centerline Value of UE/Q at $100 \mathrm{~m}$ Versus Pasquil1 Stability Classification

10.18 Estimated Numbers of Deaths per Year in the U.S. Population Attributable to Continual Exposure at a Rate of $0.1 \mathrm{rem} / \mathrm{yr}$ from Leukemia and from all Other

10.19 Assumed Values Used in Calculating Estimates of Risk Shown in Table 10.18. . . . . . . . . . . 10.26

10.20 Cancer Risk Estimates for Plutonium in Man . . . . . . 10.27

11.1 Shipping Characteristics for 6M Assumed for Analysis . $\quad 11.3$

11.2 Characteristics of a Composite U.S. Route for Plutonium Transport in the Early 1980s

11.3 Risk Sensitivity Cases for Dioxide Shipments in the U.S. in the Early 1980s . . . . . . . . . 11.13

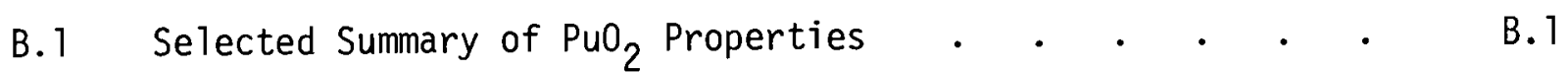




\subsection{INTRODUCTION}

Radioactive materials, in a variety of physical and chemical forms are routinely transported between nuclear facilities. The safety record for these shipments has been excellent. As the nuclear industry grows, it is expected that the number of shipments made annually will increase. In the interest of continuing to insure the health and safety of the general public, the nuclear industry and government agencies are continually improving their level of understanding of the safety-related aspects of transporting radioactive materials.

Research programs are one method of improving the level of understanding. Such a research program is being conducted by Battelle-Northwest for the Transportation Branch of the ERDA Division of Environmental Control Technology. The objective of this continuing program is to develop a methodology for quantitatively assessing the safety of transporting radioactive materials and to apply it to current and future shipping systems. A previous report ${ }^{(1)}$ described the methodology developed for quantitatively assessing the safety of transporting radioactive materials and applied it to the transport of solid plutonium dioxide and liquid plutonium nitrate by truck. Most plutonium being shipped today is being shipped by truck. As plutonium transportation requirements increase, increased utilization of other modes, such as rail and air, may become desirable. This report presents an assessment of the risk in shipment of plutonium dioxide by cargo aircraft. Comparison to the risk in truck shipment is also made.

Cargo aircraft shipment requires truck transport to or from the nearest cargo air terminal. The risk associated with the truck links must be included in the air risk to make the comparison meaningful. Previous studies $(1)$ have evaluated the risk of transporting plutonium dioxide by truck. On a per mile basis, the risk of transporting plutonium dioxide to or from the air terminal is unchanged from the previous analysis. Thus most sections of this report will consider air transport solely. In Section 11.4, the risk arising from the truck transport segment wil1 be 
added to the air transport segment. Then the total air transport system wi11 be compared with truck transport.

Risk, as used in this report, is the product of the magnitude of the possible loss and the expected frequency of occurrence of the 10ss. As described in the initial report, (1) there are two measures of risk which are important. One is the total risk, obtained by summing the risk associated with each particular loss. The other is the risk spectrum. A risk spectrum curve plots the expected frequency of $\mathrm{N}$ or more fatalities as a function of N. The risks associated with two activities are truly similar only if they have the same total risk (risk magnitude) and the same risk spectrum. Both risk measures are used in this report.

\section{REFERENCE}

1. T. I. McSweeney, R. J. Hall et al., An Assessment of the Risk of Transporting Plutonium Oxide and Liquid Plutonium Nitrate by Truck, BNWL-1846, Batte11e, Pacific Northwest Laboratories, Rich1and, WA, August 1975. 


\subsection{SUMMARY}

This report is the third of a series of reports evaluating the risk of transporting plutonium by various modes. The first report ${ }^{(1)}$ presented a methodology for assessing the risk of transporting radioactive materials and applied the methodology to the shipment of plutonium by truck. The second

report (2) applied the methodology to the shipment of plutonium by rail. This report presents the results for shipment of plutonium by cargo aircraft.

To enable easy comparison, all the plutonium shipping evaluations have used the same bases. In each, the results have been related to a future time--the early 1980s--when plutonium shipments are expected to be more frequent. The characteristics of the nuclear economy used in this analysis are:

- A total of 18 metric tons (MT) of plutonium is shipped annually, via the mode being evaluated.

- $100 \mathrm{~kg}$ of plutonium are transported per shipment. For air shipment, a truck and air segment are considered. The average shipping distance per shipment is 1,422 miles with $14 \%$ of the distance being by truck.

- Shipping systems and regulations are the same as in 1974.

- $\mathrm{PuO}_{2}$ is shipped in $6 \mathrm{M}$ containers.

The use of other shipping conditions, e.g., different shipping regulations could result in different risks than reported here.

For the purposes of this study, plutonium dioxide was assumed to be carried exclusively in the 15-gal version of the $6 \mathrm{M}$ container. Unless otherwise noted, a11 references to $6 \mathrm{M}$ containers in the report refer to this particular size. Appendix A gives a complete description of the shipping container.

In one respect, the air shipment report differs from the previous two. Since the two previous studies were completed, new regulations limiting the amount of plutonium shipped in liquid form have been drafted (10 CFR 71.42). These regulations will be in effect during the time period considered by this study and will not allow liquid nitrate shipments in the amounts assumed by 
the previous studies. Therefore, only aircraft shipments of plutonium dioxide powder were considered in this analysis.

Based on the shipping assumptions, the likelihood that an aircraft carrying a shipment will be involved in an accident is estimated to be about once in 450 years. For the projected shipping rate in the early 1980s, the likelinood of a release of plutonium as a result of shipment by air is one in 900 years for dioxide powder in the $6 \mathrm{M}$ container. The consequences of these postulated releases were estimated based on the amount of plutonium released to the environs, the probable weather conditions at the time of the accident, and the population density downwind from the accident scene. The likelihood and the consequences for these postulated releases have been coupled and expressed as a risk spectra.

Figure 2.1 shows the risk spectra for the plutonium dioxide shipments projected for the U.S. in the early 1980s. These curves can be compared to similar risk curves which are presented in the Rasmussen Report ${ }^{(3)}$ and the shipment of plutonium by other modes. Inspection of the curves indicates that the risks of shipping plutonium are small relative to other societal risks. For example, the risk curve for transporting chlorine is several orders of magnitude greater than that of transporting plutonium dioxide by air. The risk curve for the air shipment is similar to the risk curve for being killed by meteorites. The risk of death from normal air transport is many orders of magnitude above the risk added if plutonium dioxide was shipped by air. The curves also indicate that the likelihood of a plutonium release resulting in cancer death is approximately one in 15,000 years for $\mathrm{PuO}_{2}$ shipments in $6 \mathrm{M}$ containers.

The comparison of the truck and air transport modes for the same material showed truck tranport to have less risk. At the same time, the air transport of plutonium dioxide was demonstrated to have a lower risk than other commonly accepted societal risks. The major contributor to the overall risk spectra for air transport was a cargo airplane, carrying plutonium dioxide, crashing at high speed into hard rock. 


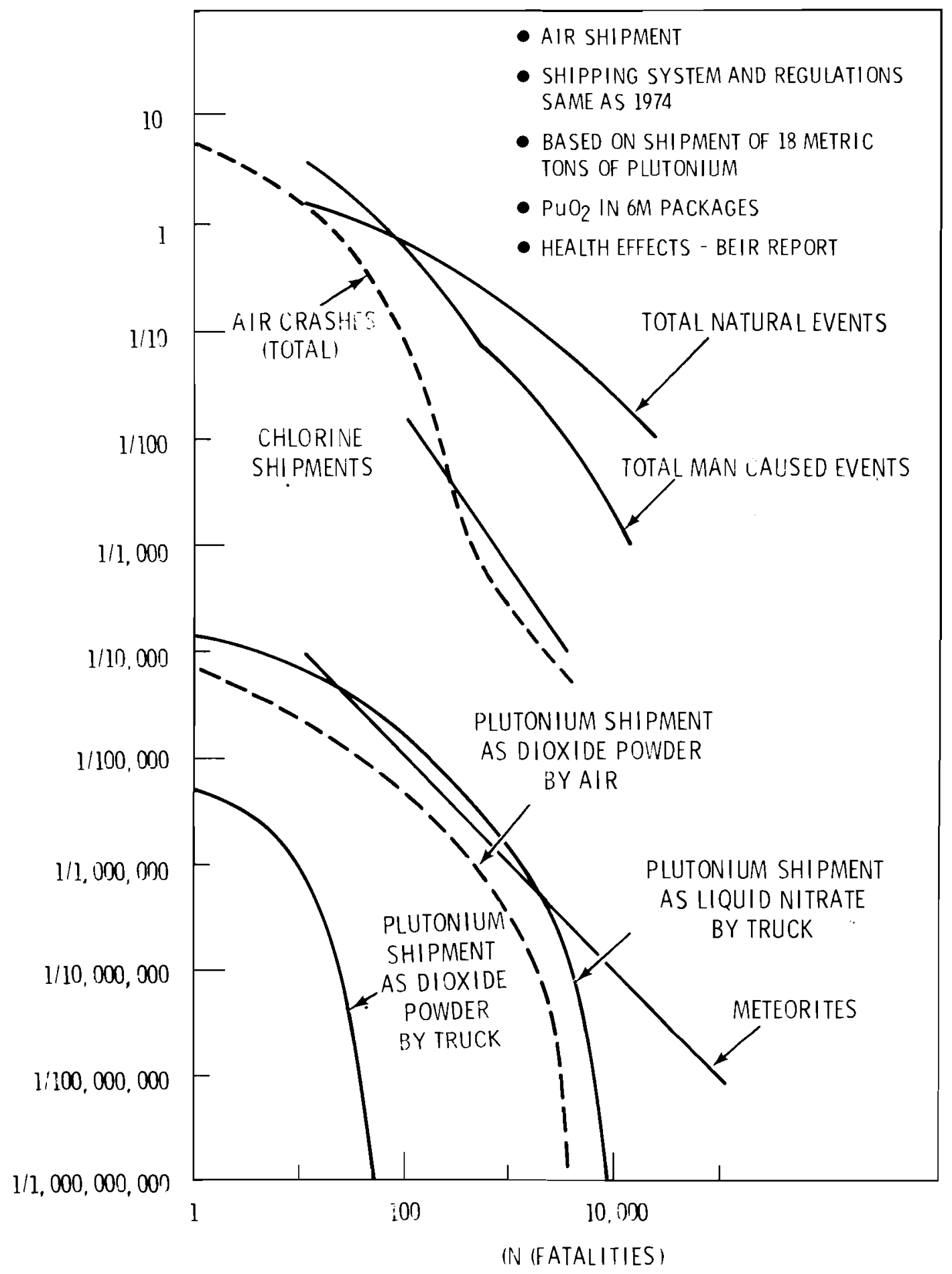

FIGURE 2.1. Risk Spectra for Plutonium Shipments in the Early 1980 s for the Entire U.S. and Other Activities 


\section{$\underline{\text { REFERENCES }}$}

1. T. I. McSweeney, R. J. Hall et al., An Assessment of the Risk of Transporting Plutonium Oxide and Liquid Plutonium Nitrate by Truck, BNWL-1846, Batte11e, Pacific Northwest Laboratories, Richland, WA, August 1975.

2. R. J. Hall et al., An Assessment of the Risk of Transporting Plutonium Dioxide and Liquid Plutonium Nitrate by Train, BNWL-1996, Battel1e, Pacific Northwest Laboratories, Richland, WA, February 1977.

3. Reactor Safety Study - An Assessment of the Accident Risks in U.S. Commercial Nuclear Power Plants, WASH-1400, U.S. Nuclear Regulatory Commission, Washington, D.C., October 1975. 


\subsection{RISK ANALYSIS MODEL}

Risk, as used throughout this report, is defined as the product of the likelihood of occurrence of an event and the consequences of an event. The risk model, described in this section has been developed from methodologies used in prior risk assessments. A detailed description of the risk model used in this report is provided in Reference 1.

The risk model, summarized in the following sections, has been developed to evaluate the risk of transporting radioactive materials. By generalizing some of the component designations it could also be applied to shipments of hazardous materials.

\subsection{RISK MODEL DESCRIPTION}

The risk assessment model provides a systematic method for handling the data germane to analysis of the safety of the transport environment. The components of the assessment model are shown in Figure 3.1. The following paragraphs provide a more detailed description of the components shown in this figure.

The model uses one fundamental equation:

$$
R=\sum_{i} R_{i} \cdot
$$

The total system risk $R$ is the sum of the risks of all accidental releases as denoted by the subscript i. Only accidental releases are considered in the model. The risk of an individual release is the product of the consequences of the release and the probability of its occurrence. This equation could be expanded into a single, long, complex equation. In the current formulation of the mode $\overline{1}$, each term in Equation (3-1) is expanded into two expressions which have more physical significance. The expanded equation for $R_{i}$ is:

$$
R_{i}=\left(A F_{R_{i}} \times P_{R_{i}}\right) \times \sum_{q}\left(C_{E_{i, q}} \times P_{E_{q}}\right) \text {. }
$$




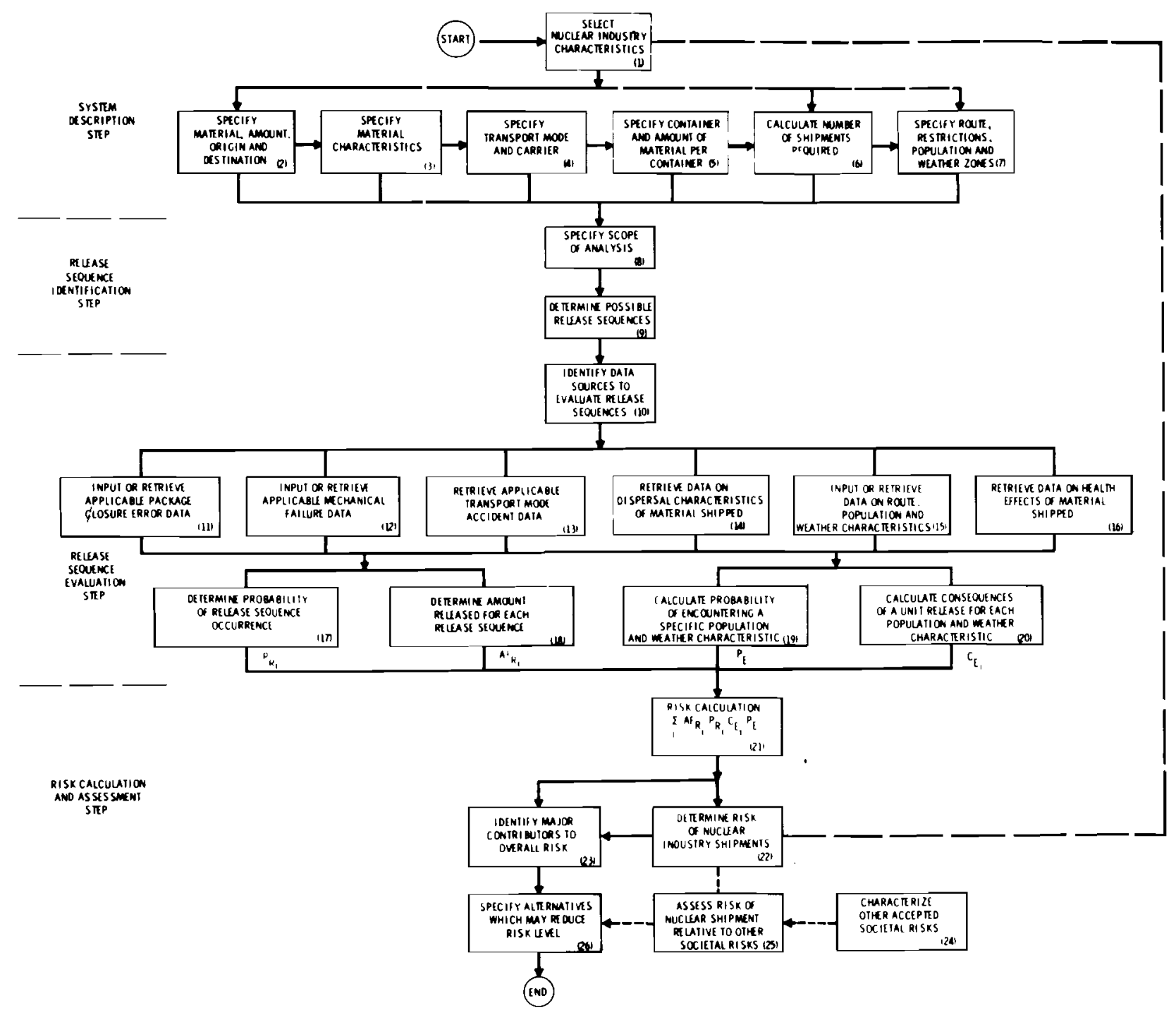

FIGURE 3.1 Model to Calculate the Risk of Shipping Nuclear Material 
The first factor, $A F_{R_{j}}$, is the product of the amount of material present in a shipment times the fraction of that material lost to the environment in the $i^{\text {th }}$ release sequence. This factor can be thought of as a source for the $i^{\text {th }}$ chain of events or failures which end with a release of radioactive material. The second factor, $P_{R j}$, is the probability that the release sequence will happen during transport. The first expression, $A F_{R_{j}} \times P_{R_{j}}$, can be thought of as a probabilistic source term for each identified release sequence.

The factor $C_{E_{i}}, q$ in the second part of Equation 3-2 is the consequences of a unit release. The subscript $q$ is added to show that the factor is a function of the specific weather conditions existing at the time of the release and the population exposed to the release. The factor represents the effect of a unit release on the exposed population in terms of either a whole body dose to man or to a specific organ. The final factor, $P_{E_{q}}$ is the probability of encountering a particular set of weather conditions within a specific population zone. The expression ${ }_{q}^{\Sigma}\left(C_{E_{i, q}} \times P_{E_{q}}\right)$ can be thought of as the consequences of a unit release of radioactive material (unit source term) under probabilistically weighted weather conditions and population distributions.

Equation 3-2 is the pivotal equation in the risk model. Two preparatory steps are needed before the terms can be evaluated. These are the system description and the release sequence identification steps. Following these two steps is the release sequence evaluation step which utilizes Equations $3-1$ and 3-2. The final step is to evaluate or assess the significance of the risk level determined for the transport system being evaluated. The relationship between the four steps is shown in Figure 3.1. The steps are briefly discussed in the following four subsections.

\subsubsection{System Description}

As shown in Figure 3.1, the system description step has seven components:

1) Select Nuclear Industry Characteristics

2) Specify Material Amount, Origin and Destinat on

3) Specify Material Characteristics 
4) Specify Transport Mode and Carrier

5) Specify Container and Amount of Material per Container

6) Calculate Number of Shipments Required

7) Specify Route, Restrictions, Population and Weather Zones.

Figure 3.2 shows examples of the types of information called for by these components. The seven components completely describe the system being evaluated.

\subsubsection{Release Sequence Identification}

The second step in the risk assessment is identification of release sequences. This requires, first, component 8 , Specify Scope of Analysis, which completes the information required to initiate work in component 9 , Determine Possible Release Sequences. The relationship of these two components to the rest of the model is shown in Figure 3.1. Component 8 sets the scope of the risk assessment by selecting the factors that will be considered in the analysis. For the present analysis, the risks from failure sequences involving both accident conditions and substandard packaging conditions are considered. The possible release sequences within the scope of the assessment are identified in component 9 by use of fault tree analysis; a method that works backwards from a release through the chains of events or failures required to breach the barriers between the material and man's environment.

\subsubsection{Release Sequence Evaluation}

The release sequence evaluation step considers each release sequence identified in the previous step and determines the factors in Equation 3-2. The assembly of these data will be described in the following subsections entitled Source Term Evaluation and Environmental Consequences Evaluation.

Source Term Evaluation. The release sequence factors in Equation 3-2, denoted by the subscript "R," represent the probability that a source of material will be released, the type of release, and the amount of material released. The evaluation of these factors requires the input of four data bases, shown in Figure 3.1 as components 11-14. These data bases are: 


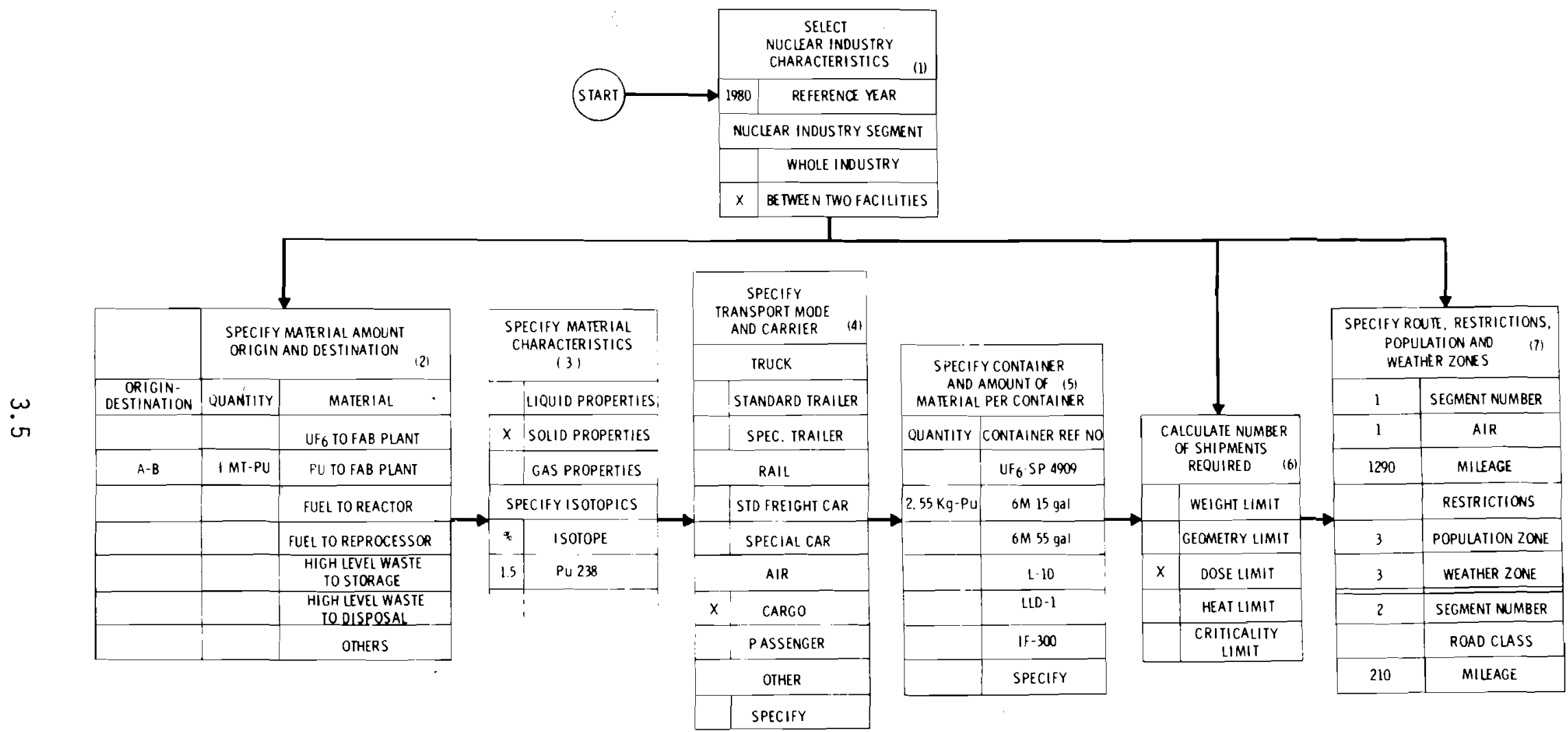

FIGURE 3.2 Information Required to Describe Transport System 
- Input or Retrieve Applicable Package Closure Error Data (11)

- Input or Retrieve Applicable Mechanical Failure Data (12)

- Retrieve Applicable Transport Mode Accident Data (13)

- Retrieve Data on Dispersal Characteristics of Material Shipped (14)

With the information from components 11 to 14 , the model evaluates the probability of a release and the source term, shown as components 17 and 18 in Figure 3.1. The source term must be expressed in equation form so that the source can be related to environmental conditions. The $F_{R_{j}}$ factors of source term expression used for various release sequences and environmental conditions are discussed in Section 9.

The "A" factor in Equation 3-2 includes terms which relate the total amount of material shipped to the fraction that is potentially dispersible. The fraction is a function of the number of containers damaged and the amount of material spilled from the damaged containers. When these terms have been evaluated for each release sequence, this part of the analysis is complete.

Environmental Consequences Evaluation. The environmental terms in Equation 3-2 are denoted by a subscript $E$. The factor $P_{E}$ represents the probability that a given set of weather and population density characteristics will be encountered. The factor $C_{E_{j}}$ represents the consequences of a unit release from an accident when it occurs in the region characterized by the weather and population density used to determine $P_{E}$. The consequences of the unit release are initially calculated as a population dose expressed in units of man-rem to a selected organ of reference. The population dose is then converted to health effects using commonly accepted methods. The evaluation of the two factors in Equation 3-2 requires the input from three data bases, shown in Figure 3.1 as components 14 to 16 . These data bases are: 
- Retrieve Data on Dispersal Characteristics of Material Shipped (14)

- Input or Retrieve Data on Route, Population and Weather Characteristics (15)

- Retrieve Data on Health Effects of Material Shipped (16)

The model uses relevant information from components 14 to 16 to evaluate the probability of experiencing a given set of weather conditions and population characteristics. These evaluations are shown as components 19 and 20 in Figure 3.1. The $P_{E}$ term in Equation 3-2 is the probability associated with the weather and population characteristics. The expanded form of this term is given:

$$
P_{E_{j, k, 1}}=P_{j / k} \times P_{k} \times P_{1} .
$$

The subscripts $j, k$ and 1 refer to the multiplicity of environmental conditions which could exist at the location of the accident. The variable $P_{j / k}$ is the probability of experiencing the $j^{\text {th }}$ atmospheric stability classification when the $k^{\text {th }}$ windspeed exists. The variable $P_{k}$ is the probability of encountering the $k^{\text {th }}$ windspeed category. The variable $P_{1}$ is the probability of encountering a specified population distribution.

These data complete the description of the four terms in the risk equation. Once all of these variables are specified, the risk calculation and assessment step, the last step, can be completed.

\subsubsection{Risk Calculation and Assessment}

The final step in the risk assessment is to sum and evaluate the risks associated with all the applicable release sequences. As shown in Figure 3.1 , this final step consists of six components numbered 21 to 26 :

- Risk Calculation (21)

- Determine Risk of Nuclear Industry Shipments (22)

- Identify Major Contributors to Overall Risk (23)

- Characterize 0ther Accepted Societal Risks (24) 
- Assess Risk of Nuclear Shipments Relative to Other Societal Risks (25)

- Specify Alternatives Which May Reduce Risk Level (26)

Reference 1 provides a more detailed description of these components.

In this report, the risk of transporting plutonium by air will be calculated and then compared with other accidental risks. One of the comparisons will be to compare the results of this air transport risk analysis with the results of the truck transport risk analysis which has been previously reported. Such comparisons place the risks of shipping plutonium in perspective.

\section{REFERENCE}

1. T. I. McSweeney, R. J. Hall et a1., An Assessment of the Risk of Transporting Plutonium 0xide and Liquid Plutonium Nitrate by Truck, BNWL-1846, Battelle, Pacific Northwest Laboratories, Richland, WA, August 1975. 


\subsection{PLUTONIUM SHIPPING REQUIREMENTS}

As discussed in Section 3, the plutonium risk assessment is based on a specific set of plutonium shipping requirements. This evaluation of the risk of shipping plutonium dioxide by air uses the same shipping data used in the previous evaluation of the risk of shipping plutonium dioxide by truck. As mentioned in the Introduction, a unique feature of the air transport is that it requires truck transport to or from the nearest cargo air terminal. Thus, when specifying the air shipping requirements, both the length of the truck and air segments must be determined.

As discussed in the previous study, ${ }^{(1)}$ since light water reactors can use either uranium or plutonium-uranium fuels, it is difficult to specify the plutonium shipping requirement for a specific year. This analysis is being performed for a time when there are 100 operating reactors, a condition which is likely to occur in the 1980s.

\section{1 NUCLEAR INDUSTRY CHARACTERISTICS}

The shipment of plutonium recovered by reprocessing fuel discharged from light water reactors (LWRs) presumes that plutonium will be used to supplement low enriched uranium; currently the only feed material for LWRs. The industry characteristics used in this evaluation are given in Table 4.1.

TABLE 4.1. Nuclear Industry Characteristics (One Year Period)

Number of Operating Power Reactors

Power Level

Number Shipping Spent Fuel to Reprocessors

Fuel Reprocessed

Total Pu Recovered and Shipped to Fabricators
100 1000 MWe $75^{(a)}$

30 MT per reactor

2250 MT total

18 MT

\footnotetext{
(a) The other 25 have not begun to ship dischaiged fuel.
} 
The number and location of fuel reprocessors and plutonium fuel fabricators are given in the following paragraphs. They represent a projection of the nuclear industry into the 1980s using a reference point of August 1975, the date when the study of the risk of transporting plutonium by truck was completed. Use of more recent industry projections would make comparisons between truck and air shipments less straightforward.

\subsection{FUEL REPROCESSORS}

At least two reprocessing plants will be needed at the time when 100 nuclear power plants are operating. The model used the AGNS facility at Barnwell, South Carolina, and the NFS facility at West Valley, New York, as the origin of all plutonium shipments. At the reference time, 12 MT of plutonium were shipped from Barnwell and 6 MT were shipped from West Valley. The quantity shipped from Barnwell is larger because the throughput is larger; $1500 \mathrm{MT} / \mathrm{yr}$ of spent fuel versus $750 \mathrm{MT} / \mathrm{yr}$ for West Valley.

\subsection{FUEL FABRICATORS}

The number and location of plutonium fuel fabricators at the reference time are more difficult to specify than for the fuel reprocessors. The capacities used for the two reprocessors are announced capacities for plants at existing sites. Except for Westinghouse, who has applied for a permit to build a large fabrication facility at Anderson, South Carolina, no other sites are known with certainty. More are needed to annually fabricate fuel containing 18 MT of plutonium.

In this analysis, as in the truck risk study, plants were located at four other facilities which currently have licenses to fabricate mixed oxide fuel. The locations of these facilities are given in Table 4.2.

TABLE 4.2. Location of Plutonium Fuel Fabrication Facilities

\begin{tabular}{|c|c|}
\hline Company & Location \\
\hline Exxon & Richland, WA \\
\hline General Electric & Pleasanton, CA \\
\hline Kerr-McGee & Crescent, OK \\
\hline Westinghouse & Cheswick, PA \\
\hline NUMEC & Apol10, PA \\
\hline
\end{tabular}


Present7y, nuclear fuel fabrication requirements are controlled by contract and not necessarily by the plutonium transport logistics. This means that an operator of several nuclear reactors may use all reprocessors and plutonium fabricators. If this occurs, then the best representation of the plutonium shipping requirements is for each fabricator to receive plutonium from each reprocessor in proportion to the relative capacities of the receiver and shipper. All fabricators are assumed to have the same plutonium requirements. The plutonium output of the reprocessing plants was stated previously. Using these assumptions each fabricator wil1 receive $3.6 \mathrm{MT} / \mathrm{yr}$; $2.4 \mathrm{MT}$ from Barnwell and 1.2 MT from West Valley.

\subsection{PLUTONIUM SHIPPING DISTANCES}

A small percentage of domestic airports have facilities for regularly scheduled air freight service, most of these being the large, international airports found in major cities. Since the fuel reprocessing plants are rather remotely located, the plutonium shipments must be carried by truck to the nearest airport with air freight service. The same holds true at the receiving end. The plutonium must be trucked from the airport to the fue 1 fabrication plant. Further complicating matters, many air freight flights will be indirectly routed, with up to two intermediate stops.

Shipment routes were determined using The National Atlas of the United States ${ }^{(2)}$ and a list of airports with air freight facilities. (3) Truck mileages were compiled using a road atlas and air miles were taken from the Official Airline Guide. (4)

Table 4.3 shows the shipping routes and distances between the reprocessing plants and fuel fabrication plants. 
TABLE 4.3. Estimated Route Distances Between Fuel Reprocessors and Fuel Fabricators (Miles)

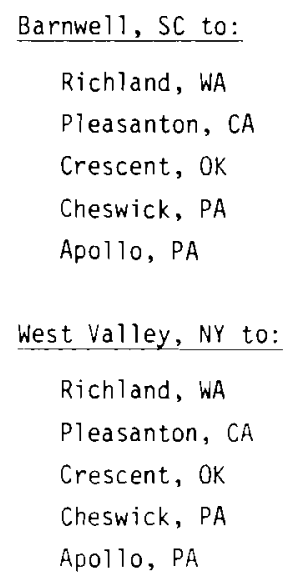

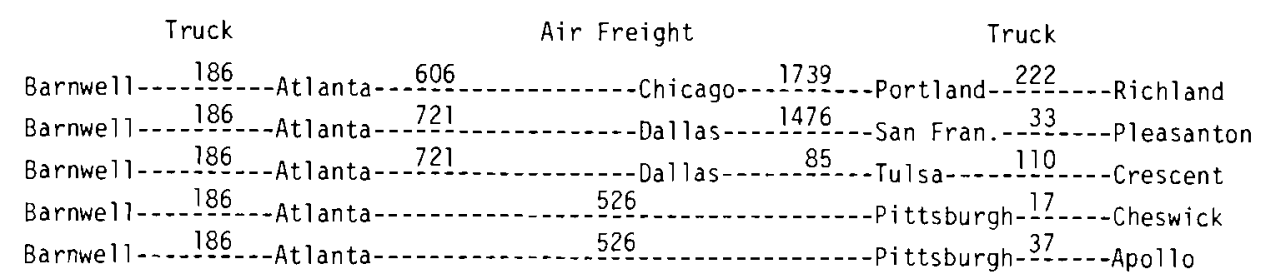

\section{REFERENCES}

1. T. I. McSweeney, R. J. Hall et al., An Assessment of the Risk of Transporting Plutonium Oxide and Liquid Plutonium Nitrate by Truck, BNWL-1846, Batte1 le, Pacific Northwest Laboratories, Richland, WA, August 1975.

2. The National Atlas of the United States, United States Department of the Interior Geological Survey, Washington, D.C., 1970.

3. Committee on Interstate \& Foreign Commerce "FAA Regulations Concerning Hazardous Air Cargo" Serial No 93-98 House of Representatives Thirty-Third Congress, Second Session, Washington, D.C., 1974.

4. The Official Airline Guide, published by the Reuben H. Donnelly Corporation, Oak Brook, IL. 


\subsection{TRANSPORT ACCIDENT ENVIRONMENT}

Failure of a container during an accident occurs when the forces generated in an accident exceed the mechanical strength of a container. This section discusses the forces or stresses which may be generated in the air accident environment and their likelihood of occurrence. Section 6 discusses the estimated mechanical strength of the $6 \mathrm{M}$ container. The use of the results from Sections 5 and 6 to estimate the likelihood of container failure in an accident is demonstrated in Section 9.

The air accident envirorment data summarized here were developed by Sandia Laboratories. (1) These data represent the most comprehensive accident environment information currently available. In Sandia's analysis the accident environment is categorized by five accident stresses: impact, crush, puncture, fire, and immersion. Impact and crush are distinguished by the duration and direction of the force. Impact forces act over periods of a few milliseconds whereas crush forces can exist for several seconds following the accident. Impact forces are applied to one side whereas crush forces are applied from several directions. Impact and crush forces are adequately differentiated by comparing the force exerted by a hammer blow to the same force exerted by a press.

Initially, each of the accident stresses was evaluated with the assumption that all stresses were independent of each other. After all five stresses were evaluated, a check was made to verify independence. From the available data it was determined that fire and impact could be treated as independent accident stresses. Although some puncture stresses require an impact type accident to generate the puncture potential, it was not possible to determine the dependency of the puncture environment on the impact environment. Therefore, it was treated as an independent accident stress. Crush and immersion imply an impact stress has been exerted; for that reason, they were treated as dependent accident stresses.

The following paragraphs briefly summarize the Sandia results. The likelihood of an accident is discussed first. Sections discussing the fire, impact, crush, immersion and puncture environments follow. 


\subsection{AIRCRAFT ACCIDENT RATES}

Because aircraft accidents are relatively infrequent events, Sandia used both civilian and military aircraft accident information as a data base. A lack of uniformity in accident definitions made it very difficult to combine these data sets. Therefore, the civilian accident definition was used to determine the frequency of airplane accidents, while the military data was used to describe the accident environment. To be classed as accident, "substantial aircraft damage" is required. Based on this definition, a representative airplane accident rate for commercial aircraft was found to be $1.0 \times 10^{-8} / \mathrm{mile}$.

A single value for the accident rate is highly desirable. However, risk assessments must consider the likelihood of accidents as a function of the population density in the vicinity of the accident. Since the accident rate is much higher in the vicinity of airports, and since the population density around airports is higher, a single number for the accident rate is not appropriate. Table 5.1 separates the basic accident rate into flight categories. These data were obtained through personal communication with W. F. Hartman of Sandia and are for al1 U.S. certified air carriers during the 1965-1972 time frame.

TABLE 5.1. Accident Rate by Flight Operations

$\begin{array}{lr}\text { Ascent, Descent, Takeoff } & 1 \times 10^{-6} / \text { operation } \\ \text { Landing } & 2.8 \times 10^{-6} / \text { Operation } \\ \text { Ground Operation, Taxi } & 7 \times 10^{-7} / \text { Operation } \\ \text { Inflight (Including } & 3.6 \times 10^{-9} / \text { Mile } \\ \text { Ditching) }\end{array}$

These four categories of flight operations adequately characterized the nature of accidents both in the vicinity of an airport, and during the flight. Inflight accidents are defined as those which occur during normal cruise. For commercial carriers, this will be at altitudes exceeding i0,000 feet above mean sea level (MSL). These accidents typically occur well away from the airport. Takeoff, ascent and descent are combined together as one class of accidents and include accidents which occur before normal cruise is established and after descent to landing has commenced. Therefore, 
these were assumed to occur below 10,000 ft above MSL. A $422 \mathrm{ft} / \mathrm{sec}$ ( $250 \mathrm{knot}$ ) speed limit is imposed on all operations below this altitude. It will be conservatively assumed that these accidents will occur over suburban areas. The landing accident occurs during final approach at altitudes below $200 \mathrm{ft}$. These accidents occur within the confines of the airport when the airplane is operating at close to $i$ ts stall speed. Accidents occurring during ground operations and taxi are included to complete the categorization of accidents. Except for the fire stress, this accident category presents either small or nonexistant stress environments to a radioactive material package.

In the following paragraphs discussing each of the accident stress environments, the accident class will be one of the variables considered.

\subsection{FIRE ENVIRONMENT}

The accident fire stress can range from minor to severe depending on the fire size, location, temperature and duration. Little quantitative data on the temperature or intensity of accident fires is available in accident reports. Although local temperature conditions could vary considerably, involvement of the jet fuel produces the dominant fire stress. Combustibles present in the plane may burn longer, and aluminum, if ignited, may burn far hotter than jet fuel. Such fire conditions are not dominant, however, because they are less severe (combustibles burning) or they are highly improbable (aluminum ignition).

For a jet fuel fire, theoretical and experimental studies show the fire intensity to be reasonably simulated by a $1850^{\circ} \mathrm{F}$ black body flame temperature. Table 5.2 shows the frequency of fires for the accident categories based on the military accident records. While the probabilities of fire and impact are not assumed to be independent (about $41 \%$ of the accidents involve impact but roughly two-thirds of the fires occur in conjunction with impact accidents), the severities are assumed to be independent. 
TABLE 5.2 Fire Frequency, Given an Aircraft

Accident Classification

Accident Classification

Takeoff, Ascent, Descent

Landing

Ground Operation, Taxi

Inflight
Likelihood of Fire per Accident

0.53

0.31

0.42

0.29

Figure 5.1 shows the cumulative fire duration distribution for aircraft accidents. This curve is used for all accident classifications and assumes a $1850^{\circ} \mathrm{F}$ effective fire temperature. It is recognized that some differences will exist since landing fires will usually involve less fuel than will takeoff fire accidents.

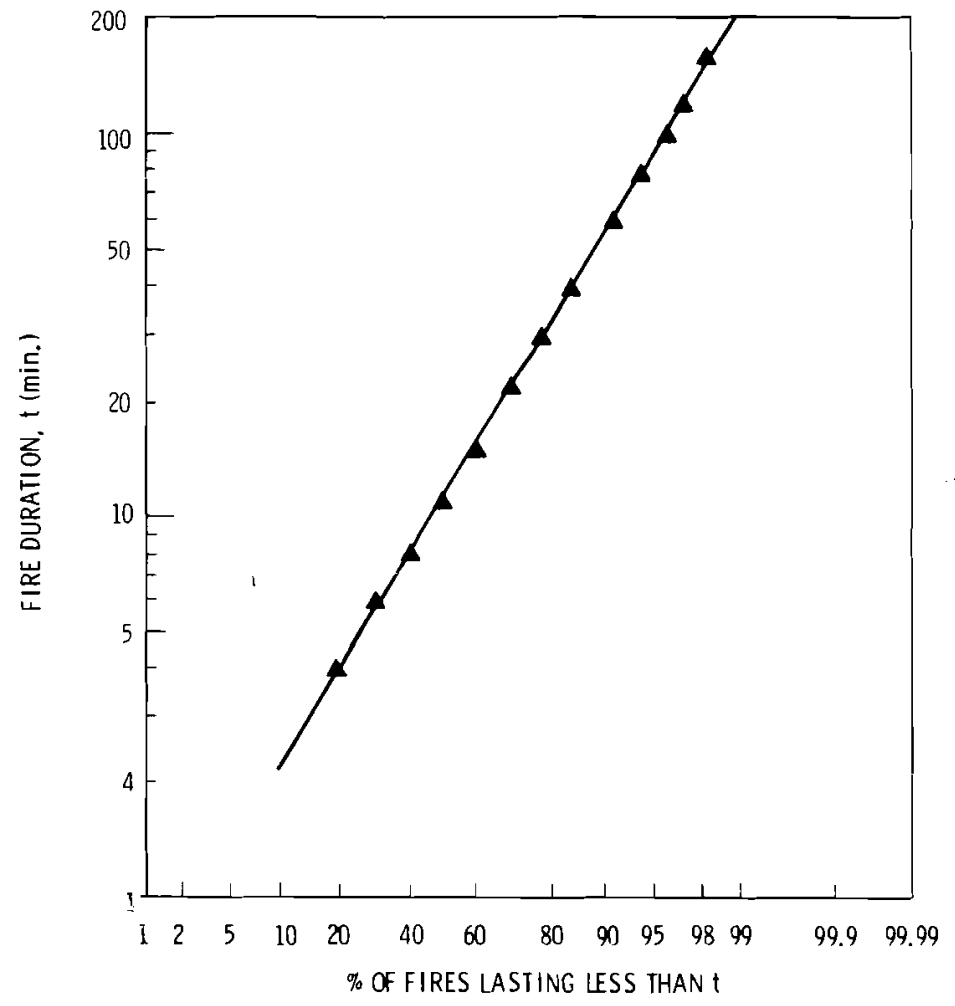

FIGURE 5.1 Cumulative Distribution of Fire Duration for Aircraft Accidents Involving Fire 


\subsection{IMPACT ENVIRONMENT}

Sandia found that both the likelihood and severity of impact stresses were a function of the accident classification. Table 5.3 shows the likelihood of occurrence of impact stresses given an aircraft accident.

TABLE 5.3. Frequency of Occurrence of Accident Generate and Impact Stresses

Accident Classification

Takeoff, Ascent, Descent

Landing

Ground Operation, Taxi

Inflight
L.ikelihood of Impact Stresses/Accident

0.58

0.64

0

0.43

The magnitude of the impact stresses is also a function of the accident classification. During takeoff, ascent and descent, the aircraft speed is limited by the $422 \mathrm{ft} / \mathrm{sec}$ (250 knot) speed regulation imposed at altitudes below 10,000 ft above MSL. By definition, landing accidents occur during final approach, when the plane is within $200 \mathrm{ft}$ of the ground. At this altitude, the plane is operating at speeds not greatly exceeding its stall speed, and its angle of approach is very shallow so that its velocity normal to the runway is low. The velocity limits for these two accident classifications effectively place an upper bound on the impact stress environment. Ground operations and taxi present no significant impact environment. Accidents occurring inflight, which include ditching, pose the greatest impact stresses because there could be cases where the plane is traveling at its normal cruising speed $(800-850 \mathrm{ft} / \mathrm{sec})$.

Container damage is influenced by both the impact velocity and the surface impacted. The likelihood of impacting various surfaces of the three accident categories is shown in Table 5.4.

Figure 5.2 shows the cumulative distributions for impact stress, expressed as normal impact velocity, for the three accident classifications presenting impact stresses. The curves have been "normalized" to express the probability of impacting onto an unyielding surface at the stated velocity. 
TABLE 5.4 Estimated Likelihood of Impacting Various Surfaces for the Three Accident Classifications Posing an Impact Environment

Accident Classification Impact Surface

Runway

Water

Soft Soil

Hard Soil

Soft Rock

Hard Rock
Likelihood of Impact/Accident Classification

Takeoff, Ascent Descent Landing Inflight
0.07
0.53
0.00

0.17

0.09

0.18

0.26

0.13

0.28

0.37

0.19

0.40

0.08

0.04

0.09

0.05

0.02

0.05

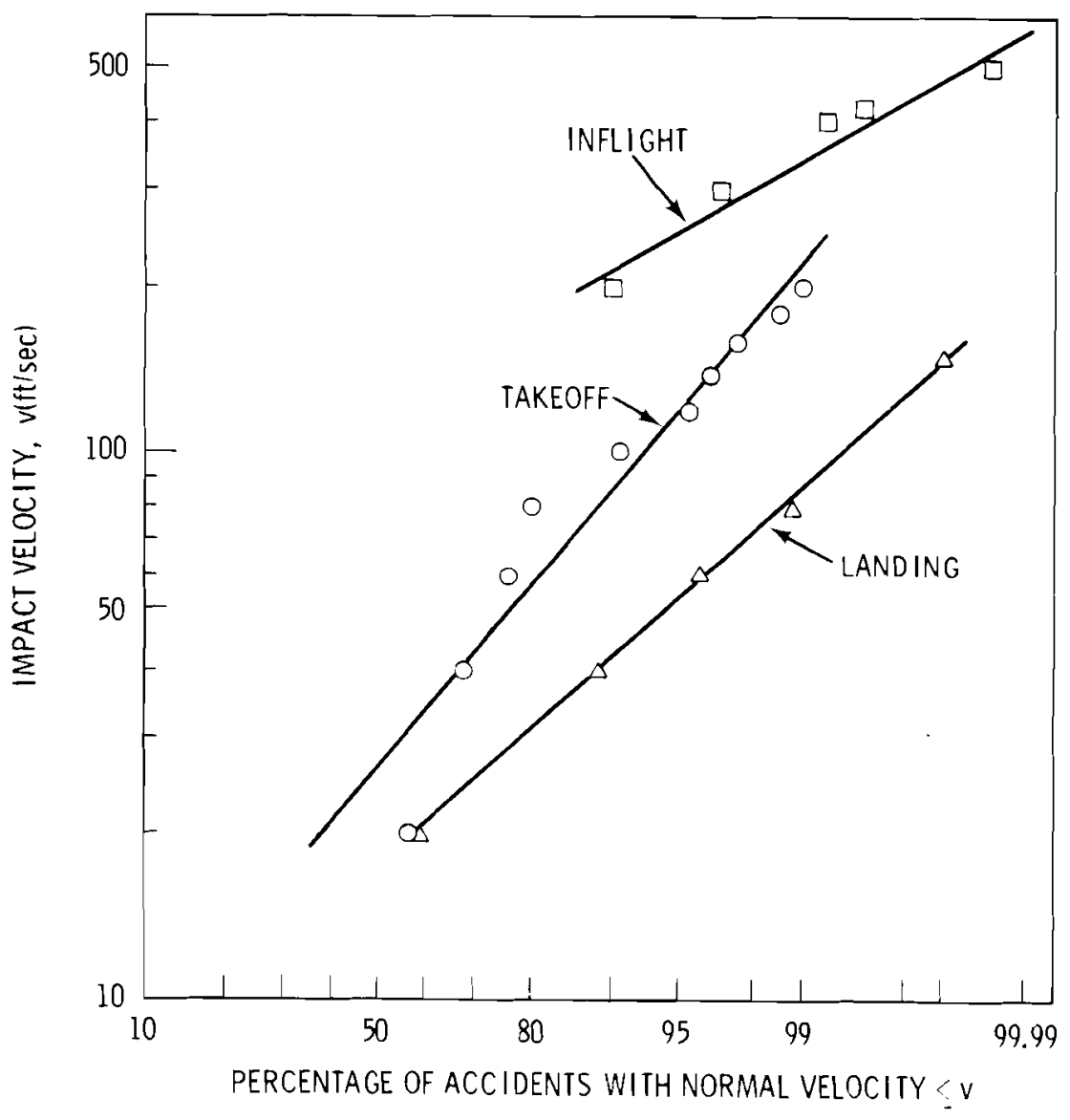

FIGURE 5.2. Cumulative Distribution of Impact Forces Yielding an Environment $<\mathrm{v} \mathrm{ft} / \mathrm{sec}$ onto an Unyielding Target Given that an AirCraft Accident has Occurred 
The curve for inflight accidents was developed from NTSB data by Sandia (3) while the remaining curves were developed from the Sandia accident data using the information in Table 5.4. Because (as will be shown later) the impact forces resulting from inflight accidents dominate the risk, the use of the more reliable NTSB data over that from the accident data base is justified. NTSB data for the other two categories were not available.

\subsection{CRUSH ENVIRONMENT}

Crush requires an initiating force which can only be generated in an impact accident. Based on Sandia's findings, the probability of a quasistatic type of crush resulting from the weight of parts of the aircraft is quoted in Reference 1 as being on the order of 0.05 . More recent work by Sandia $^{(2)}$ suggests localized loads as large as 70,000 lbs may be present on the container if it is compressed between the surface and one of the beams of the floor above. It has not been possible to predict the probability of these occurrences. Also, in fully loaded cargo compartments, crush forces resulting from the inertia of other cargo may lead to sizeable loads. In many instances, hazardous materials are carried in a position near the rear of the aircraft, thus reducing the chance of initial crush.

Because of the present inability to adequately assess these hazards, it was conservatively assumed that the crush environment will be severe enough to fail the outer container in $5 \%$ of all impact accidents.

\subsection{IMMERSION}

Except for posing a recovery problem, in flights across the United States immersion presents little hazard to container integrity. Table 5.5 presents the likelihood of immersion for each accident classification. The cumulative distribution for immersion depth is given in Figure 5.3.

\subsection{PUNCTURE}

Like crush, the puncture environment was very difficult to quantify. It is estimated that the likelihood of puncture for each accident class except taxi and ground operation is 0.06 . Because quantitative data are not available, container failure is assumed when it is struck. 
TABLE 5.5 Likelihood of Immersion for

Selected Accident Classifications

Likelihood of Immersion

Accident Classification per Accident Classification

Takeoff, Ascent, Descent 0.17

Landing

0.09

Ground Operations, Taxi

0.00

Inflight

0.18

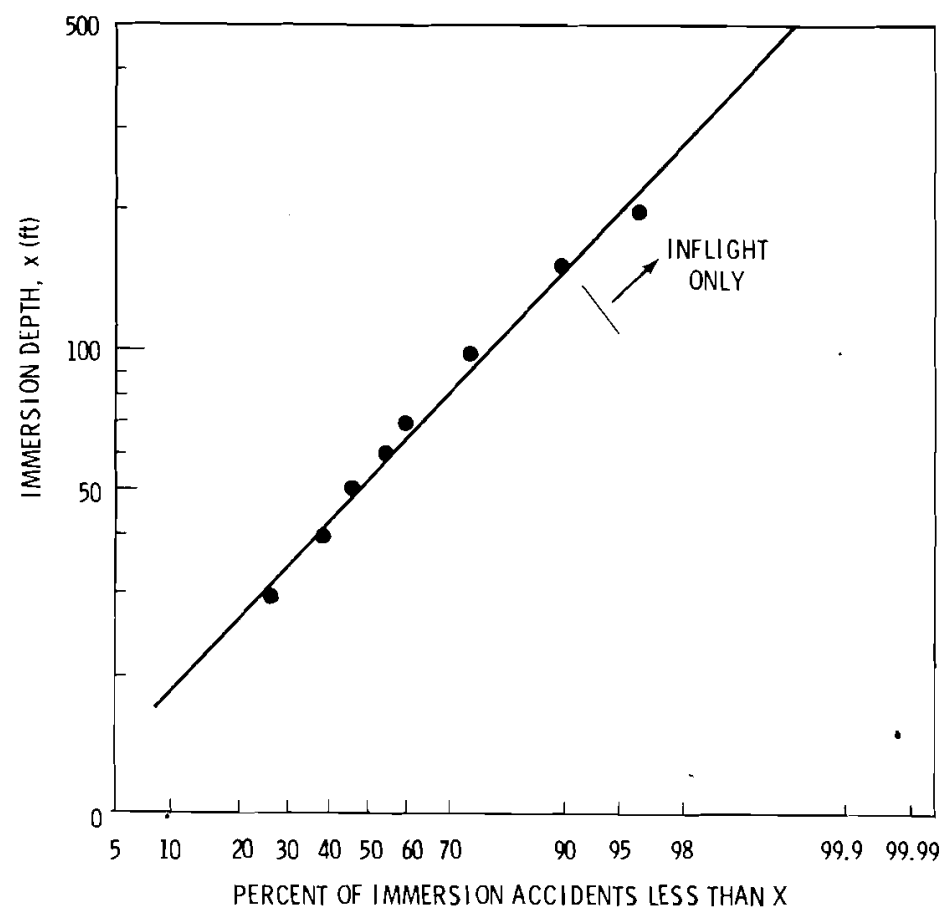

FIGURE 5.3. Cumulative Distribution of Immersion Depth for A11 Accident Classifications

This conservative assumption is not expected to be critical because of the severity of the impact environment. A dominance of the puncture stress in the risk assessment presented in Section 11 would imply that a more detailed evaluation of the puncture environment is required. 


\section{REFERENCES}

1. R. K. Clarke, T. J. Foley, W. F. Hartman and D. W. Larson, Severities of Transport Accidents, Volume III - Cargo Aircraft, SLA-75-001, Sandia Laboratories, Albuquerque, NM, July, 1976.

2. Private communication, W. F. Hartman, Sandia Laboratories, to T. I. McSweeney.

3. Private Cómmunication, W. F. Hartman, Sandia Laboratories, to J. F. Johnson. 


\subsection{PACKAGE FAILURE THRESHOLDS}

The previous section described the environment imposed on containers during aircraft accidents. Estimates of the failure thresholds for the $6 \mathrm{M}$ package are presented in this section. The concept of a failure threshold (a point below which all "identical" packages will survive and above which they will all fail) is a simplification of this application of the risk model. Mechanical failure points of containers are distributed in stress level. There is a most probable level that will result in failure, but in any group of "identical" containers there are some that will fail above or below this most probable value. However, it is felt that the simplifications in this section are consistent with the detail in the knowledge of the accident environment and that the analysis gives a reasonable estimate of the risk of package failure in an accident. To assess whether or not the package will fail in the accident environment, the results of this section must be used with other information on the stresses to which the package may be exposed. These assessments are made in Sections 9 and 11 .

The package failure thresholds reported here were obtained through both destructive testing and mathematical analysis. Physical tests were performed by Sandia Laboratories. ${ }^{(1,2)}$ These covered not only impact, crush, puncture, fire and immersion tests, but also high speed impact tests onto an unyielding surface. The analytical results represent estimates of failure thresholds obtained in using the elastic theory of structure behavior. The analysis is limited to cases of side drop or loading (i.e., the axis of the package perpendicular to the direction of the applied load). The failure points using elastic theory are also believed to be less than the actual strength of the container, although the exact degree of conservatism is unknown.

This section describes the analyses performed to estimate the failure thresholds for the 6M container. A description of this container is presented in Appendix A. The detailed calculations per formed on the container are shown in Appendix $C$. 
The analyses enabled the direct evaluation of the side impact and puncture accident sequences for the $6 \mathrm{M}$ container. The results from analysis of these accident sequences can be applied to other conditions. For example, analyzing container impact using elastic theory neglects the time variable. This means that the results of crushing can be inferred from the impact results. This can be accomplished by equating the energy in the container prior to impact to the work performed on the container in deformation. Thus:

$$
E=1 / 2 m V_{2}^{2}=m g h_{1}=F d
$$

where,

$m$ is the mass of the container

$v_{2}$ is the velocity of the container at impact

$h_{1}$ is the initial drop height

$d$ is the deformation of the container after impact

$F$ is the force representing an equivalent crush force.

The kinetic energy just before impact, $1 / 2 \mathrm{mv}_{2}^{2}$, was initially potential energy represented by the term "mgh 1 ." This energy is dissipated by deforming the container an amount " $d$ " using a force " $F$." The force in this equation represents a crush force. In the case of crushing, the force can come from many directions whereas the impact is imposed on one side. This represents one major distinction between crush and impact analyses.

The results of high speed container impact tests performed at Sandia Laboratories were used to estimate impact fajlure thresholds for the 15-gal size $6 \mathrm{M}$ container considered in this study. Although the containers used in the Sandia tests were smaller, 10-gal size 6M's, the tests provide valuable insight to container failure mechanisms, and it is felt that any errors resulting from the use of the information are conservative in nature.

The following sections summarize the failure thresholds for the 15-gal. $6 \mathrm{M}$ outer container and the 2R inner container. Impact and puncture failure thresholds will be discussed for each barrier. Since Sandia is still performing high speed impact tests, these results represent the present state of understanding, which future experimental results may greatly enhance. 
As discussed in Section 5, five accident stresses were considered in this study. Only two, impact and puncture, are evaluated here. Valid reasons can be presented for not evaluating the remaining three: fire, crush, and immersion. The fire environment is not evaluated as a container failure mechanism for $\mathrm{PuO}_{2}$ powder shipments because the powder is thermally stable at elevated temperatures and cannot cause overpressurization of the container. Appendix B presents the significant chemical and physical properties of $\mathrm{PuO}_{2}$ powder. Crush was not considered because the tests conducted on typical Type B containers at Sandia(1) show that these containers will withstand almost all of the infrequently occurring crush loads which have been estimated to occur in aircraft accidents. Crush forces severe enough to fail the $6 \mathrm{M}$ outer container were conservatively assumed to occur in $5 \%$ of the accidents involving impact. This degree of quantification is acceptable so long as crush does not control shipment risk. Immersion poses a recovery problem but generates no stresses which can cause failure. Thus, the failure thresholds for fire, crush and immersion need not be quantified in this section.

\subsection{OUTER DRUM FAILURE THRESHOLDS}

Analytical calculations have been performed to determine the drop height which would result in rupture of the 1b-ga1., specification 6M, outer container. A side drop onto an unyielding surface was assumed, with all the energy absorbed by the container in an elastic deformation mode. (a) The drop height required to pop the lid off the outer container was determined to be $194 \mathrm{ft}$. Failure or loss of the lid was assumed to occur when the perimeter of the lid in the deformed state was smaller than the undeformed inside circumference of the clamp ring.

Analytical calculations were performed to determine the drop height onto a 6-in. diameter pin required to fail the outer drum. The calculations, presented in Appendix $C$, showed that a drop of 133 in. is required.

These two failure points wil1 be used in Sections 8 through 11 to evaluate the likelihood of a release during air transport of plutonium.

$\overline{(a)}$ For a discussion of these assumptions see Appendix $C$. 


\subsection{R FAILURE THRESHOLDS}

A drop height of $194 \mathrm{ft}$, required to fail the outer drum, is equivalent to an impact velocity of $111 \mathrm{ft} / \mathrm{sec}$ onto an unyielding surface. From the results presented in Section 5, impact velocities in excess of $111 \mathrm{ft} / \mathrm{sec}$ onto rock surfaces (relatively unyielding) are not uncommon. Thus, failure of the outer drum in air accidents can be expected in some airplane accidents. As a result, the $2 \mathrm{R}$ inner container becomes the primary barrier controlling release.

In previous studies, the uncertainties associated with analytical predictions of $2 \mathrm{R}$ failure thresholds were found to be relatively large. Assumptions, thought to be highly conservative, had to be made to evaluate failure. For this study, the preliminary results of Sandia's high speed impact tests were available to obtain container failure threshold data. (2)

In the impact tests, 6M containers, (10-gal size) and inner bird assemblies of LLD-1 containers were impacted onto selected types of surfaces, at different container orientations, and with velocities ranging from 200 to over 700 feet per second. As a reference point, the terminal velocity of a $6 \mathrm{M}$ container has been calculated to be $283 \mathrm{ft} / \mathrm{sec}$. (4) The inner bird assembly of the LLD was tested without the birdcage because of the 1 imited impact strength of the outer structure. The entire 6M package was tested. Results of tests of both types of containers were used to determine impact failure thresholds because the inner containers of both shipping containers are nearly identical.

The results of the impact tests are shown in Tables 6.1 and 6.2. Mg0 powder was used to simulate $\mathrm{PuO}_{2}$ powder in the tests; selected because of its similar bulk density and because gross container failures were expected, making a radioactive simulant unwise. The containers were impacted onto three target surfaces: a 5-inch thick steel plate (an unyielding surface), a concrete target, and a soil target.

Based on the results of the Sandia tests, it was determined that a $2 R$ (inner) container could fail at a level corresponding to a $225 \mathrm{ft} / \mathrm{sec}$ impact onto an unyielding surface. The impact failure threshold is very 
likely to be angle dependent, however, because of the limited amount of test data, the threshold used in this study was conservatively assumed to involve side impact only.

\section{TABLE 6.1. 6M Test Results $(2)$}

\begin{tabular}{|c|c|c|c|c|c|}
\hline Target & $\begin{array}{l}\text { Speed } \\
(\mathrm{ft} / \mathrm{sec}) \\
\end{array}$ & $\begin{array}{l}\text { Attitude(a) } \\
\text { (degrees) }\end{array}$ & $\begin{array}{c}2 R \text { Visual } \\
\text { Structural } \\
\text { Penetrations }(b) \\
\end{array}$ & $\begin{array}{l}2 R \text { Gross } \\
\text { Structura ] } \\
\text { Failures }(\mathrm{c}) \\
\end{array}$ & $\begin{array}{l}\text { Best Estimate } \\
\text { Released Contents } \\
\text { (1b/Percent) }\end{array}$ \\
\hline Stee 1 & 415 & 62 & Yes & $\operatorname{Yes}^{(d)}$ & $0.03 / 0.4$ \\
\hline Stee 1 & 306 & 58 & Yes & $\operatorname{yes}^{(d)}$ & Trace \\
\hline Steel & 245 & 59 & Yes & $\operatorname{Yes}^{(d)}$ & Trace \\
\hline Steel & 306 & 0 & Yes & No & Trace \\
\hline Steel & 331 & 55 & Yes & Yes & $0.12 / 1.5$ \\
\hline Steel & 294 & 83 & No & No & None \\
\hline Concrete & 377 & 24 & No & No & None \\
\hline Concrete & 535 & 0 & Yes & Yes & $0.1 / 1.5$ \\
\hline soil & 420 & 5 & No & No & None \\
\hline Soil & 391 & 71 & No & No & None \\
\hline Soi? & 760 & 22 & No & No & None \\
\hline \multicolumn{6}{|c|}{$\begin{array}{l}\text { (a) Attitude is angle between cylindrical axis of container and target } \\
\text { at impact. } \\
\text { (b) Implies small cracks or openings, cocked } 1 \mathrm{id} \text {, etc., in the } 2 R \text { container. } \\
\text { (c) Implies large openings or structural breakup in the } 2 \mathrm{R} \text { container. } \\
\text { (d) Package had cast-iron } 2 \mathrm{R} \text { container plug; plug was replaced with carbon } \\
\text { steel plugs in later tests. }\end{array}$} \\
\hline
\end{tabular}

\section{TABLE 6.2. LLD-1 Test Results(3)}

\begin{tabular}{|c|c|c|c|c|c|}
\hline Target & $\begin{array}{l}\text { In } \\
\text { Speed } \\
\text { ft/sec })\end{array}$ & $\begin{array}{l}\text { Attitude(a) } \\
\text { (degrees) }\end{array}$ & $\begin{array}{c}2 \mathrm{R} \text { Visual } \\
\text { Structural (b) } \\
\text { Penetrations } \\
\end{array}$ & $\begin{array}{l}\text { 2R Gross } \\
\text { Structura? } \\
\text { Failures (c) }\end{array}$ & $\begin{array}{l}\text { Best Estimate } \\
\text { Released Contents } \\
\text { (1b/Percent) }\end{array}$ \\
\hline Steel & 275 & 77 & Yes & Yes & - \\
\hline Steel & 170 & 90 & No & No & -- \\
\hline Steel & $40-60$ & (5) & No & No & None \\
\hline Steel & 216 & 70 & No & No & None \\
\hline Steel & $70-100$ & (6) & No & No & None \\
\hline Steel & $70-80$ & (7) & No & No & None \\
\hline Steel & 277 & 70 & - Yes & No & Trace \\
\hline Steel & 315 & 73 & No & No & Trace \\
\hline Steel & 385 & 15 & Yes & Yes & $0.54 / 5.8$ \\
\hline Steel & 299 & 6 & Yes & Yes & Trace \\
\hline Steel & 230 & 2 & Yes & Yes & Trace \\
\hline Steel & 391 & 87 & No & No & Trace \\
\hline Concrete & 408 & 4 & Yes & Yes & $0.15 / 1.6$ \\
\hline Soil & 674 & 7 & No & No & None \\
\hline
\end{tabular}

(a) Attitude is angle between cylindrical axis of container and target at impact.

(b) Implies small cracks or openings, cocked lid, etc., in the $2 R$ container.

(c) Implies large openings or structural breakup in the $2 R$ container. 
Containers striking softer targets, e.g., sand, earth, concrete, could be expected to withstand larger impact forces. Based on preliminary evaluations of impact test results, ${ }^{(4)}$ if an impact velocity of $300 \mathrm{ft} / \mathrm{sec}$ onto stee 1 is required to breach the $2 \mathrm{R}$ container, a $400 \mathrm{ft} / \mathrm{sec}$ impact onto rock or concrete is required to breach the same container. Impact velocities onto soil could be more than double those onto concrete before failure would be likely.

Soil impacts are unique in several respects. In one test, an entire 6M container was impacted onto soil at a velocity in excess of $700 \mathrm{ft} / \mathrm{sec}$ at an orientation angle of approximately $22^{\circ}$. The impact caused the inner container to penetrate the celotex ${ }^{R}$ and outer drum to a depth of 20 inches into the soil. Some minor deformations were noted but there were no breaches of the container and no material was released. Even if a release had occurred, the major effect would have been some soil contamination. Such a release is relatively easy to clean-up and poses little hazard to the general public.

The minimum drop height required to cause puncture of the inner vessel alone when dropped on a 6-in. diameter pin was calculated as approximately $4000 \mathrm{in.}$ This failure mode, which takes no cognizance of the energy absorption properties of the outer container and Celotex ${ }^{R}$ material, is one which cannot occur for the conditions described; the vessel would fail in some other mode long before the energy required for puncture could be generated. The most likely mode would be that of the inner vessel bending over the pin upon impact, resulting in the skin of the vessel being stretched until cracking occurs. If one considers the inner vessel alone, with no support from the outer container or energy absorbing properties of the Celotex ${ }^{R}$, then incipient cracking could occur in the inner vessel wall at a minimum drop height of 37 in. This figure was used in subsequent evaluations and represents a lower bound of the drop height; the actual drop height would be much higher due to the reinforcing effect of the neglected structural components of the $6 \mathrm{M}$ container.

\subsection{M FAILURE THRESHOLD SUMMARY}

Previous sections have described what is presently known concerning the failure thresholds of the two major structural components of the $6 \mathrm{M}$ container; 
the outer drum and the $2 R$ inner container. The failure thresholds are summarized in Table 6.3. For the purposes of this study, it was conservatively assumed that in the impact accident environment, the protection contributed by the outer container is negligible.

TABLE 6.3. FaiTure Thresholds for 15-Gal 6M Shipping Containers

\begin{tabular}{|c|c|c|c|}
\hline \multirow[b]{2}{*}{ Failure Thresholds } & \multicolumn{3}{|c|}{ Container Barrier } \\
\hline & Outer & $2 \mathrm{R}$ & Outer $+2 \mathrm{R}$ \\
\hline Impact Vel & $111 \mathrm{ft} / \mathrm{sec}$ & $225 \mathrm{ft} / \sec ^{(a)}$ & $225 \mathrm{ft} / \sec ^{(a)}$ \\
\hline Puncture Height & $133 \mathrm{in.}$ & 170 in. (b) & 170 in. (b) \\
\hline
\end{tabular}

(a) Side impact onto unyielding surface

(b) Inner vessel failure occurs by bending

Failure thresholds tests for impact are the subject of a continuing study at Sandia. The results presented here are preliminary. Future experiments may show the results presented in Table 6.3 to be conservative. In addition, the analyses performed in this study are based primarily on the elastic behavior of the materials. The effects of plastic behavior have not been included. The inclusion of such effects would give calculated results as drop heights greater than those calculated and shown in Table 6.3. Elementary mechanics show that a structure of ductile material, such as most grades of steel, absorbs so much energy that it undergoes large plastic deformations many times greater than that absorbed by the same structure in a purely elastic mode. Though some of the equations applied in this study are empirical in nature, being based on model tests, the basic mathematical theory employed was still that of linear elasticity. Such a treatment is inherently conservative, giving drop height figures that should be used as lower bounds rather than being completely definitive. The failure thresholds reported here should be used in correlation with the forces expected to exist during accidents.

\section{REFERENCES}

1. Max McWhirther, et al., Final Report on Special Tests of Plutonium Oxide Shipping Containers to FAA Flight Recorder Survivability Standards, Sand 75-0446, Sandia Laboratories, Albuquerque, NM, Sept. 1975. 
2. L. L. Bonzon, and M. McWhirter, "Special Tests of Plutonium Shipping Containers," (IAEA-SR-10/22), presented at the IAEA International Seminar on the Design, Construction and Testing of Packaging for the Safe Transport of Radioactive Materials, Vienna, Austria, August 1976.

3. T. I. McSweeney, R. J. Hall et al., An Assessment of the Risk of Transporting Plutonium 0xide and Liquid Plutonium Nitrate by Truck, BNWL-1846, Battelle, Pacific Northwest Laboratories, Richland, WA, August 1975.

4. L. L. Bonzon and J. T. Schamaun, "Container Damage Correlation with Impact Velocity and Target Hardness," (IAEA-SR-10/21), presented at the IAEA International Seminar on the Design, Construction and Testing of Packaging for the Safe Transport of Radioactive Materials, Vienna, Austria, August 1976. 


\subsection{CONDITIONS OF PACKAGES DURING TRANSPORT}

To obtain a data bank of package conditions during transport for use in the risk analysis, a survey was conducted of companies and laboratories who routinely receive plutonium.

Since the purpose of the survey was to evaluate packaging condition during transport, the contents of the package were of secondary importance. Since the same containers are used to ship plutonium, ${ }^{23} U$ and highly enriched $235 \mathrm{U}$, packaging condition data on all are relevant and were therefore, included in the data base.

The air shipment evaluation in this document considers only plutonium dioxide shipments in the $6 M$ container. The survey was much broader. The results of the entire survey are presented here because there is a certain amount of similarity between all the containers surveyed and because the goal of this section was to compile the broadest possible data base for determining the occurrence frequency of off-normal packaging conditions.

\subsection{SCOPE OF SLIRVEY}

To determine the package condition information which should be in the data bank, fault trees were constructed for the $L-10$ and the $6 \mathrm{M}$ packages. Fault tree terminology and symbolism are shown in Table 7.1. Fault trees are shown in Figures 7.1 and 7.2 .

The fault trees traced each step of package loading and closure and identified all conditions that could possibly affect package containment integrity. The conditions of particular interest, however, were those involving the primary containment vessel.

Based on the information identified in the fault trees, questionnaires were prepared for use in the survey of the nuclear industry. These questionnaires are shown in Appendix B of Reference 1. 
TABLE 7.1 Fault Tree Symbolism

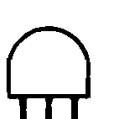

output

"AND" logic gate. The simultaneous occurrence of inputs is required to cause an output.

inputs

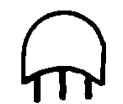

output

"OR" logic gate. The occurrence of any one of the inputs will result in an output.

inputs

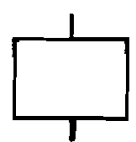

Fault event that results from the logical operation of two or more fault'events. It is always the output from a logic gate.

Basic fault event. It requires no further development. Data regarding frequency and mode of failure can be derived empirically.

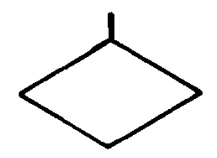

Inferred fault event. Any failure except a primary failure which is not developed further due to lack of information, time or money or due to the low probability of occurrence. It can also be used where other analyses give sufficient information to indicate that further analysis would be redundant.

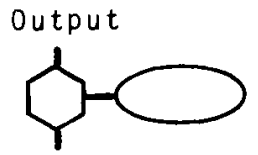

Input

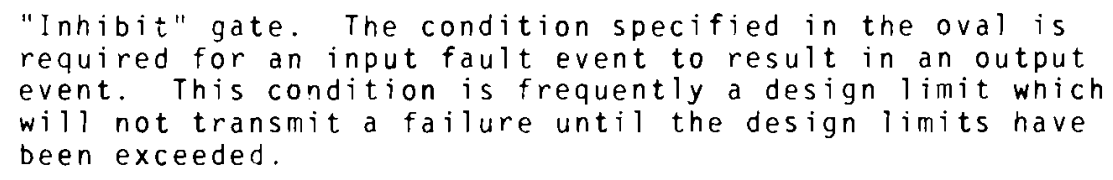
event. This condition is frequently a design limit which will not transmit a failure until the design limits have been exceeded.

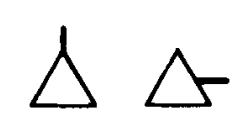

Transfer symbol denoting that failure also impacts on other branches of fault tree. A line at the apex of the triangle represents a "transfer in." A line in the side represents a "transfer out." A number is placed in the triangle to identify transfer locations.

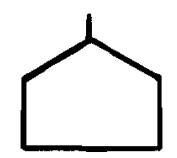

\footnotetext{
"House" defines an event that must occur, or is expected to occur, due to design and normal operating conditions.
} 


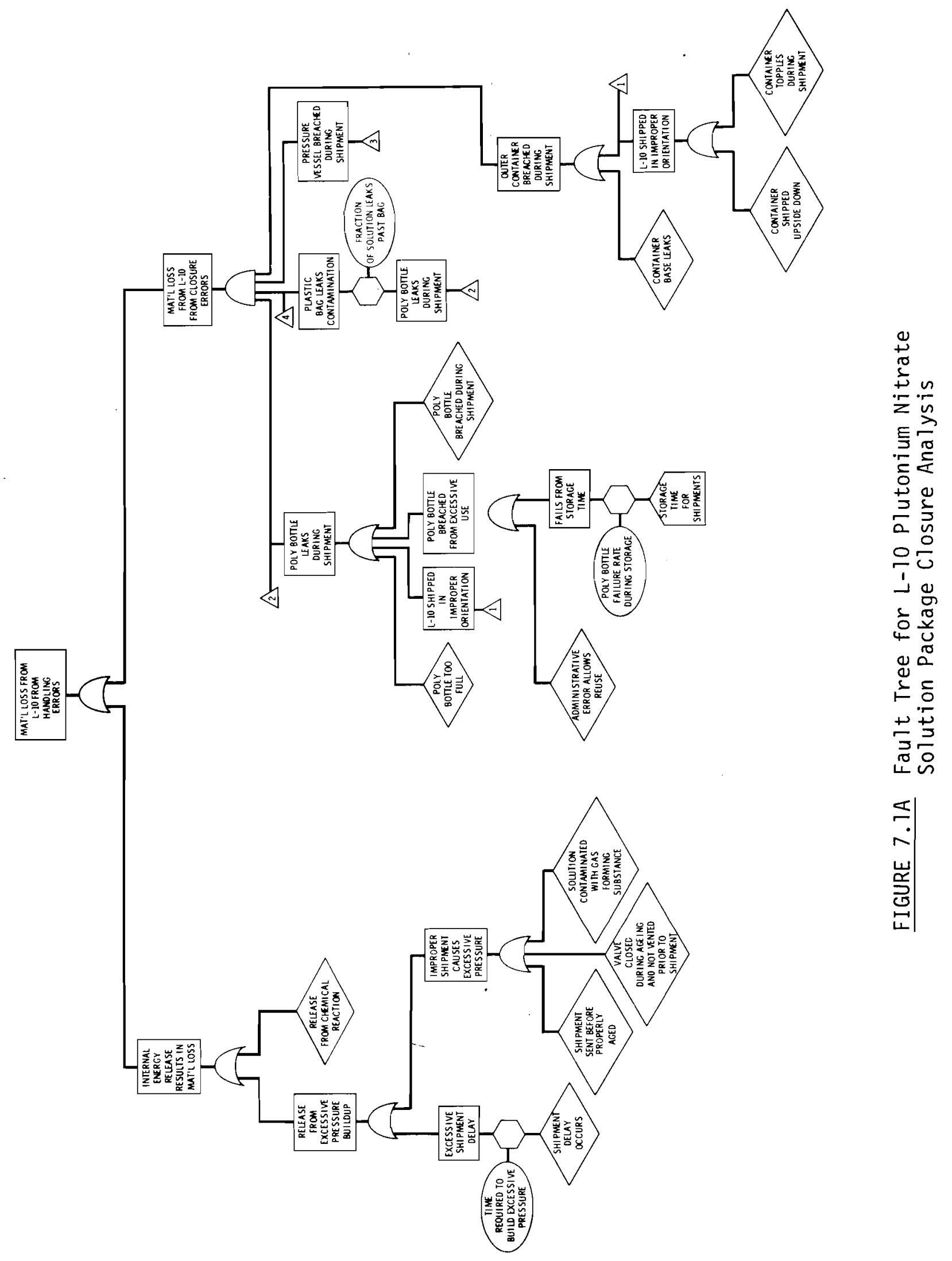




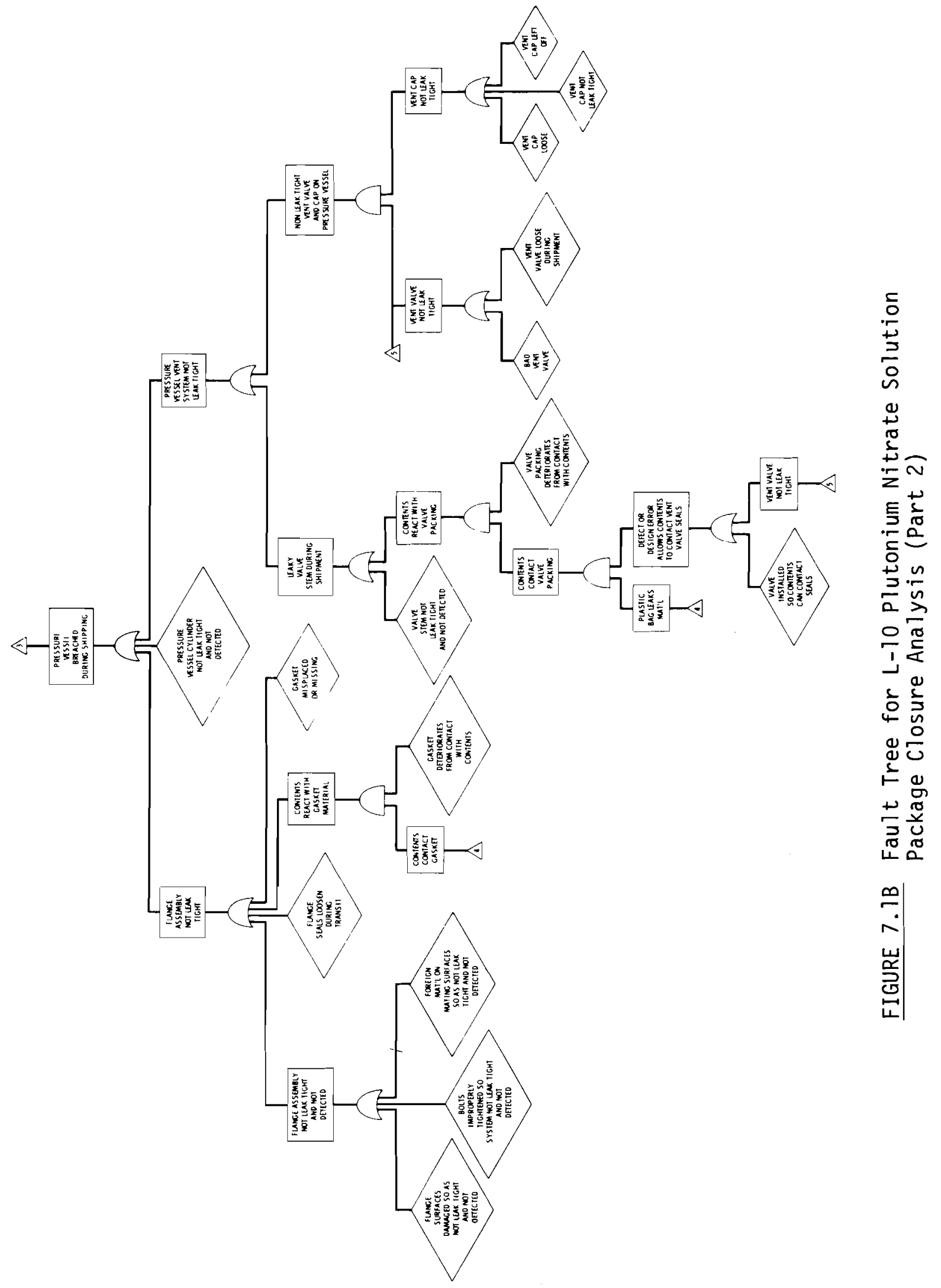




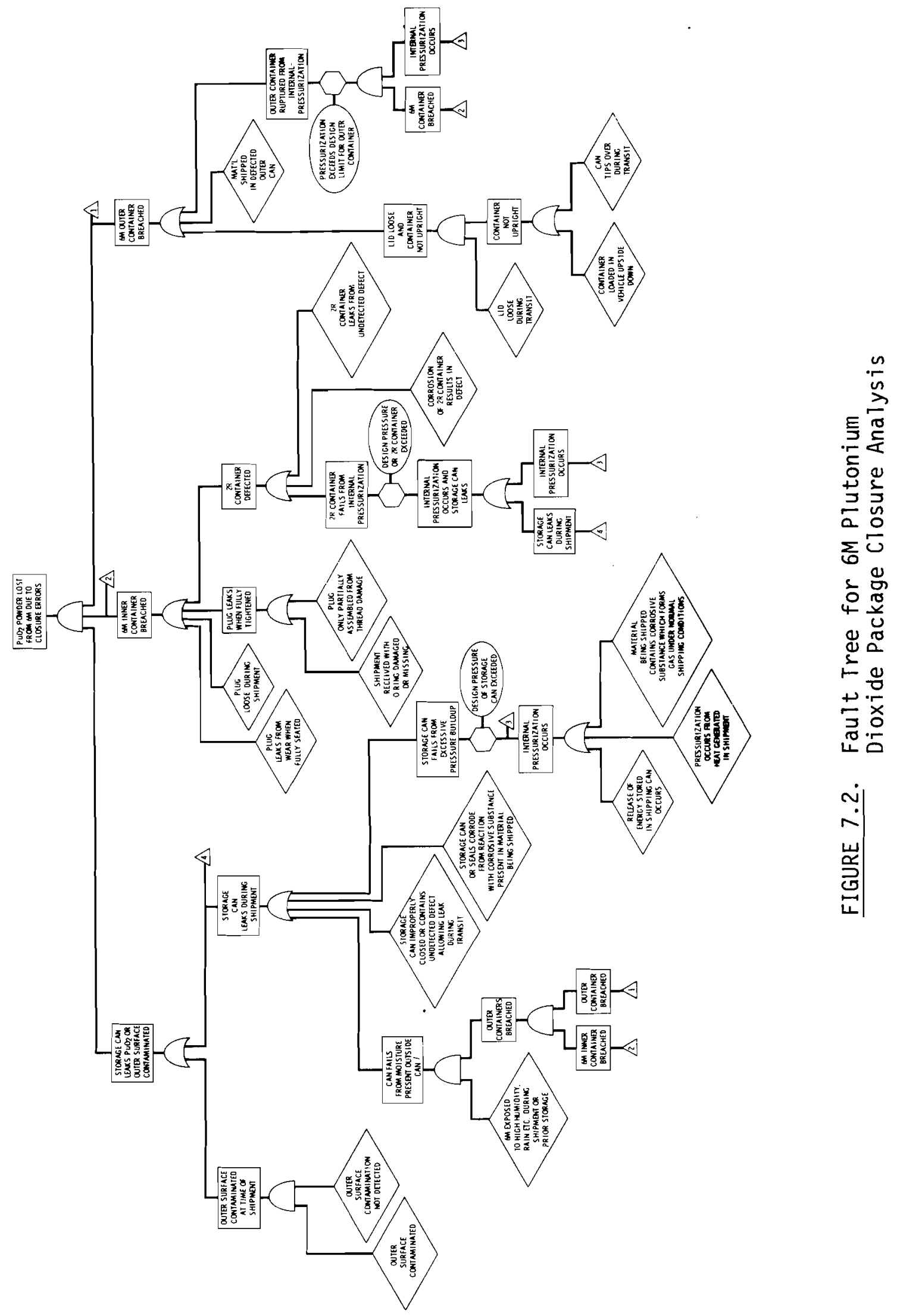




\subsubsection{Packages Included in Survey}

As described in the introduction to this section, a broad class of shipping containers was included in the survey. Specific containers considered include: the L-10 and L-3 containers designed to ship liquid plutonium nitrate solutions, the $6 \mathrm{M}$ and LLD containers designed for oxide powder and metal button shipments. A description of the $6 \mathrm{M}$ is given in Appendix $\mathrm{A}$. Detailed descriptions of the other containers can be obtained from Reference 2.

\subsubsection{Sites Included in Survey}

The companies and laboratories visited are listed below.

Argonne National Laboratory

Argonne, Illinois

E. I. duPont deNemours

Savannah River Plant

Aiken, South Carolina

Union Carbide Corporation

Oak Ridge National Laboratory

Oak Ridge, Tennessee

Kerr-McGee Nuclear Corporation

Oklahoma City, Oklahoma

Los Alamos Scientific Laboratory

Los Alamos, New Mexico
Rocky Flats Plant

The Dow Chemical Company

Golden, Colorado

New York State Atomic and

Space Development Authority

New York, New York

NUMEC

Babcock and Wilcox Company

Apo 110, Pennsylvania

Atlantic Richfield Hanford

Company

Richland, Washington

\subsubsection{Time Period Covered by Survey}

The survey set out to cover the time period 1970-1974. Due to the limited time for the survey and the format of records kept by the plutonium users, this period was considered flexible. Some experience prior to 1970 was included, and not all experience in the 1970-1974 period could be included.

\subsection{RESULTS OF SURVEY}

After completion of the survey, the data were assembled and tabulated. The results are presented below. 


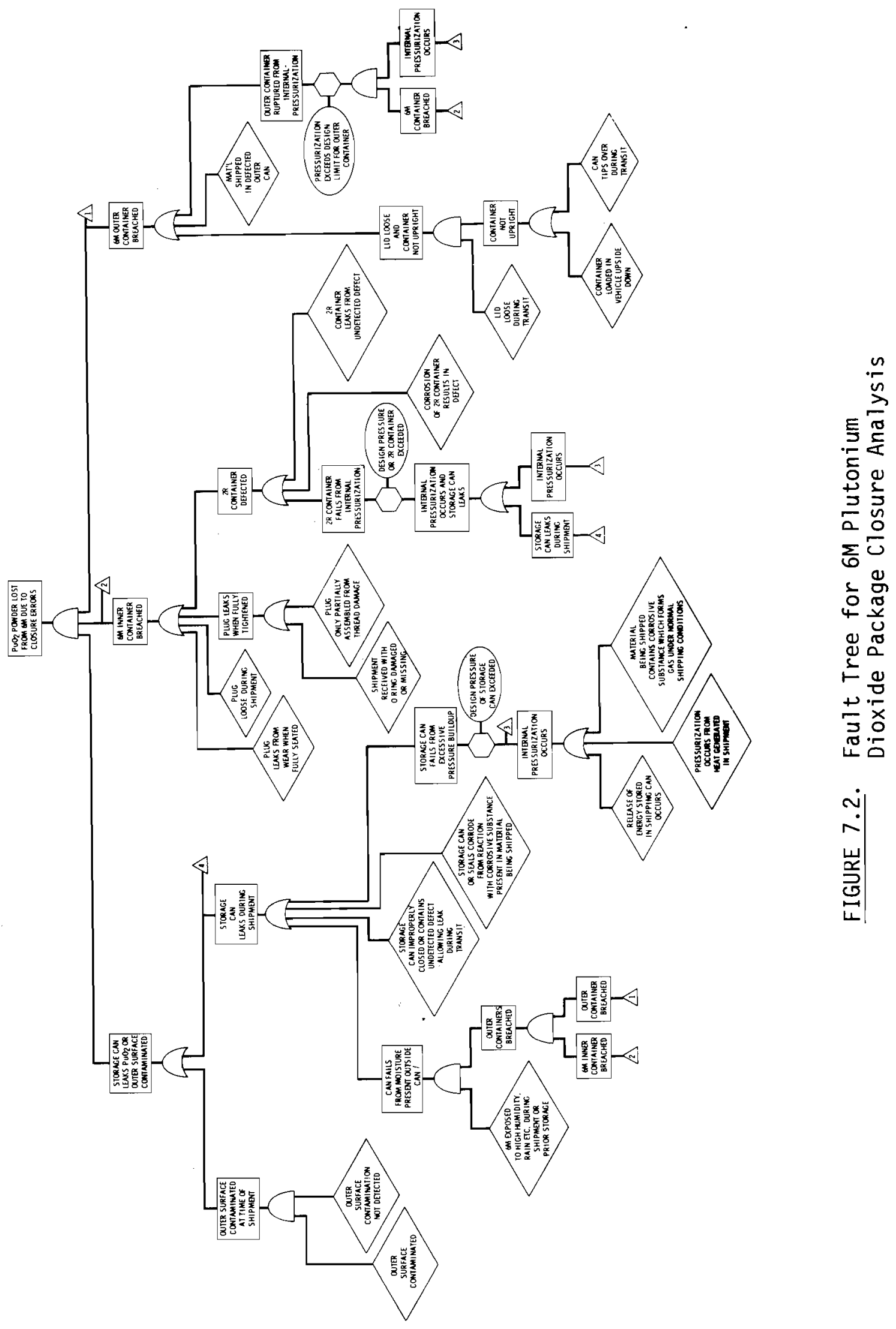




\subsubsection{Packages Included in Survey}

As described in the introduction to this section, a broad class of shipping containers was included in the survey. Specific containers considered include: the L-10 and L-3 containers designed to ship liquid plutonium nitrate solutions, the 6M and LLD containers designed for oxide powder and metal button shipments. A description of the $6 \mathrm{M}$ is given in Appendix $A$. Detailed descriptions of the other containers can be obtained from Reference 2.

\subsubsection{Sites Included in Survey}

The companies and laboratories visited are listed below.

Argonne National Laboratory

Argonne, Illinois

E. I. duPont deNemours

Savannah River Plant

Aiken, South Carolina

Union Carbide Corporation

Oak Ridge National Laboratory

Oak Ridge, Tennessee

Kerr-McGee Nuclear Corporation

Oklahoma City, Oklahoma

Los Alamos Scientific Laboratory

Los Alamos, New Mexico
Rocky Flats Plant

The Dow Chemical Company

Golden, Colorado

New York State Atomic and

Space Development Authority

New York, New York

NUMEC

Babcock and Wilcox Company

Apol10, Pennsylvania

Atlantic Richfield Hanford

Company

Richland, Washington

\subsubsection{Time Period Covered by Survey}

The survey set out to cover the time period 1970-1974. Due to the limited time for the survey and the format of records kept by the plutonium users, this period was considered flexible. Some experience prior to 1970 was included, and not all experience in the 1970-1974 period could be included.

\subsection{RESULTS OF SURVEY}

After completion of the survey, the data were assembled and tabulated. The results are presented below. 


\subsubsection{Number of Shipments and Packages}

A summary of the number of packages covered by the survey is given in Table 7.2. The total is about 775 shipments, which includes $2130 \mathrm{~L}-3$ and L-10 type packages and about 4100 LLD and 6M type packages. As previously indicated, several shipments of ${ }^{233} U$ in $L-10$ packages are included with the results for liquid $\mathrm{Pu}\left(\mathrm{NO}_{3}\right)_{4}$, and several shipments of plutonium metal in LLD and $6 \mathrm{M}$ packages are included with the $\mathrm{PuO}_{2}$ results. These additions were felt to be justified since the primary objective of this study was to obtain information on package closure which generally is not dependent on content.

\subsubsection{Final Data Compiled for Use in Risk Assessment Model}

A surmary of observations made by those contacted in the survey is presented in Table 7.3. It should be emphasized that, in the extensive experience sampled by the survey, a complete loss of packaging integrity has never been observed.

\subsubsection{Limitations of Survey}

Even though the information obtained in the survey (Table 7.3) provides a reasonably good base for the risk assessment model, certain limitations should be recognized. First, for the most part, observations were made by personnel recollections. Consequently, the time periods in which particular abnormal conditions occurred and the number of occurrences were not certain.

Second, nearly all of the sites visited indicated that they now use a check-off sheet to help assure that packages are properly and securely closed. Some of these sheets have been in use for as long as 10 years while others have been implemented more recently. The implementation of quality assurance (QA) requirements by the USAEC and quality control (QC) procedures by shippers during 1972 and 1973 would have a significant effect on any package closure information obtained. Most packaging faults occurred prior to 1972. Al1 those interviewed pointed out that very few package closure deficiencies have been observed since about 1972 . 
TABLE 7.2 Estimated Number of Shipments and Packages Included in Survey

(period covered: 1970-1974)

SHIPMENTS

(A11 package types)

Number

775

PACKAGES SHIPPED

$\mathrm{Pu}\left(\mathrm{NO}_{3}\right)_{4}$ Solution Packages $2130^{(\mathrm{a})}$

( $L-3$ and $L-10$ )

$\mathrm{PuO}_{2}$ Packages

LLD- 1

$6 \mathrm{M}$

$2700-3000^{(b)}$

Total Packages

$\sim 6200$
(a) Includes several $233 \mathrm{U}$ packages that were shipped in L-3S and L-10s in the same manner as liquid plutonium nitrate.
(b) Includes several plutonium metal packages which were shipped in the same manner as
plutonium dioxide
(c) There were 806 packages in storage not included in this survey which were scheduled to be unpacked by July 1975 .

Because of these factors, the results reported in Table 7.3 are considered to be conservative and not necessarily representative of current package conditions during transport. 


\section{TABLE 7.3. Data Bank - Package Closure Experience Obtained by Survey (For Period 1970-1974)}

\begin{tabular}{cc} 
Number of & $\begin{array}{c}\text { Occurrence } \\
\text { Frequency } \\
\text { Occurrence }\end{array}$ \\
\hline
\end{tabular}

Remarks

Part I - PLUTONIUM NITRATE SOLUTION SHIPMENTS (L-3 and L-10 Packages)

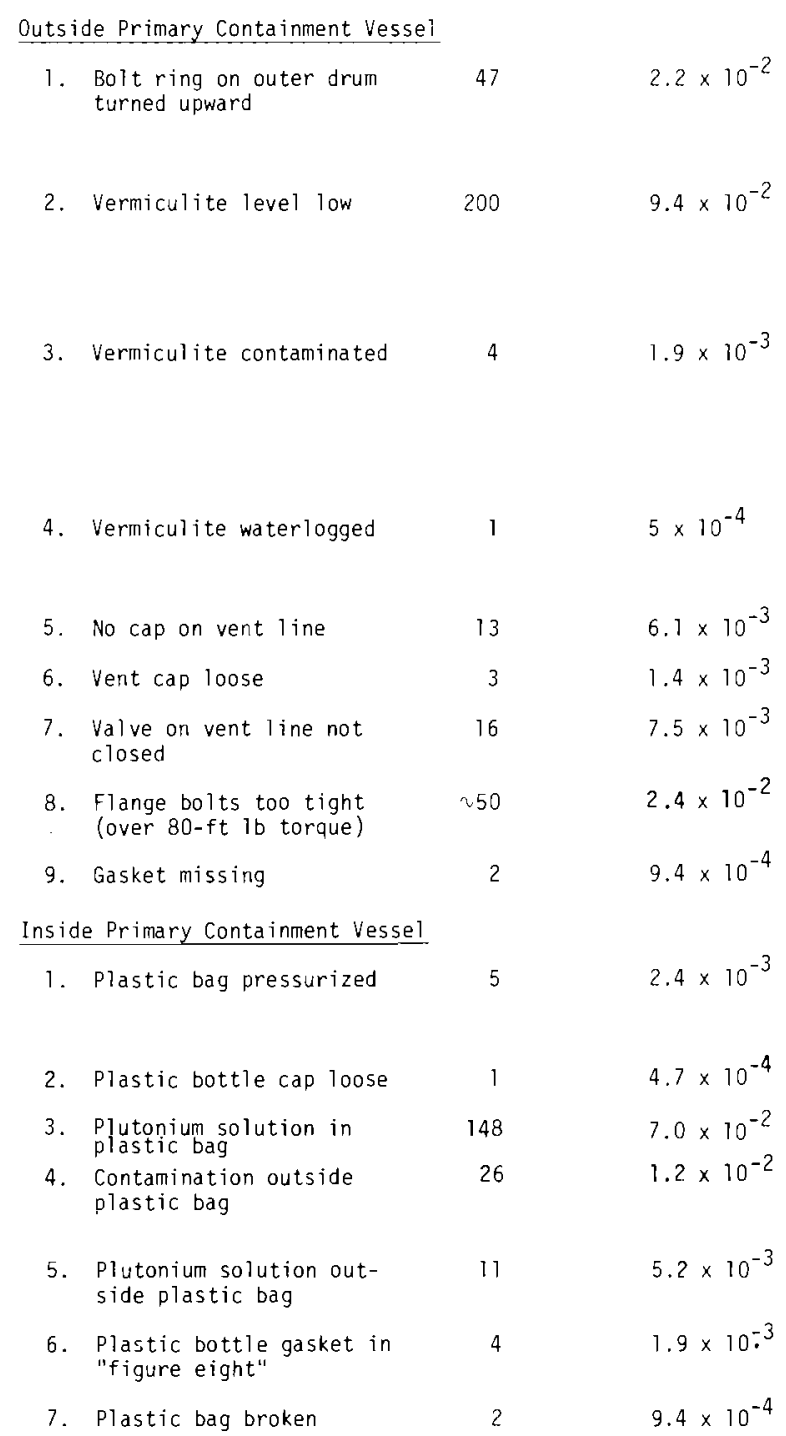

The bolt ring closure is designed to be attached so that the bolt is down against the drum rather than upward, although not a requirement

Vermicutite is normally 6 in. above top of containment vessel lid. If too low, fire protection may not be adequate. In two instances the vermiculite bags around top were missing.

In each instance contamination is believed to have resulted at the time of closure by the shipper, not by leakage from the vessel. The amount of plutonium involved in contamination was considered negligible from viewpoints of criticality hazard.

Source of water not certain. Could have entered as rain through vent holes in older design.

In no instance was the valve open and the vent line cap missing or loose at the same time.

Contrary to expectations before the survey, relatively few plastic bags were found to be pressurized by receivers of $\mathrm{Pu}\left(\mathrm{NO}_{3}\right)_{4}$.

Gasket twisted when tightening 


\section{TABLE 7.3. (Contd)}

Occurrence $\quad \begin{gathered}\text { Number of } \\ \text { Occurrence }\end{gathered} \quad \begin{gathered}\text { Fccurrence } \\ \text { (per containency received) }\end{gathered}$

Part II - PLUTONIUM DIOXIDE SHIPMENTS IN 6M PACKAGES

Outside Primary Containment Vessel

1. Hole in outer drum

2. Bolt rings turned upward

3. Bolt ring bolt loose (finger tight)

4. Bolt ring bolt broke off while tightening

Inside Primary Containment Vessel

1. Can bulged due to internal pressure

2. Contamination outside of can

3. Contamination o: plastic bag

Part III - PLUTONIUM DIOXIDE SHIPMENTS IN (LLD-1 PACKAGES)

Outside Primary Containment Vessel

1. Locking cover loose I

2. Plug in $2 R$ containment vessel not tight 2

66

$1.6 \times 10^{-3}$

$5.3 \times 10^{-2}$

$1.2 \times 10^{-1}$

6 of 300

$2 \times 10^{-2}$
$5 \times 10^{-4}$

Remarks

These holes occurred during relatively minor transportation mishaps.

See first remark, Part I

Although loose, wire seal prevents bolt from coming off.

In preparing drums for shipment bolts broke during final tightening operation.

In these two instances, the cans were not ruptured.

(Source of contamination was evidently \{packaging operation, not can leak.

These estimates are based on the recollection of those interviewed in terms of percentage of total packages received. The estimate could be conservatively high. What apparently happens is that the plug loosens due to vibration during transport. In one instance the plug had worked its way completely out of the containment vessel by the time the package reached its destination.

Long handled wrench required to remove plug
4. Plug extremely tight

5. 0 ring missing

Inside Primary Containment Vessel

1. Can bulged due to internal pressure

2. Can breached or not completely sealed upon arrival

3. Contamination outside can but not outside containment vessel
$2.4 \times 10^{-4}$

$2.4 \times 10^{-4}$

$3.9 \times 10^{-3}$

11

2

3
$4.9 \times 10^{-4}$

$1.1 \times 10^{-3}$

$1.1 \times 10^{-3}$ 


\section{REFERENCES}

1. T. I. McSweeney, R. J. Hall et al., An Assessment of the Risk of Transporting Plutonium Oxide and Liquid Plutonium Nitrate by Truck, BNWL-1846, Battelle, Pacific Northwest Laboratories, Richland, WA, August 1975.

2. Directory of Packagings for Transportation of Radioactive Materials, Division of Waste Management and Transportation, WASH 1279, United States Atomic Energy Commission, Washington, DC, 1973. 


\subsection{RELEASE SEQUENCE IDENTIFICATION}

Plutonium is not currently shipped by air (except for medical and national defense purposes) and no release has occurred during any air shipment of plutonium in the past. Therefore, possible ways that releases could occur (release sequences) must be identified by a reasoning process. The information provided in Sections 5, 6, and 7 gives a basis for identifying events or combinations of events which could result in a release of plutonium.

This section describes a formalized procedure for identifying combinations of conditions which could result in a release. The first step in the procedure is to develop fault trees using the techniques described in Section 8.1. Section 8.2 presents the fault trees developed for the air shipment of plutonium dioxide powder in 6M containers. The second step in the procedure is to develop a list of release sequences from the fault tree. The development of these release sequences will be discussed in Section 8.3.

\subsection{FAULT TREE CONSTRUCTION}

The fault tree analysis technique was developed in the 1960s in the aerospace industry to identify design deficiencies before actual space flight of the equipment. Basically the procedure is to assume a failure and work backwards to identify component failures which could cause or contribute to the failure. The fault tree should be related to individual components for which failure data are available. For instance, in an electronic circuit the basic failure might occur in a resistor. In practice, fault trees seldom are developed to that degree. What occurs instead is development of fault trees in terms of basic system modules. Using the electronic example, one would carry the possible failure back through the fault tree only to the amplifier which contained the resistor. Such a fault tree is called a Top Level Fault Tree since it usually identifies only large systems which could result in a failure. 
The methodology applied to transportation of plutonium involves postulating of a release of plutonium during transport and then examining of the series of events which must have occurred to cause the release. This form of reasoning is thought to be more inclusive than beginning with an initiating event and working toward a release, (i.e., constructing accident scenarios or decision trees). At the same time, quantification of the release requires specifications of an ordered sequence of events or accident scenarios. From this analysis, the tree constructed using the fault tree methodology is used as the basis for estimating the total release probability. Then the tree is broken down into all the possible release sequences. In effect, all the accident scenarios will be obtained from the fault tree. When properly applied, the accident scenarios obtained from using the fault tree methodology are likely to be more complete than the alternative method of trying to list all the accident scenarios without the aid of any formalized reasoning process.

\subsection{FAULT TREES FOR SHIPMENT OF PU0 2 IN 6M CONTAINERS}

The transportation of plutonium by air involves two separate modes of transportation. A motor carrier must take the plutonium from the reprocessing plant to the nearest cargo airport and another motor carrier must pick up the plutonium from an airport closest to the fabrication plant and transport it to the fabrication plant. The fault trees for evaluating release sequences during truck transport have been previously reported (1) and will not be repeated here.

Fault trees for the air shipment of plutonium oxide in 6M containers will be presented in this section. The fault trees include the effects of the aircraft accident environment, and packaging condition; effects of sabotage or diversion are not considered. The fault tree developed to determine applicable failure sequences is presented in Figure 8.1. A 1ist of identified events or failure elements which could contribute to a release is shown in Table 8.1 . 


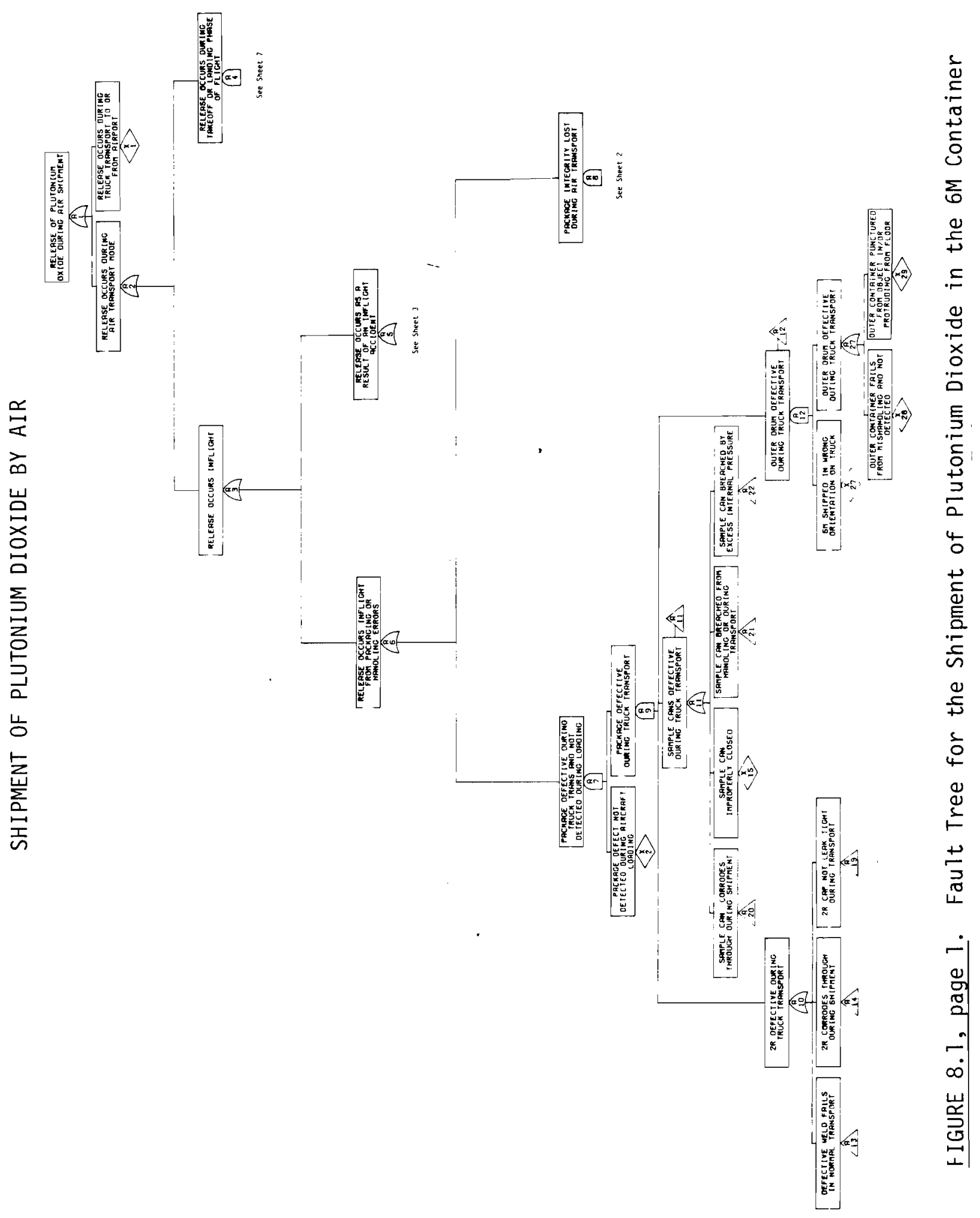




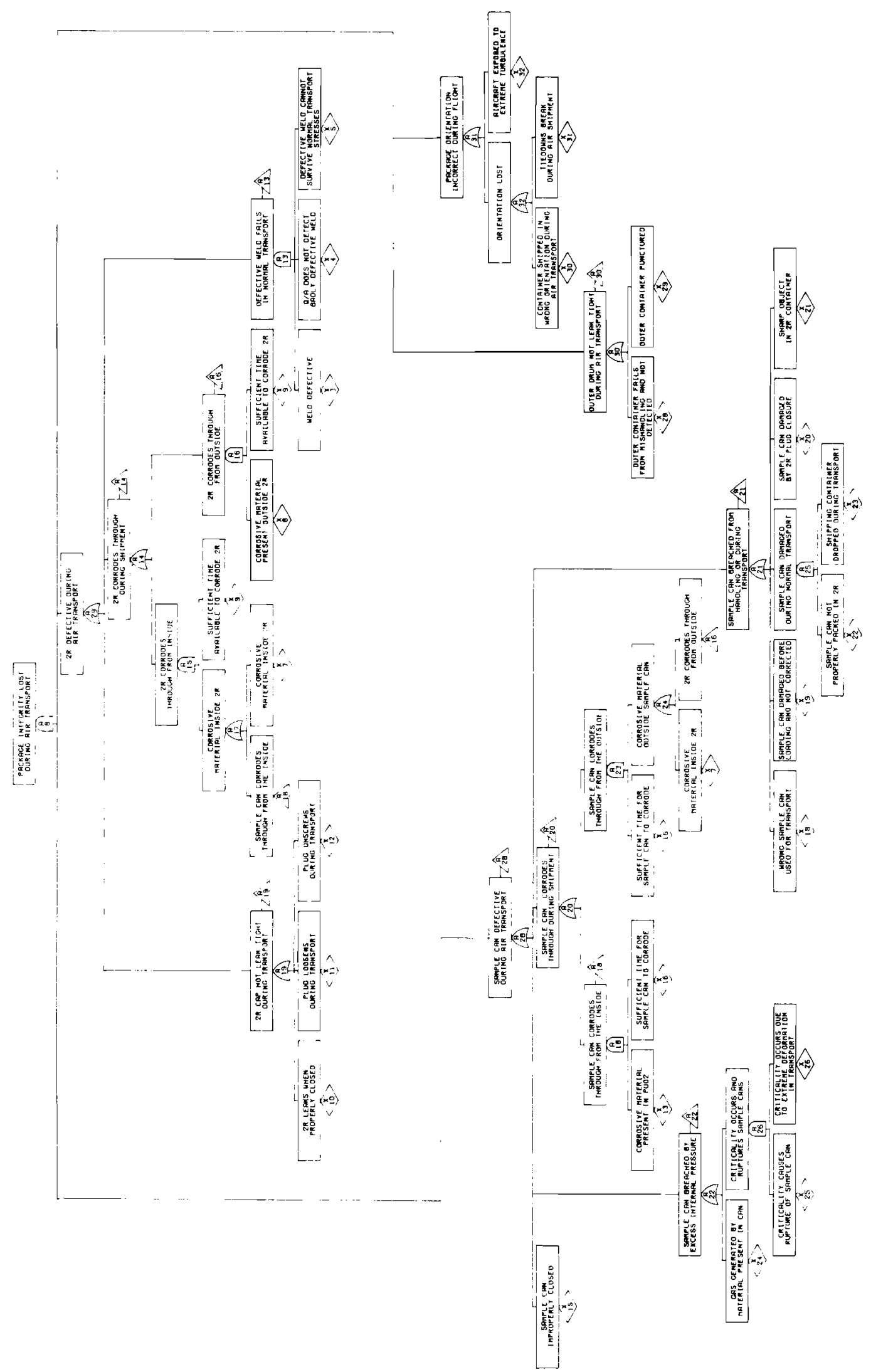

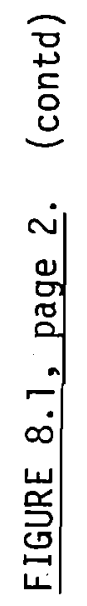




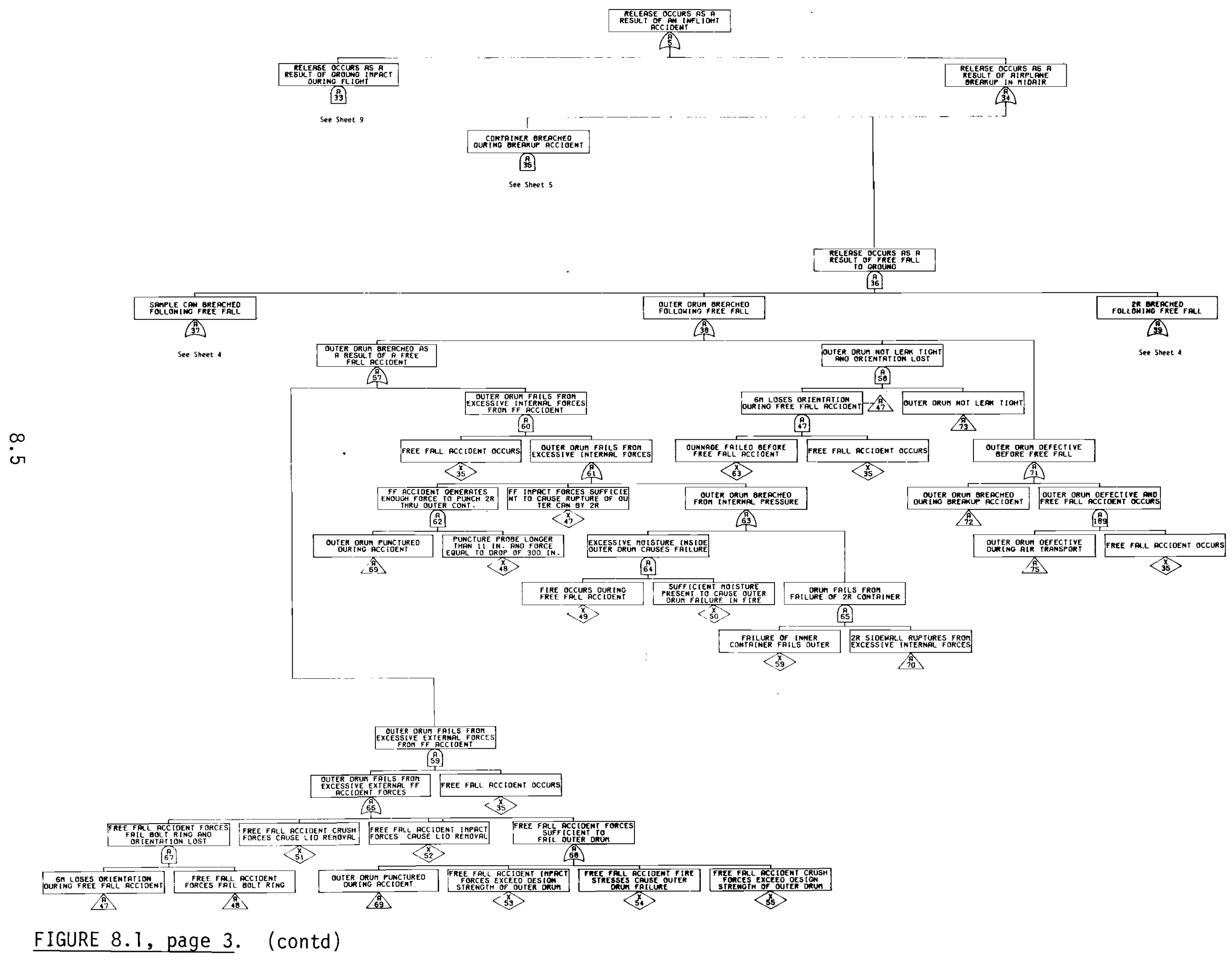




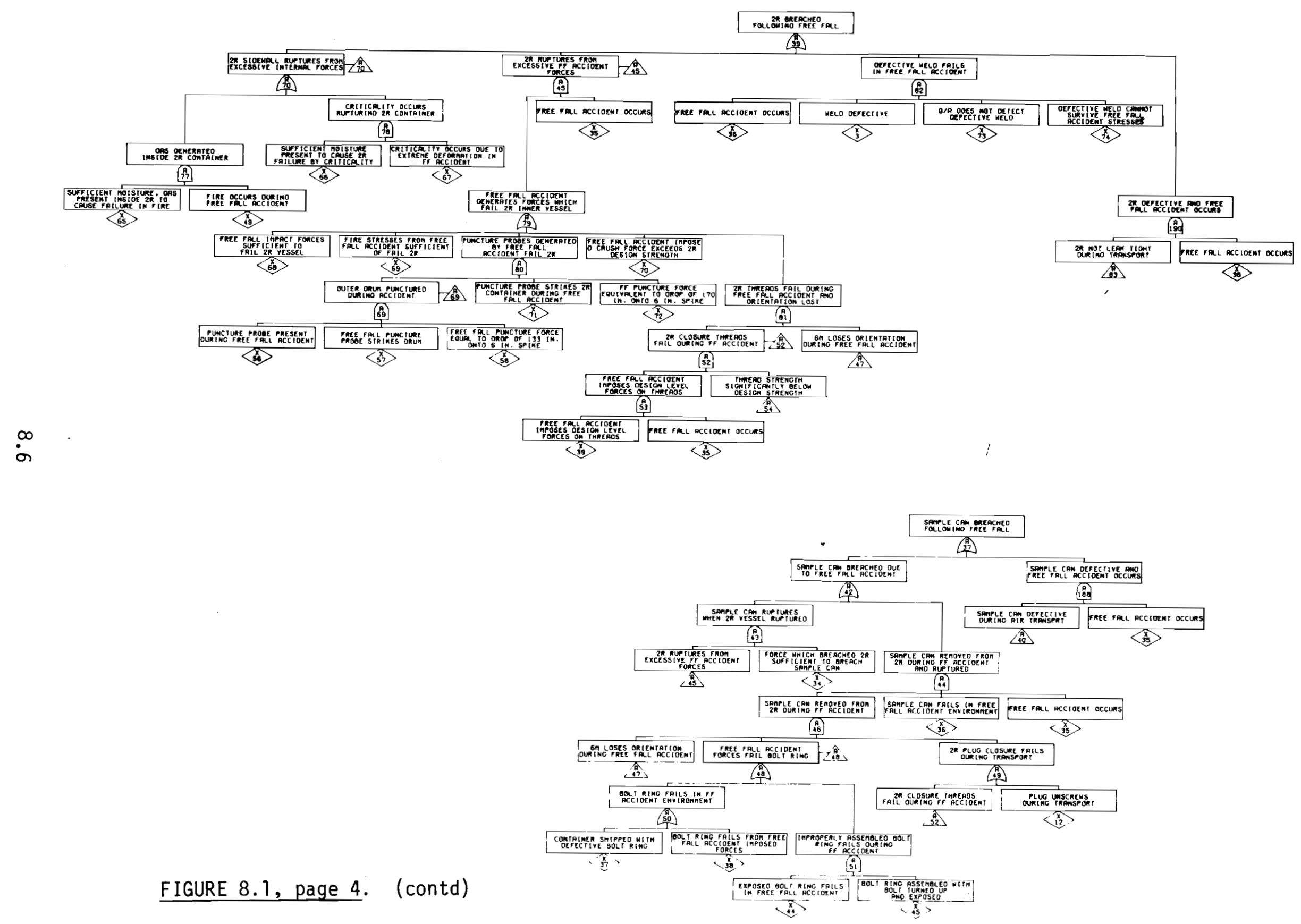




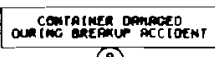

35

\begin{tabular}{|c|c|c|}
\hline 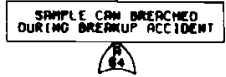 & 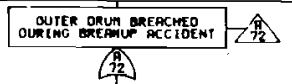 & 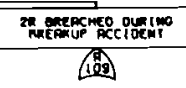 \\
\hline
\end{tabular}

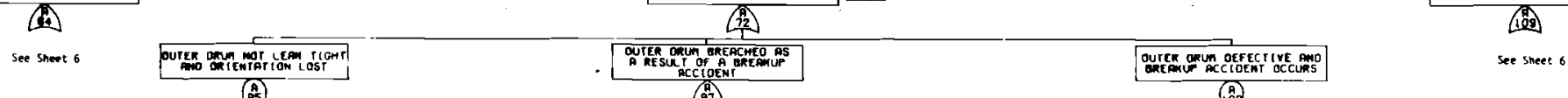

FIGURE 8.1 , page 5. (contd) 

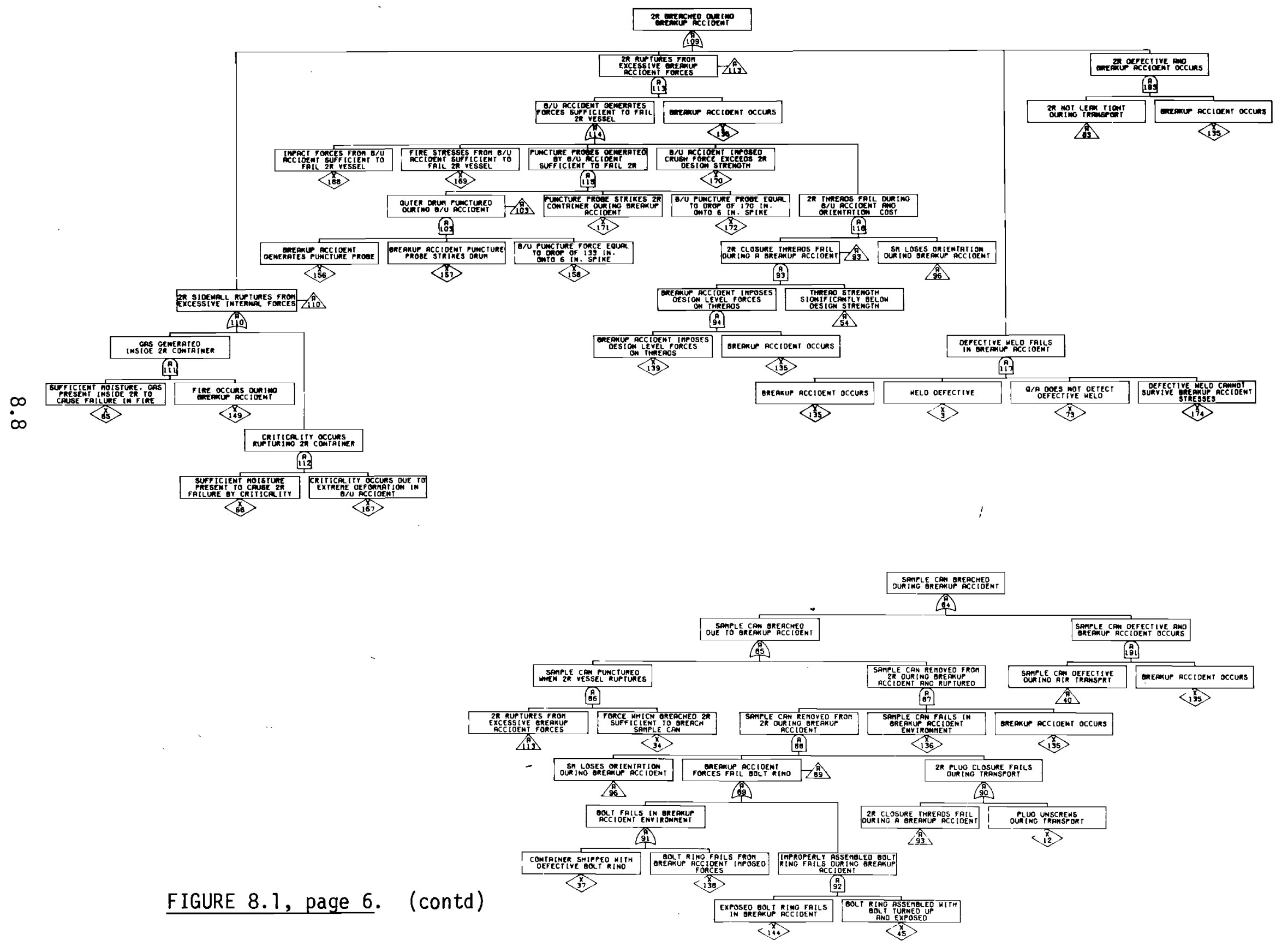


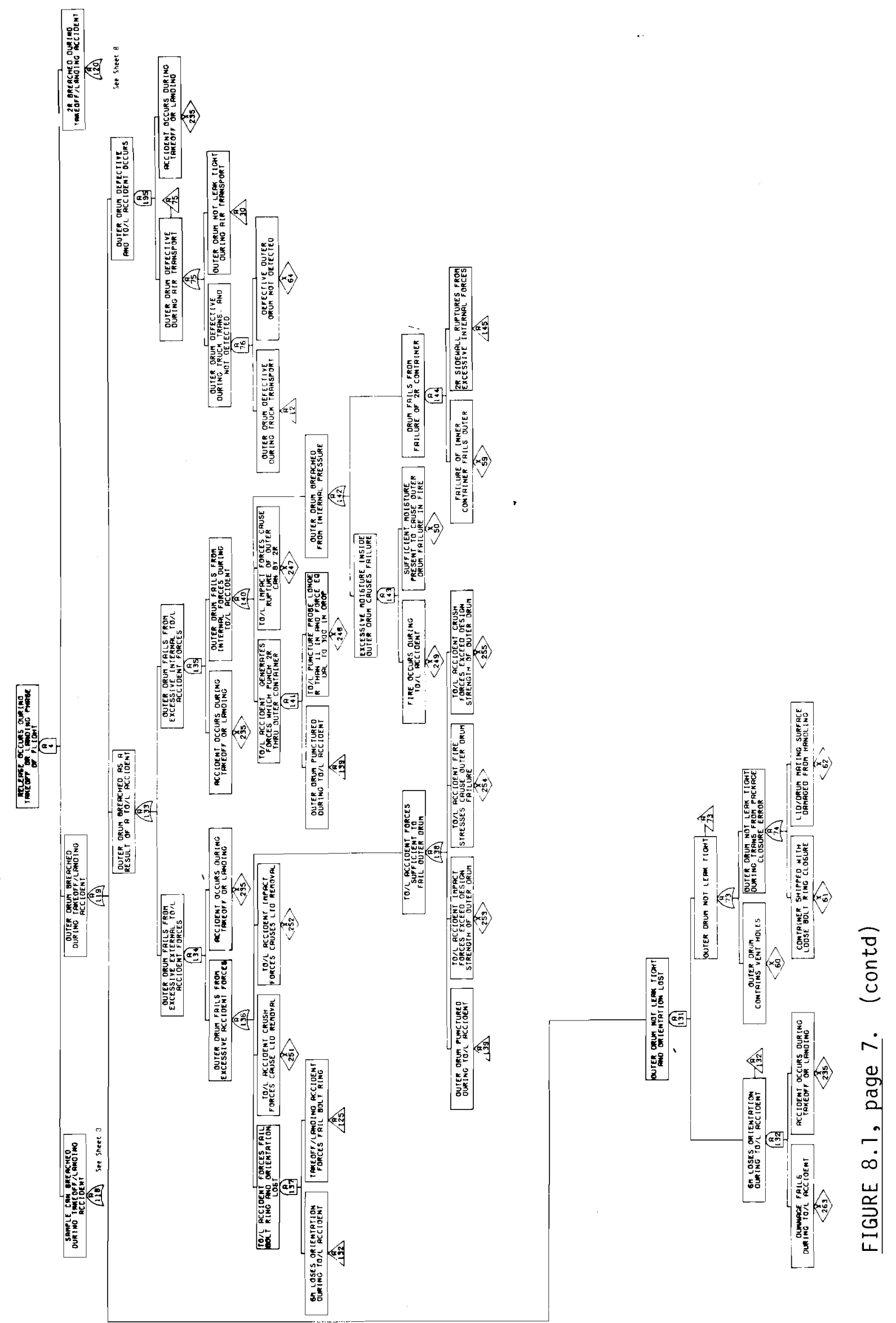

8.9 


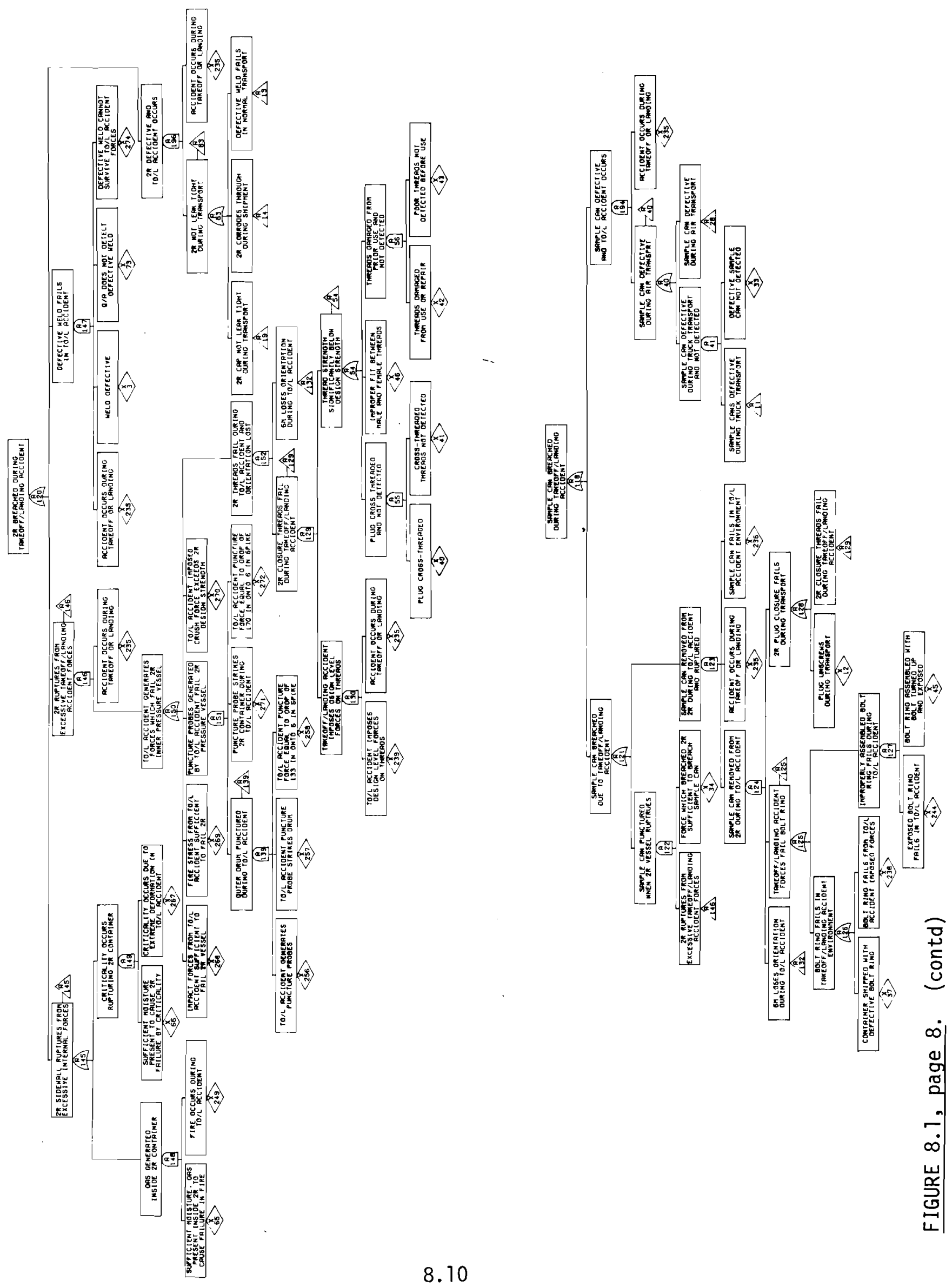




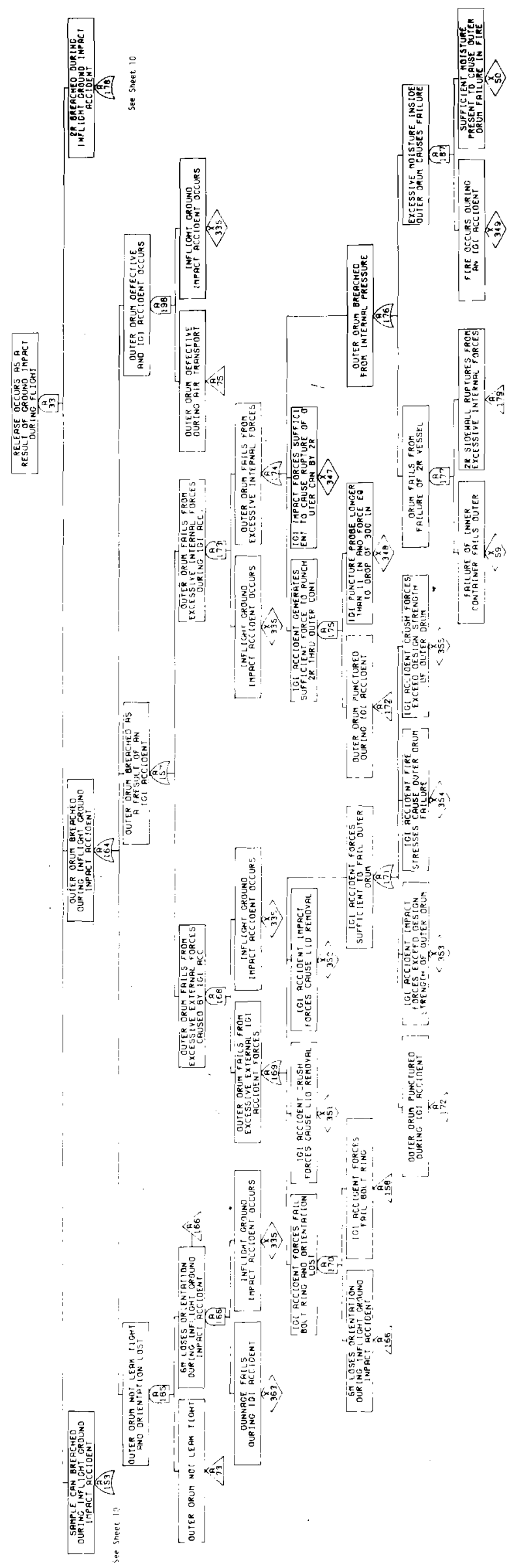

高

递 

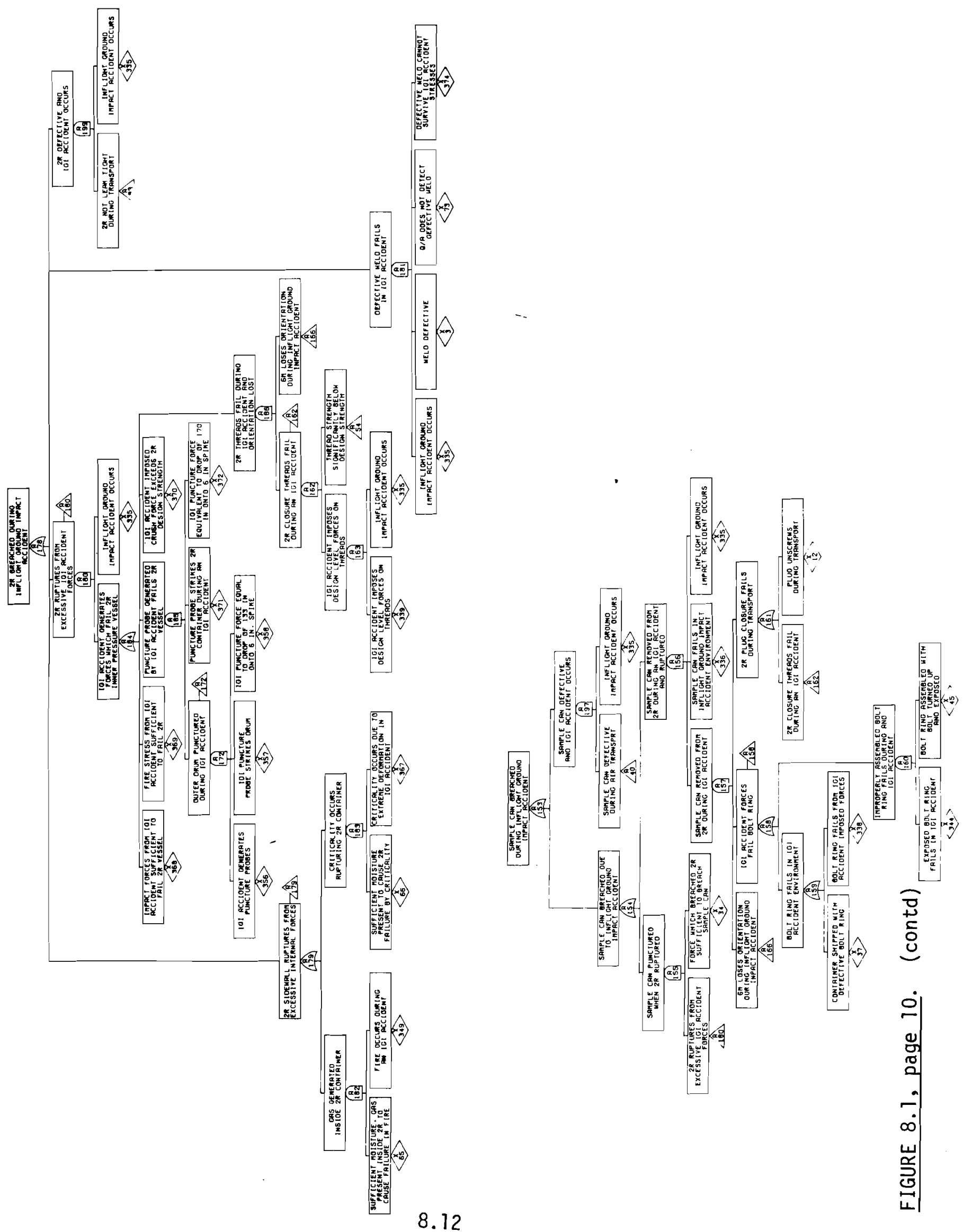


\section{TABLE 8.1 Listing of Basic Events for 6M Analysis}

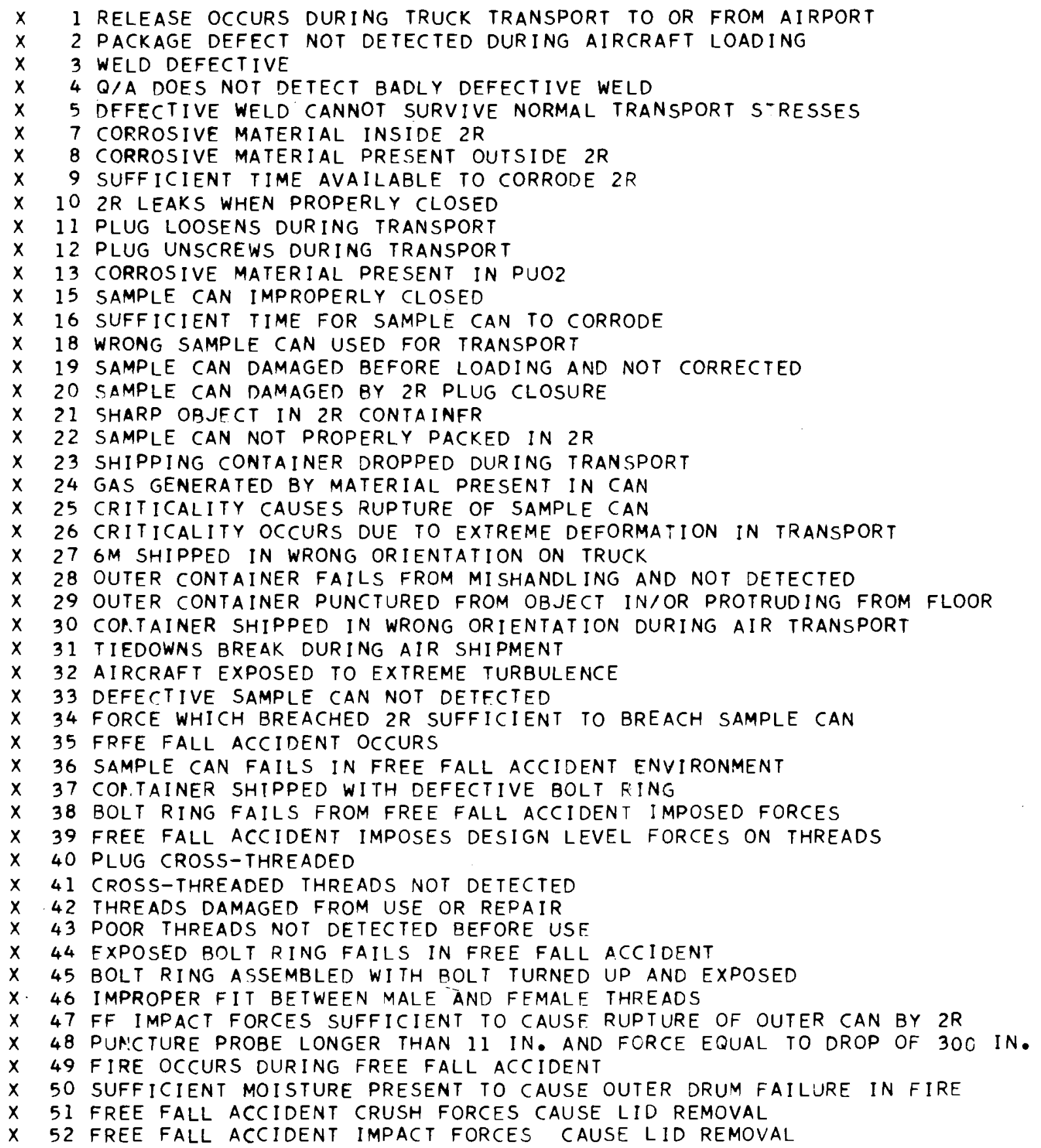


TABLE 8.1 (Cont'd)

$X \quad 53$ FREE FALL ACCIDENT IMPACT FORCES EXCEED DESIGN STRENGTH OF OUTER DRUM

$X \quad 54$ FREE FALL ACCIDENT FIRE STRESSES CAUSE OUTER DRUM FAILURE

$X \quad 55$ FREE FALL ACCIDENT CRUSH FORCES EXCEED DESIGN STRENGTH OF OUTER DRUM

$X \quad 56$ PUNCTURE PROBE PRESENT DURING FREE FALL ACCIDENT

$X \quad 57$ FREE FALL PUNCTURE PROBE STRIKES DRUM

$X \quad 58$ FREE FALL PUNCTURE FORCE EQUAL TO DROP OF 133 IN. ONTO 6 IN. SPIKE

$X \quad 59$ FAILURE OF INNER CONTAINER FAILS OUTER

$X$ 60 OUTER DRUM CONTAINS VENT HOLES

$X \quad 61$ CONTAINER SHIPPED WITH LOOSE BOLT RING CLOSURE

$X \quad 62$ LID/DRUM MATING SURFACE DAMAGED FROM HANOLING

$X \quad 63$ DUNNAGE FAILED BEFORE FREE FALL ACCIDENT

$X \quad 64$ DEFECTIVE OUTER DRUM NOT DETECTED

$X \quad 65$ SUFFICIENT MOISTURE, GAS PRESENT INSIDE $2 R$ TO CAUSE FAILURE IN FIRE

$X \quad 66$ CUFFICIENT MOISTURE PRESENT TO CALISE 2R FAILIJRE BY CRITICALITY

$X \quad 67$ CRITICALITY OCCURS DUE TO EXTREME DEFORMATION IN FF ACCIDENT

$X \quad 68$ FREE FALL IMPACT FORCES SUFFICIENT TO FAIL $2 R$ VESSEL

$X \quad 69$ FIRE STRESSES FROM FREE FALL ACCIDENT SUFFICIENT OF FAIL $2 R$

$X$ TO FREE FALL ACCIDENT IMPOSED CRUSH FORCE EXCEEDS $2 R$ DESIGN STRENGTH

$X 71$ PUNCTURE PROBE STRIKES $2 R$ CONTAINER DURING FREE FALL ACCIDENT

$X 72$ FF PUNCTURE FORCE EQUIVALENT TO DROP OF 170 IN. ONTO 6 IN. SPIKE

$X 73$ Q/A DOES NOT DETECT DEFECTIVE WELD

$X \quad 74$ DEFECTIVE WELD CANNOT SURVIVE FREE FALL ACCIDENT STRESSES

$X 135$ BREAKUP ACCIDENT OCCURS

$X 136$ SAMPLE CAN FAILS IN BREAKUP ACCIDENT ENVIRONMENT

$X 138$ BOLT RING FAILS FROM BREAKUP ACCIDENT IMPOSED FORCES

$X 139$ BREAKUP ACCIDENT IMPOSES DESIGN LEVEL FORCES ON THREADS

$X 144$ FXPOSED BOLT RING FAILS IN BREAKUP ACCIDENT

$X 147 \mathrm{R} / U$ IMPACT FORCES SUFFICIENT TO CAUSE RUPTURE OF OUTER CAN BY $2 R$

$X 148$ B/U PUNCTURE PROBE LONGER THAN 11 IN., FORCE EQUAL TO DROP OF $3001 \mathrm{~N}$.

$X 149$ FIRE OCCURS DURING BREAKUP ACCIDENT

$X 151$ BREAKUP ACCIDENT CRUSH FORCES CAUSE LID REMOVAL

$X 152$ BREAKUP ACCIDENT IMPACT FORCES CAUSE LID REMOVAL

$X 153 \mathrm{~B} / L$ ACCIDENT IMPACT FORCES EXCEED DESIGN STRENGTH OF OUTER DRUM

$X 154 \mathrm{~B} / U$ ACCIDENT FIRE STRESSES CAUSE OUTER DRUM FAILURE

$X 155$ B/U ACCIDENT CRUSH FORCES EXCEED DESIGN STRENGTH OF OUTER DRUM

$X 156$ BREAKUP ACCIDENT GENERATES PUNCTURE PROBE

$X 157$ BREAKUP ACCIDENT PUNCTURE PROBE STRIKES DRUM

$X 158$ B/U PUNCTURE FORCE EQUAL TO DROP OF 133 IN. ONTO 6 IN. SPIKE

$X 163$ DUNNAGE FAILS DURING BREAKUP ACCIDENT

$X 167$ CRITICALITY OCCURS DUE TO EXTREME. DEFORMATION IN B/U ACCIDENT

$X 168$ IMPACT FORCES FROM B/U ACCIDENT SUFFICIENT TO FAIL $2 R$ VESSEL

$X 169$ FIRE STRESSES FROM B/U ACCIDENT SUFFICIENT TO FAIL $2 R$ VESSEL

$X 170 \mathrm{~B} / U$ ACCIDENT IMPOSED CRUSH FORCE EXCEEDS 2R DESIGN STRENGTH

$X 171$ PUNCTURE PROBE STRIKES 2R CONTAINER DURING BREAKUP ACCIDENT

$X 172 \mathrm{~B} / U$ PUNCTURE PROBE EQUAL TO DROP OF 170 IN. ONTO 6 IN. SPIKE

$X 174$ DEFECTIVE WELD CANNOT SURVIVE BREAKUP ACCIDENT STRESS

$X 235$ ACCIDENT OCCURS DURING TAKEOFF OR LANDING

$x 236$ SAMPLE CAN FAILS IN TO/L ACCIDENT FNVIRONMENT

$\times 238$ BOLT RING FAILS FROM TO/L ACCIDFNT IMPOSED FORCES 
TABLE 8.1 (Cont'd)

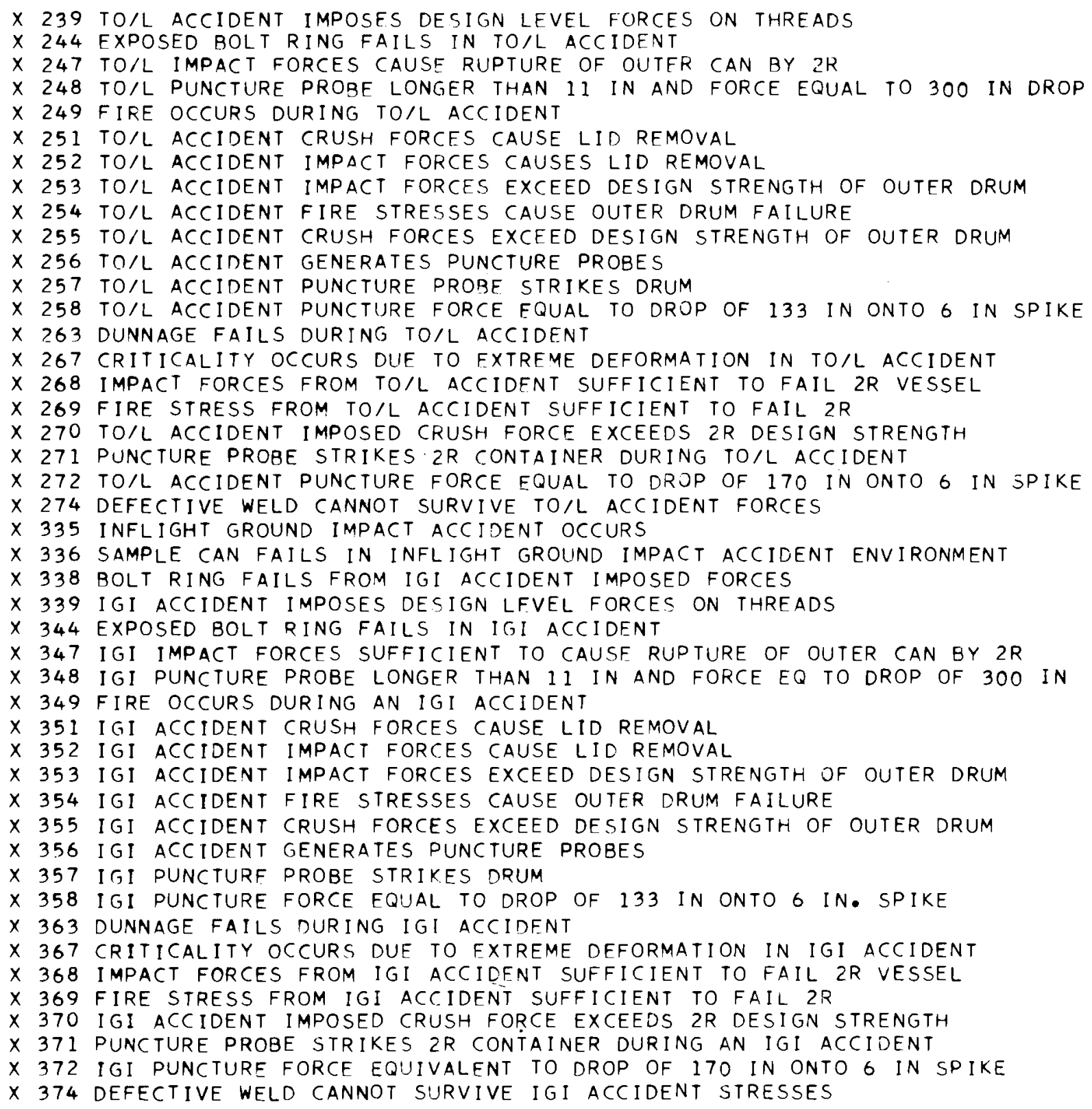


In this analysis, three barriers between the plutonium and man's environment were considered. The first barrier was the sample can. This is a thin-walled sealed can, resembling a produce can, which provides containment during handling. It is not intended to be an accident resistant barrier although tests at Sandia ${ }^{(2)}$ show that in some cases, it does prevent a release from occurring. In general, little credit is taken for this barrier when evaluating the likelihood of a release. The second barrier is the $2 R$ vessel, described in Appendix $A$. This is a heavy-walled steel cylinder with a welded plate on one end and a screwed plug on the other. This container is the primary containment barrier during an accident. The third barrier is the $6 \mathrm{M}$ outer container, also described in Appendix $A$. This is an 18-gauge steel drum with a ring closure. As shown in Section 6.0, it provides little protection for the $2 \mathrm{R}$ in ground impact type airplane accidents. It does provide protection and a degree of containment for many accidents in which the impact velocities are low or the surface impacted is relatively soft. The vast majority of airplane accidents fall in this category.

In the truck accident evaluation, a fourth barrier, the van, was also included in the analysis. Because the fuselage is normally unable to maintain its integrity during an air accident, and even in the most minor mishaps must technically be breached to allow the crew to exit, no credit is given to the fuselage as a containment barrier.

\subsection{RELEASE SEQUENCES}

The fault tree can be thought of as a compact notation for identifying and displaying thousands of release sequences. A release of plutonium to the atmosphere requires the concurrent failure of all three barriers. Thus, combining a release sequence for one barrier with a release sequence for each of the other barriers identifies a possible sequence of events which breach all three barriers. All release sequences can be obtained by permuting lists of barrier release sequences. This concept of barrier release sequences is a powerful tool if the fault tree is small enough to allow easy identification of the "cut sets" (combinations of events forming 
a sequence). In the case of the tree shown in Figure 8.1, the large number (and size) of release sequence prevents easy identification. Therefore, a computer code, FAULTG ${ }^{(3)}$ has been employed to identify the release sequences. The use of this code will be discussed in greater detail in Chapter 9. Release sequences identified by this code are not barrier release sequences, but total or system release sequences. That is, only the combinations of barrier release sequences which actually result in a release to the environment are shown. These cut sets are screened in this code to ensure that no duplicate sequences are considered.

\section{REFERENCES}

1. T. I. McSweeney, R. J. Hall et a1., An Assessment of the Risk of Transporting Plutonium Oxide and Liquid Plutonium Nitrate by Truck, BNWL-1846, Battelle, Pacific Northwest Laboratories, Richland, WA, August 1975.

2. Lloyd Bonzon, Sandia Laboratories, Private Communication.

3. T. H. Smith et al., A Risk-based Fault Tree Analysis Method for Identification, Preliminary Evaluation, and Screening of Potential Accidental Release Sequences in Nuclear Fuel Cycle Operations, BNWL-1959, Battelle, Pacific Northwest Laboratories, Richland, WA, January 1976. 


\subsection{RELEASE SEQUENCE EVALUATION}

The previous chapter presented the fault tree for the air shipment of plutonium (in the form of plutonium dioxide) in the 6M container. From the fault tree, a long list of release sequences can be identified. For example, the occurrence of the following four events is one release sequence which will result in a loss of plutonium dioxide from the 6M:

X35 Free Fal1 Accident Occurs

X53 Free Fal1 Accident Impact Forces Exceed Design Strengths of Outer Drum

X68 Free Fall Impact Forces Sufficient to Fail 2R Vessel

X34 Force Which Breached 2R Insufficient to Breach Sample Can

The fault tree can be thought of as a compact notation for summarizing several thousand release sequences. These release sequences are the common element in the risk assessment. As shown in Figure 9.1, based on the release sequences, both the frequency and the release fraction must be determined for each release sequence. This section presents the basic data required to evaluate all release sequences.

Either of two approaches may be taken to evaluate the probability and consequences of a release during transport. The most direct and detailed evaluation would be obtained from a Monte Carlo computer simulation of the transport system. Shipments would travel along shipment routes until an accident occurs; then each container in the shipment would be evaluated for failure. This is a very efficient way to analyze events which occur frequently. However, as events occur less frequently, much longer running times on the computer are required to obtain the same degree of accuracy. The second approach analyzes a multicontainer shipment essentially as if only one container is in the shipment. The analysis permits only one container failure in an accident but at an accident frequency multiplied by the number of containers in the shipment. This is a good assumption only when the failure rate is low. In this section, the release fractions and the occurrence frequency for events will be determined using the second method. The validity of the method is demonstrated in Section 11 and Appendix D. 


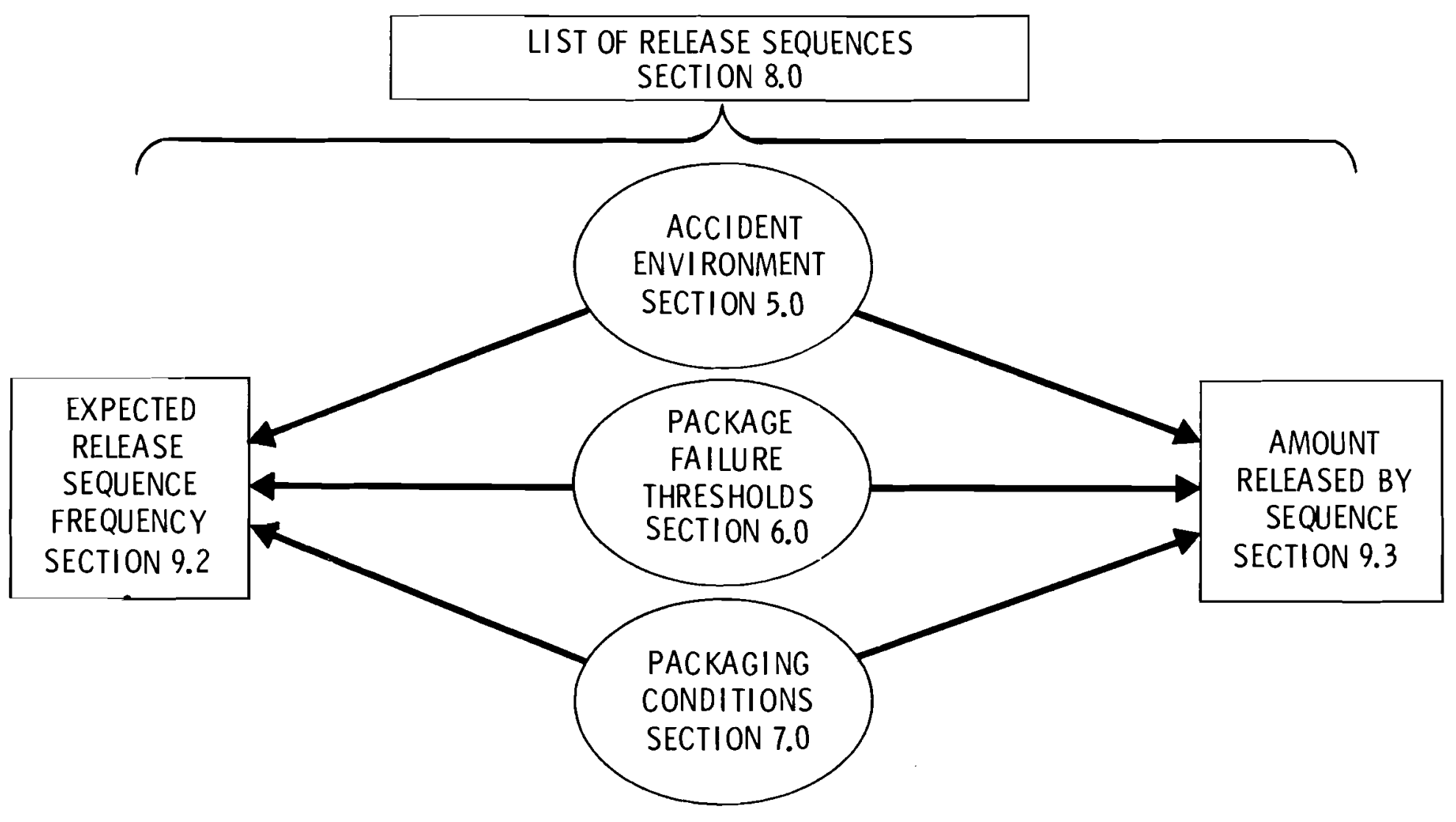

FIGURE 9.1. Release Sequence Evaluation 
The fundamental elements in the analysis are the basic event probabilities. The fault tree in Section 8 was developed down to a point where data on basic events could be obtained either through analysis or survey. The basic event probabilities are presented in Section 9.1.

The probability data in Section 9.1 are then used to develop the information on Release Sequence Probabilities summarized in Section 9.2. Release Fractions are evaluated in 9.3, and Section 9.4 summarizes the results of the chapter by showing how release sequences are evaluated from the failure release fractions and probabilities.

\subsection{BASIC EVENT PROBABILITIES}

The following paragraphs provide a sequential list of failure probability estimates for plutonium dioxide shipments in the 6M container. The numbering sequence corresponds to the numbering sequence shown in the fault trees. Since the fault tree is made up of several similar branches, a numbering system was used to help identify similar elements in these branches. Event numbers 1 through 34 describe package conditions as a result of cargo handling and loading. Free fall (FF) accident events are numbered 35 through 74 , breakup (B/U) accident elements 135 through 174 , takeoff and landing (TO/L) accidents 235 through 274, and inflight ground impact (IGI) accidents are numbered 335 through 374 . Thus, events with the last two digits are all similar. For example, events $\times 35, \times 135, \times 235$, and $\times 335$ are the frequencies for the various types of aircraft accidents used in the tree. The other events follow the same pattern. Events numbered from 1 to 374 are identified in the fault tree shown in Figure 8.1 of Section 8. Table 8.1 listed the events as they were titled and keyed in the fault tree. Occurrence frequencies for each event are presented in the following paragraphs:

Release 0ccurs During Truck Transport to or From Airport (X1). Truck transport to the cargo air terminal is required. Previous studies (1) have determined the risk of shipping plutonium dioxide entiræly by truck. On a per mile basis, the risk of transporting material to the air terminal is the same as reported in the truck evaluation. The details of the truck 
evaluation will not be shown here. In Section 11.2, the risk from the truck transport portion of the air transport mode will be summarized. Subsequent sections will then add the risk arising from the air transport part to get the entire risk of shipping plutonium dioxide by air.

Packing Defect Not Detected During Aircraft Loading (X2). Cargo handlers at airports do not have the tools or the expertise to inspect cargo for packing defects. Thus, except for obvious damage to the outer drum, defects would not be detected. Therefore, the probability of not detecting a packing defect during aircraft loading has been assigned a value of 1.0 .

Weld Defective (X3). Experience at Battelle-Northwest indicates that about $2 \mathrm{ft}$ of every $100 \mathrm{ft}$ of weld requires repair to meet the quality standards for this type of equipment. Since close to $2 \mathrm{ft}$ of weld is required to fabricate the $2 R$ inner container, a value of 0.02 per container was used for this element. This value was used throughout the study, for both the truck and air analyses.

Q/A Does Not Detect Badly Defective Weld $(X 4)$. This element is used in the analysis in combination with element $X 5$, Defective Weld Cannot Survive Normal Transport Stresses. The only normal transport stresses that might affect the weld are minor jostling and vibration. Any weld so defective that it would not be able to withstand normal transport stresses would show obvious defects and could not escape detection by qual ity assurance procedures. In addition, 10 CFR Part 71 , Subpart D requires shippers to determine, prior to initial use and each subsequent use, that the packaging has no significant defects. Based on these considerations, a value of zero was used for $\mathrm{X} 4$.

Defective Weld Cannot Survive Normal Transport Stresses (X5). It was conservatively assumed that the probability of a badly defective weld failing under normal transport stresses was 1.0 per defective weld.

(x6). Not used. 
Corrosive Material Inside 2R (X7). In the analysis, it is assumed that there is sufficient time during transport for the thin-walled sample can to corrode through if corrosive material is present. Thus, it makes essentially no difference whether the corrosive material is initially in the $\mathrm{PuO}_{2}$ or inside the $2 \mathrm{R}$ container. The sample can breaches referred to in $x 13$ could have resulted from either internal or external corrosive action. The occurrence probability for this element is included in $\times 13$. Therefore, it was set at zero here.

Corrosive Material Present Outside $2 \mathrm{R}(\mathrm{X} 8)$. The plutonium receivers survey indicated that of approximately 6200 packages received, none had any significant corrosive material present outside the $2 \mathrm{R}$ vessel. Assuming a constant probability for the presence of corrosive material no occurrences in the shipment of 6200 containers indicates an occurrence rate of less than $10^{-4}$ per container at the $50 \%$ confidence 1evel. A value of $10^{-4}$ per container was used for $x 8$. This value was used in both the truck and air shipment risk analyses.

Sufficient Time Available to Corrode 2R (X9). Although there has been some failure of sample cans, possibly due to corrosion, time in transit and material are inadequate to fail the $2 R$. Therefore, this element was set at zero.

2R Leaks When Properly Closed (X10). This event is included in the X11 value. Therefore, its value was set at zero here.

Plug Loosens During Transport (X11). Based on the plutonium receivers survey, the occurrence rate of $2 \mathrm{R}$ plugs being loose during transport is 0.2 per container. This event with its.assigned value was used to calculate the risks involved in both air and truck shipments.

Plug Unscrews During Transport (X12). Based on the plutonium receivers survey including LLD statistics, the occurrence rate of the $2 R$ plug unscrewing during transport is estimated to be $4 \times 10^{-4}$ per container. This event was also used in evaluating both truck and air risks. 
Corrosive Material Present in $\mathrm{PuO}_{2}\left(\mathrm{X}_{13}\right)$. The plutonium receivers survey did not specifically indicate any instances where corrosive material was present in the $\mathrm{PuO}_{2}$. However, it did reveal three instances in the receipt of about 4000 6M and LLD-1 packages where the sample can was breached or not completely sealed. The cause of the breaches was not determined. Although improper closure is considered the most likely cause of breach, the breaches could have been caused by corrosion. Since, in time, corrosion could potentially lead to greater consequences (failure of the $2 \mathrm{R}$ container) than improper closure of the sample can, for this analys is the breaches were all assumed to be due to corrosion. Therefore, a probability of $8 \times 10^{-4}$ was used for $\times 13$. The same value was used in the air and truck transport evaluations.

$(\mathrm{X} 14)$. Not used.

Sample Can Improperly Closed (X15). The sample can failures indicated in the plutonium receivers survey could have been caused by improper closure or corrosion. The occurrence probability for this element is included in X13. Therefore, it was set at zero here.

Sufficient Time for Sample Can to Corrode (X16). The sample can is thin-walled. Therefore, it was conservatively assumed that if corrosive material were present there would be sufficient time during transport for it to corrode through the sample can. A value of 1.0 was used for $X 16$.

\section{(X17). Not used.}

Wrong Sample Can Used for Transport (X18). Cans which are too large or too small could be more susceptible to damage during transport. In the survey results, the cause of the sample can damage included under $\times 13$ in this evaluation was not ascertained. One reason could have been use of the wrong cans. In this evaluation the failure data was included under $\mathrm{X} 13$ and set at zero here.

Sample Can Damaged Before Loading and Not Corrected (X19). The survey results could not determine the cause of sample can failure. Therefore, the element was included in $X 13$ statistics. Its value was set at zero here. 
Sample Cans Damaged by 2R Plug Closure $(\times 20)$. This event is included in the $X 13$ value. Therefore, its value was set at zero here.

Sharp Object in $2 \mathrm{R}$ Container (X21). This event is included in the $\mathrm{X} 13$ value. Therefore, its value was set at zero here.

Sample Cans Not Properly Packed in 2R (X22). This event is included in the $X 13$ value. Therefore, its value was set at zero here.

Shipping Container Dropped During Transport (X23). This event is included in the $X 28$ value. Therefore, its value was set at zero here.

Gas Generated by Material Present in Can (X24). Based on the plutonium receivers survey using both $6 M$ and LLD statistics, the occurrence rate of gas generation in the sample can during transport is estimated to be $5 \times 10^{-4}$ per container. The same value was used in both the truck and transport evaluations.

Criticality Causes Rupture of Sample Can (X25). If criticality occurs, the sample can will rupture. Therefore, this element was set at 1.0.

Criticality Occurs Due to Extreme Deformation in Transport (X26).

Forces capable of crushing containers together sufficiently to form a critical array do not occur during normal transportation. Since this is independent of mode of transport, this event was used in the analysis of both truck and air phases of the shipment and its value was zero in both.

6M Shipped in Wrong Orientation on Truck (X27). The plutonium receivers survey indicated that of approximately 6200 packages received, none had been shipped in the wrong orientation. Assuming a constant probability of misorientation, no wrong orientations of 6200 containers indicates a misorientation rate of less than $10^{-4}$ per container at the $50 \%$ confidence level. A value of $10^{-4}$ per container was used for $\times 27$. 
Outer Container Fails from Mishandling and Not Detected (X28). Based on the plutonium receivers survey, the probability that a container will have an undetected breach during transport is estimated to be $2 \times 10^{-3}$ per container. The same value has been used in the air and truck transport evaluations.

Outer Container Punctured from Object in/or Protruding from Floor Board (X29). No distinction could be made between X28 and X29 from the survey results. Therefore, both events were included under $X 28$ and this element was set at zero.

Container Shipped in Wrong Drientation During Air Transport (X30). A value of $10^{-4}$ per container was used for misorientation during truck shipment (X27). Since the statistics are not expected to be mode dependent, a value of $10^{-4}$ will also be used in the air transport evaluation.

Tiedowns Break During Air Shipment (X31). According to air freight statistics, $1 \%$ of the cargo aircraft arriving at their destination have a pallet with unsecured cargo, usually as a result of an aircraft loading error. There are 40 pallets per airplane. A11 plutonium dioxide containers would be shipped on a single pallet, and the probability that the tiedowns on that particular pallet would be loose or broken is $0.01 \times 0.025$ or $2.5 \times 10^{-4}$. This is conservative, since a11 hazardous materials are doubly checked by the aircraft crew prior to takeoff.

Aircraft Exposed to Extreme Turbulence (x32). Since most flights experience some type of turbulence, the value of this element was conservatively set at 1.0 .

Defective Sample Can Not Detected (X33). Unless the entire shipping container was damaged, it is doubtful that a defective sample can would be detected. The value assigned to this event was 1.00 .

Force Which Breached 2R Sufficient to Breach Sample Can (X34). Very high forces are required to breach the 0.25 -in. thick $2 \mathrm{R}$ container. The additional force required to rupture a sample can is very small in comparison. Thus, a value of 1.0 was used for this element. 
Free Fall Accident Occurs (X35). For containers to free fall to the earth, the airplane must have been involved in a midair accident which ruptured the fuselage and broke the pallet tiedowns. Based on the Sandia(2) evaluation of the aircraft accident environment, a midair accident resulting in aircraft disintegration could be encountered at a rate of $1.6 \times 10^{-10}$ accidents/mile. The fault tree is based on one container being shipped 1500 miles. Therefore, the likelihood of a free fall accident occurring is $2.4 \times 10^{-7}$ accidents/container shipped $1500 \mathrm{miles}$.

Sample Can Fails in Free Fall Accident Environment (X36). A sample can is a thin-walled sealed steel container which is not designed to survive ground impact following free fall. Therefore, a value of 1.0 was assigned as the probability of this event occurring.

Container Shipped with Defective Bolt Ring (X37). Survey results indicate that $2 \%$ of the bolt rings fail when they are being tightened. This indicates that some bolt rings will be close to their failure point during a shipment. In this analysis, $\times 37$ was set at 0.02 failures/container involved in an accident.

Bolt Ring Fails from Free Fall Accident Imposed Forces (X38). This element was included in $\times 52$. Therefore, it was set at zero here.

Free Fall Accident Imposes Design Level Forces on Threads (X39). Forces on the threads are expected to be inward acting and would tend to jam the plug in more tightly rather than remove it. Therefore, this element was set at zero. This argument was also used for events $\times 139$, $\times 239$, and $\times 339$.

Plug Cross Threaded $(X 40)$. This element is one possible cause of thread damage. Statistics from the survey are included in $\times 42$. This element was set at zero.

Cross Threaded Threads Not Detected $(x 41)$. This element was set at zero. It is included in $\times 42$. 
Threads Damaged from Use or Repair (X42). Based on the plutonium receivers survey and LLD statistics, the occurrence rate of the container having damaged threads during shipment is estimated to be $2 \times 10^{-4}$ per container.

Poor Threads Not Detected Before Use (X43). The value of this element was set at 1.0 since the value for $X 42$ is based on use of $2 R$ vessels with damaged threads.

Exposed Bolt Ring Fails in Free Fall Accident (X44). The value of this element was estimated to be $4 \times 10^{-3}$ bolt ring failures per container involved in a free fall accident. It was estimated on the basis of the solid angle in which a probe must strike a protruding bolt to cause failure. This analysis and value were also used in evaluating events $\times 144, \times 244$, and X344 because failure is independent of accident type.

Bolt Ring Assembled with Bolt Turned Up and Exposed (X45). Based on the plutonium receivers survey, the occurrence rate of the bolt ring turned up during transport is estimated to be 0.05 per container.

Improper Fit Between Male and Female Threads (X46). This element was set at zero. It is included in $\times 42$.

Free Fal1 Impact Forces Sufficient to Cause Rupture of Outer Can By $2 R(X 47)$. Sandia test results $(3)$ have shown that a near end-on impact of the $6 M$ container onto soil at velocities in excess of $391 \mathrm{ft} / \mathrm{sec}$ will cause the $2 R$ to punch itself through the outer drum. As the 6M falls, it will tumble end over end. Thus, it will strike the ground at a random angle between 0 and $180^{\circ}, 90^{\circ}$ being classes as an end-on impact. The angle must be within $221 / 2^{\circ}$ of $90^{\circ}$ for the impact to be classified as a near end-on impact. A $45^{\circ}$ angle of a semicircle represents $25 \%$ of the possible impact angles. Thus, the fraction of impacts classed as end-on is 0.25 . The likelihood of the container impacting soil is estimated to be 0.68 . Therefore, the probability that the 6M container will impact onto a soil surface in the proper orientation for this event to occ ir is estimated to be $(0.25)(0.68)=0.17$ per container involved in a free fall accident. However, since the terminal velocity of this particular type 6M container has been calculated to be approximately $280 \mathrm{ft} / \mathrm{sec}$, the container wi11 not reach 
a velocity during free fal1 sufficient to cause rupture of the outer drum by the $2 \mathrm{R}$ upon impact. The value assigned to this event was zero.

Free Fa 11 Puncture Probe Longer Than 11 in. and Force Equal to Drop of $300 \mathrm{in.}(\mathrm{X} 48)$. Analys is has shown that an 11-in. 1ong (minimum) puncture probe with a force equal to a drop of greater than $300 \mathrm{in}$. onto a 6-in. diam spike is required to punch the $2 \mathrm{R}$ container through the outer drum. Based on the high velocity which a container in free fall attains, a11 container puncture probe interactions have sufficient energy to punch the $2 R$ from the outer drum if the axis of the $2 R$ and the puncture probe are nearly parallel. As a minimum, the probe must strike the top or bottom of the $2 R$ such that the solid angle of impact is less than the apex angle of an imaginary cone formed by lines drawn through the center of mass of the $2 R$ and the top or bottom edge of the $2 R$. Since the $2 R$ has an $O D$ of $5.56 \mathrm{in}$. and an overall length of $11.8 \mathrm{in}$., the apex angle of the imaginary cone is $25^{\circ}$. As the $6 \mathrm{M}$ falls, it will tumble end over end. Thus, the angle of impact, measured between 0 and $180^{\circ}$ is expected to be entirely random. The likelihood of the impact being within the $25^{\circ}$ acceptance angle is therefore 0.14 . In addition to the angle requirement, the probe must strike the top or bottom of the inner container following puncture of the outer drum. The fraction of probes striking both surfaces is dependent on the area ratio. The ratio of cross sectional area of the $2 R$ to the outer drum is 0.128 ; thus the fraction of probes striking the top or bottom of the $2 R$, given impact with the top or bottom of the $6 M$ at an angle relative to the axis of the $2 R$ of less than $25^{\circ}$, is 0.128 . To push the $2 R$ through the outer drum the probes must be 11 in. 1ong. Sandia estimates the likelihood of probe bending is proportional to probe length. Their analysis was based on a 4-in. probe length. Thus, the requirement for an 11-in. probe reduces the puncture probability by the ratio of $4 / 11$. The above factors are multiplied together to get the expected frequency of punching the $2 R$ through the outer drum given puncture of the outer drum. The expected frequency of punching the $2 \mathrm{R}$ through the $6 \mathrm{M}$, given puncture 
of the $6 \mathrm{M}$ is therefore $0.14 \times 0.128 \times 4 / 11=0.0065$ per puncture probe strike of outer drum. A similar analysis was used in the evaluation of events $\times 148, \times 248$, and $\times 348$.

Fire Occurs During Free Fall Accident (X49). Although there is a possibility of fire during the initial breakup accident, it will not impose stresses capable of failing the 6M container. Furthermore, the free fall accident itself scatters the wreckage of the plane over a wide area so that the possibility of a ground fire occurring which is of sufficient intensity to cause failure of the package is highly improbable. Therefore, a value of zero was assigned to this element.

Sufficient Moisture Present to Cause Outer Drum Failure in Fire (x50). The plutonium receivers survey indicated no instances where water was present in the $6 \mathrm{M}$ containers. Even if water were present, the outer drum would not fail in a fire due to the limited free volume and the presence of vent holes. Therefore, the value of $\times 50$ was set to zero for this evaluation.

Free Fall Accident Crush Forces Cause Lid Removal (X51). Crush can occur only if all of the containers impact the earth as a single unit. This implies that the plane intact. The tiedown strips on the pallet are not substantial enough to allow such a sequence. For this reason the value for $\times 51$ was set to zero.

Free Fall Accident Impact Forces Cause Lid Removal (X52). Based on the results of high-speed impact tests performed at Sandia, (3) the outer drum failure is expected if the $6 \mathrm{M}$, traveling at its terminal velocity, strikes the earth. Sandia estimates that only 0.015 of the accidents will occur over water. For these cases, failure of the outer drum is not expected. Thus for 0.985 of the accidents which result in airplane breakup, the outer drum of al1 the 6Ms involved in the accident will fail. Thus, the analysis wi11 use a value for $X 52$ of $0.985 /$ container involved in a breakup accident.

Free Fall Accident Impact Forces Exceed Design Strength of Outer Drum (x53). The evaluation performed to obtain a value for $x 52$ did not distinguish between outer drum failure and 1id removal: Thus, the value for $X 52$ is included in the statistics used to evaluate $\times 52$. For this reason, the value of $X 52$ was set to zero. 
Free Fall Accident Fire Stresses Cause Outer Drum Failure (X54). For the same reasons given in $\mathbf{X 4 9}$, this element was assigned a zero value.

Free Fall Accident Crush Forces Exceed Design Strength of Outer Drum (X55). This element was included in $X 51$ and was given a value of zero here.

Puncture Probes Present During Free Fa11 Accident (X56). Puncture probes will almost always be present on the ground where a free falling container impacts. This element was conservatively given a value of 1.0.

Free Fall Puncture Probe Strikes Drum (X57). Sandia estimates ${ }^{(2)}$ that the probability of a free falling container impacting a puncturing agent, such as a tree, structure, or jutting rock, is no larger than 0.1 . Thus the value assigned to this event is 0.1 per container involved in a free fall accident.

Free Fal1 Puncture Force Equal to a Drop of 133 in. onto a 6 -in. Spike (X58). Analysis has shown that a puncture probe with a force equivalent to that experienced when a $6 \mathrm{M}$ container is dropped 133 in. onto a 6-in. diam spike will breach the outer container. Considering the extreme heights from which a container falls during the free fall accident, allowing it to reach a terminal velocity of approximately $280 \mathrm{ft}$ per second, it was assumed that any puncture probe striking the container at the proper angle would be capable of causing a rupture of the outer vessel. Furthermore, the probe would need to be stout enough to puncture the drum and not fail due to bending. Sandia estimates that a probe will be accepted if the angle of the probe relative to the vector drawn between the center of mass and the impact point is less than $30^{\circ}$. The fraction of probes which will strike within an angle of $30^{\circ}$, assuming the $6 \mathrm{M}$ to be tumbling end over end is 0.167 . Thus, the value used for $X 58$ was 0.167 per container struck.

Failure of Inner Container Fails Outer (X59). This element was conservatively set at 1.0 .

Outer Drum Contains Vent Holes (X60). A1l outer drums contain vent holes to permit heat dissipation. Therefore this element was set at 1.0. 
Container Shipped with Loose Bolt Ring Closure (X61). Based on the survey data presented in Section $7,12 \%$ of a 11 containers had bolt rings which were finger tight upon receipt. A tenth of an inch slack in the bolt ring is enough to make it 10ose. When this is compared with the 0.23-in. expansion required to remove the bolt ring, the loose ring is not a significant failure mechanism which is likely to remove the lid. However, it would provide an additional pathway for release if the material were free inside the drum. Thus, the value used for $\times 61$ was $0.12 /$ container. This value was used in both the truck and air shipment evaluations.

Lid, Drum Mating Surface Damaged from Handling (X62). The plutonium receivers survey indicated that although some containers showed visible surface damage, no defects in the 1id, drum mating surface were noted during receipt of approximately 3500 drum-type containers. Assuming a constant probability of damage, no defects in 3400 containers indicates a damage rate of less than $2 \times 10^{-4}$ per container at the $50 \%$ confidence level. A value of $2 \times 10^{-4}$ per container was used for $\times 62$. This value was used for both the truck and air shipment evaluations.

Dunnage Failed During Free Fall Accident (X63). As defined, a free fall accident must be preceded by an aircraft breakup in which the containers are dislodged from their shipping configuration. The value of this event was set at 1.0 .

Defective Outer Drum Not Detected $(x 64)$. This element was conservatively set at 1.0. This same value was used in the truck shipment evaluation.

Sufficient Moisture, Gas Present Inside 2R to Cause Failure in Fire $(x 65)$. Moisture present inside the $2 R$ could cause the $2 R$ to fail in a fire from excessive pressure buildup. However, there would have to be the equivalent of several hundred grams of water present for creation of sufficient pressure to fail the $2 R$ should it be involved in a fire. The weighings and analyses performed to meet safeguards shipping regulations would detect the accidental addition of several hundred grams of water prior to shipment. Thus, $\times 65$ was set at zero. 
Sufficient Moisture Present to Cause 2R Failure by Criticality (X66). A $6 \mathrm{M}$ package with the plutonium retained in the $2 \mathrm{R}$ container cannot become critical regardless of water content. Therefore, the value for this element was set at zero.

Criticality Occurs Due to Extreme Deformation in Free Fall Accident (X67). The characteristics of the $6 M$ shipping package and loading restrictions prevent criticality in normal transport and during severe accidents. A single $6 \mathrm{M}$ could be crushed down to the $2 \mathrm{R}$ container and immersed in water and criticality still would not occur. However, if an array of $6 \mathrm{M}$ containers were extremely crushed together and the array immersed in water, criticality would theoretically be possible. If any of these conditions are not present, criticality cannot occur. Based on the Sandia evaluation of the air accident environment, a severe crush environment is not encountered during air transport accidents. Thus, the probability that criticality resuits from an air transport accident was set to zero. This evaluation is also valid for events $\times 167, \times 267$, and X367.

Free Fall Impact Forces Sufficient to Fail 2R Vessel (X68). Fai1ure threshold values presented in Section 6 indicate that an impact onto an unyielding surface at velocities in excess of $225 \mathrm{ft} / \mathrm{sec}$ are sufficient to cause failure of the $2 R$ inner container. Calculated terminal velocities of both the $2 R$ and entire $6 M$ package are in excess of this value. Material presented in Section 5 indicates that approximately $14 \%$ of the surface below an airplane in flight can be classified as unyielding (hard and soft rock). Therefore, a value of 0.14 was assigned to this element. Information from this analysis is also included in the analysis of events X168 and X268.

Fire Stresses from Fire Following Container Free Fall to Earth Sufficient to Fail 2R Vessel (X69). This element is used in conjunction with (X49) which was set to zero. Fires are not expected following ground impact of debris from a midair aircraft breakup accident. If a fire did occur, the fire induced stresses would not be sufficient to fail the 2R. For this reason, (X69) was assigned a zero value. 
Free Fall Accident Imposed Crush Force Exceeds 2R Design Strength (X70). For the same reasons presented in the evaluation of $\times 51$, this element was given a value of zero.

Puncture Probe Strikes 2R Container During Free Fall Accident (X71). Only non-bending probes at least 8 in. long can strike the 2R container. Furthermore, since the $2 \mathrm{R}$ container does not extend the full height of the outer drum of the $6 \mathrm{M}$ container not a11 probes $8 \mathrm{in}$. 1 ong will actually strike the $2 R$. The fraction of the centerline of the outer drum occupied by the $2 R$ is $14 \mathrm{in.} / 21.5 \mathrm{in} .=0.65$. Since the acceptance angle of the probe decreases linearly with probe length and the puncture data presented in Section 5 is based on a mean probe length of 4 in., half the probes puncturing the outer drum will not have the proper angle to puncture the $2 R$. Thus, of the probes failing the outer drum, the expected frequency of strikes at the proper angle for penetration of the $2 R$ was set at $0.65 \times$ $0.5=0.33$ per puncture of the outer drum. This value was used for events $\mathrm{X} 71, \times 171, \times 271, \times 371$ and in the truck shipment analysis.

Free Fal1 Accident Puncture Force Equivalent to Drop of 170 in. onto a 6-in. Spike (X72). Analysis has shown (Appendix C) that a puncture probe with a force equal to that experienced when $6 \mathrm{M}$ container is dropped from 170 in. onto a $6-i n$. diam probe could breach the $2 R$ vesse 1 . The terminal velocity of a $6 \mathrm{M}$ container is approximately $280 \mathrm{ft} / \mathrm{sec}$. A $2 \mathrm{R}$ failure is expected in all cases, given a strike onto a puncture probe $(X 71)$. Thus, the value of $X 72$ was conservatively set at 1.0 .

Q/A Does Not Detect Defective Weld (X73). This element is used in conjunction with $X 74$, name $1 y$, defective weld does not survive in aircraft breakup accident environment. Elements $(X 4)$ and $(X 5)$ considered weld failure during normal transport. $Q / A$ is expected to detect badly defective welds. However, evaluations of Q/A performance consistently show that minor defects are noticed and corrected in $85 \%$ of the cases encountered. Therefore, $X 73$ was set at 0.15 for this analysis. 
Defective Weld Cannot Survive Free Fall Accident Stresses (X74). Considering the high stresses involved in a free fall impact onto the ground, the likelihood that any defective weld would fail in such an environment was conservatively set at 1.0.

(X75) through (X134). Not used.

Breakup Accident Occurs (X135). This element is identical to (X35). Therefore, a value of $2.4 \times 10^{-7}$ accidents/1500 mile shipment was used here.

Sample Can Fails in Breakup Accident Environment (X136). Considering the relatively fragile nature of the sample can and the rather small forces required to breach it, it was conservatively assumed that the breakup accident force would be sufficient to cause failure. The value used for $\mathrm{X} 136$ was 1.0. This analysis is also used in determining events $\times 236$ and $\times 336$.

(X137). Not used.

Bolt Ring Fails from Breakup Accident Imposed Forces (X138). This element was included in X37. Its value is set at zero here.

Breakup Accident Imposes Design Level Forces on Threads (X139). This element was set at zero. See $\times 39$.

(Xi40) through (X143). Not used.

Exposed Bolt Ring Fails in Breakup Accident (X144). A value of $4 \times 10^{-3}$ per container involved in a breakup accident was used. See analysis of $\mathrm{X} 44$ for explanation.

(X145) and (X146). Not used.

Breakup Impact Forces Sufficient to Cause Rupture of Outer Can by $2 \mathrm{R}(\mathrm{X} 147)$. Impact forces encountered in a midair breakup type accident are not sufficient to cause the $2 \mathrm{R}$ inner vessel to punch through the outer container. The value of this event was set at zero. 
Breakup Accident Puncture Probe Longer than 11 in. and Force Equal to Drop of $300 \mathrm{in} .(\times 148)$. The Sandia puncture accident environment analysis shows that $2 \%$ of the probes which strike the outer container will possess sufficient energy to push the $2 \mathrm{R}$ container through the outer drum. Paralleling the analysis for event $x 48$, it is found that the frequency for event $\times 148$ is $1.3 \times 10^{-4}$ per strike of the outer container.

Fire Occurs During Breakup Accident (X149). Data ${ }^{(4)}$ on military air transport accidents show that in approximately $75 \%$ of all midair breakup accidents, fire is involved. Therefore, a frequency of 0.75 per breakup accident was used.

$(X 150) . \quad$ Not used.

Breakup Accident Crush Forces Cause Lid Removal (X151). Crush forces in the breakup accident were considered insignificant due to the definition of this type of accident, and the fact that impact forces are usually much greater. The value of this element was set at zero.

Breakup Accident Impact Forces Cause Lid Removal (X152). This event was included in $X 37$ and is given a value of zero here.

Breakup Accident Impact Forces Exceed Design Strength of Outer Drum (X153). It was assumed, for purposes of this analysis, that $50 \%$ of the impacts (with other containers, aircraft structure, etc.) will be with a force exceeding the strength of the outer 6M container. The value of this event was set at 0.50 per container involved in a breakup accident.

Breakup Accident Fire Stresses Cause Outer Drum Failure (X154). Any fire present in a breakup accident environment is not of sufficient severity to cause a failure of the outer drum. The value assigned to X154 was zero.

Breakup Accident Crush Forces Exceed Design Strength of Outer Drum (X155). During the breakup or disintegration of an aircraft, forces will tend to separate the containers from the airplane. Any crush forces present wil1 be over-shadowed by impact forces. For this reason, X155 was given a value of zero. 
Breakup Accident Generates Puncture Probes (X156). Based on results of the study of aircraft accident environments, ${ }^{(5)}$ the probability of experiencing puncture probes in such an accident was found to be 0.12 .

Breakup Accident Puncture Probe Strikes Drum (X157). Puncture probes must be present and must impact with the container at the proper angle and with sufficient energy to cause a puncture type breach. Sandia's accident environment analysis ${ }^{(2)}$ suggests a value of 0.015 per accident as representative of conditions in an aircraft accident. This value considers both the probability that puncture probes will be generated, and the probe's geometry, stiffness, and angle of contact. The frequency with which a container is struck was assigned a value of 0.015 per container involved in a breakup accident. This value was used also for events $\times 257$ and $\times 357$.

Breakup Puncture Force Equal to Drop of 133 in. onto a 6 -in. Spike (X158). In Appendix $C$, it is shown that a drop of at least 133 in. onto a 6-in. diameter spike is required to breach the outer drum of the 6M. Using the Sandia ${ }^{(2)}$ puncture analysis, of those puncture probes which strike the container, probes with sufficient energy to breach it can be expected at a frequency of 0.825 per container strike. This analysis was used for events $\times 258$ and $\times 358$ also.

(X159) through (X162). Not used.

Dunnage Fails During Breakup Accident (X163). This element was conservatively set at 1.0 .

(X164) through (X166). Not used.

Criticality Occurs Due to Extreme Deformation in Breakup Accident (X167). Breakup accident forces will tend to separate the containers and prevent a criticality. The value of this element was set to zero. See $x 67$ for a more complete discussion of this failure element.

Impact Forces from Breakup Accident Sufficient to Fail 2R Vessel $(X 168)$. Forces found in the breakup accident environment are not sufficient to fail the $2 R$. The value assigned to $x 168$ was zero. See $\times 68$ for more justification. 
Fire Stresses from Breakup Accident Sufficient to Fail 2R Vessel (X169). For the same reasons given in $\mathrm{X} 154$, this element was set equal to zero.

Breakup Accident Imposed Crush Force Exceeds 2R Design Strength (X170). For the same reasons as presented in the analysis of $\times 155$, this event was assigned a probability of zero.

Puncture Probe Strikes 2R Container During Breakup Accident (X171). The analysis is identical to that presented for $X 71$. The value assigned to this event is 0.33 .

Breakup Accident Puncture Probe Equal to Drop of 170 in. onto a 6-in. Spike (X172). This event is similar to X72. Equations developed by Sandia show that $80 \%$ of the probes which strike the outer drum will have sufficient additional energy to breach the $2 R$ vessel. Thus, the value of $X 172$ was set at 0.80 .

(X173). Not used.

Defective Weld Cannot Survive Breakup Accident Stress (X174). The $2 R$ vessel is protected from all but the very severe accident stresses by the outer drum and the Celotex ${ }^{R}$ insulation. Therefore, the weld should survive accidents less severe than, e.g., puncture of the outer drum (likelihood of less than 0.05 per accident). A value of 0.05 per defective weld-accident was used for $x 174$. This analysis also applies for events $\times 274$ and $\times 374$.

(X175) through (X234). Not used.

Accident Occurs During Takeoff or Landing (X235). Data on Air Force transport aircraft accidents ${ }^{(4)}$ suggest that $54 \%$ of the recorded accidents occurred during takeoff or landing. If the $1 \times 10^{-8}$ accident per mile rate used by Sandia for all accidents is used, the rate for takeoff or landing accidents is found to be $5.4 \times 10^{-9}$ accidents per mile. Since the risk is calculated for a 1500-mile trip, the value for $\times 235$ used in this analysis is $8.1 \times 10^{-6} / 1500 \mathrm{mile}$ shipment.

Sample Can Fails in Takeoff/Landing Accident Environment (X236). This element was conservatively set at 1.0. See event $\times 136$. 
(X237). Not used.

Bolt Ring Fails from Takeoff/Landing Accident Imposed Forces (X238).

This element has been included in $\times 37$, and has been set to zero here.

Takeoff/Landing Accident Imposes Design Level Force on Threads (X239).

This element was set to zero. See $\times 39$ for explanation.

(X240) through (X243). Not used.

Exposed Bolt Ring Fails in Takeoff/Landing Accident (X244). This element was given a value of $4 \times 10^{-3}$. See $\times 44$ for analysis.

(X245) and (X246). Not used.

Takeoff/Landing Accident Impact Forces Sufficient to Cause Rupture of Outer Can by $2 \mathrm{R}\left(\mathrm{X}_{247)}\right.$. Using information supplied by Sandia, ${ }^{(5)}$ it can be shown that impact forces in a takeoff/landing accident are not sufficient to cause the $2 R$ to rupture the outer container. This element was set to zero. The analysis of $\times 47$ contains al1 necessary parameters for container failure.

Takeoff/Landing Puncture Probe Longer than 11 in. and Force Equal to $300 \mathrm{in.}$. Drop (X248). Using the equations derived in Sandia's puncture environment analysis, (2) $2 \%$ of all probes which strike the outer container will be capable of causing the $2 \mathrm{R}$ to be ejected from the protective outer container. Using this value and the analysis presented in the evaluation of $\mathrm{X} 48$, we find that the rate for $\times 248$ is $1.3 \times 10^{-4}$ per puncture of the outer drum.

Fire Occurs During Takeoff/Landing Accident (X249). Based on information compiled by Sandia ${ }^{(6)}$ on the fire environment involved in civilian aircraft accidents, the occurrence rate of fires is estimated to be 0.55 fires per takeoff/landing accident.

(x250). Not used.

Takeoff/Landing Accident Crush Forces Cause Lid Removal (X251). This event was included in $\times 255$; therefore, its value here is zero. 
Takeoff/Landing Impact Forces Cause Lid Removal (X252). This event was included in the evaluation of event $\times 253$. Its value was set at zero here.

Takeoff/Landing Impact Forces Exceed Design Strength of Outer Drum (X253). Based on data supplied by Sandia ${ }^{(5)}$ on the impact forces expected in takeoff and landing accidents, and the failure threshold value of an outer 6M drum, the probability that a container will experience impact forces severe enough to cause failure is 0.058 .

Takeoff/Landing Accident Fire Stresses Cause Outer Drum Failure (X254). Fire stresses, acting alone, cannot fail the outer drum. No conditions which could cause failure, such as moisture in the Celotex ${ }^{R}$, were found in the plutonium receivers survey. Therefore, this element was set at zero.

Takeoff/Landing Accident Crush Forces Exceed Design Strength of Outer Drum (X255). As shown in the anaiysis performed by Sandia, (2) a crush accident environment can be expected in $5 \%$ of a 11 takeoff and landing accidents involving impact (68\%). It was conservatively assumed that all crush forces generated are sufficient to cause a breach of the outer drum through structural failure, lid removal, or a combination of both. The frequency assigned to this event was 0.034 per container involved in a takeoff/landing accident.

Takeoff/Landing Accident Generates Puncture Probes (X256). Based on analysis by Sandia, ${ }^{(5)}$ it was found that puncture probes would be present in $12 \%$ of takeoff or landing accidents. The value of X256 is 0.12 .

Takeoff/Landing Accident Puncture Probe Strikes Drum (X257). This evaluation is identical to that used for event $X 157$. A value of 0.015 per container involved in a takeoff/landing accident was used.

Takeoff/Landing Accident Puncture Force Equal to Drop of 133 in. onto a 6-in. Spike (X258). The analysis of event X158 was performed using the equations developed by Sandia for all aircraft accident types. Since these equations do not distinguish between the types of accidents used in this report, the value 0.825 per container strike was also used for the value of $\times 258$. 
(X259) through (X262). Not used.

Dunnage Fails During Takeoff/Landing Accident (X263). Tiedowns are typically designed to withstand $5 \mathrm{~g}$ 's before failing. While this is adequate for normal transport, many accidents easily exceed this level. Sandia's analysis ${ }^{(2)}$ suggests that $25 \%$ of airplane accidents involve forces of sufficient magnitude to cause tiedowns to fail. Therefore, a value of 0.25 per takeoff/landing accident was assigned to this element.

(X264) through (X266). Not used.

Criticality 0ccurs Due to Extreme Deformation in Takeoff/Landing Accident (X267). The probability assigned to this event was zero. See the analysis of $\times 67$ for a complete explanation.

Impact Forces from Takeoff/Landing Accident Sufficient to Fail 2R Vessel (X268). Impact forces expected in a takeoff or landing accident are not sufficient to cause failure of the $2 R$ vessel. This element was assigned a zero value. The analysis is similar to that performed for $\times 68$.

Fire Stresses from Takeoff/Landing Accident Sufficient to Fail 2R (X269). The material being shipped is stable at high temperatures. Thus, there is insufficient stress generated in a fire to cause failure. For this reason, $\times 269$ was set at zero.

Takeoff/Landing Accident Imposed Crush Force Exceeds 2R Design Strength $(\times 270)$. Analysis $(1)$ and testing $(3)$ have shown that very large crush forces are required to cause failure of the $2 \mathrm{R}$ vesse1. Forces of the magnitude required to crush a $2 \mathrm{R}$ are expected at a frequency of no more than $10^{-6}$ per container accident.

Puncture Probe Strikes 2R Container During Takeoff/Landing Accident (X271). A frequency of 0.33 per puncture of the outer drum was used for $\times 271$. The analysis used is discussed under event $\times 71$.

Takeoff/Landing Accident Puncture Force Equal to Drop of $170 \mathrm{in}$. onto a 6-in. Spike (X272). Based on the equations presented in chapter 5, $80 \%$ of the probes which strike the drum will have sufficient additional 
energy to breach the $2 R$ vessel. Thus, the expected frequency for $X 272$ is set at $0.82 R$ failures per $2 R$ strike.

$(\times 273) . \quad$ Not used.

Defective Weld Cannot Survive Takeoff/Landing Accident Forces (X274). A value of 0.05 per defective weld-accident was used for $\times 274$. The analysis is identical to that used for $\times 174$.

(X275) through (X334). Not used.

Inflight Ground Impact Accident Occurs (X335). Data from Air Force investigations of military transport accidents ${ }^{(4)}$ suggest that $9.5 \%$ of all accidents involve an airplane crashing into a mountain side or the ground (but not while attempting to takeoff or 1and). If the accident rate of $1 \times 10^{-8}$ accidents/mile is used, then we can assume a rate of $9.5 \times 10^{-10}$ inflight ground impact accidents per mile. Since this evaluation is based on a 1500-mile shipment distance, the value for $\times 335$ used in this analysis is $1.42 \times 10^{-6} /$ container shipped 1500 miles.

Sample Can Fails in Inflight Ground Impact Accident (X336). In view of the relative frailty of an unprotected sample can, the probability of event $\times 336$ occurring was set at 1.0 .

(X337). Not used.

Bolt Ring Fails from Inflight Ground Impact Accident Imposed Forces (X338). This element was included in X37. Therefore, it is set at zero here.

Inflight Ground Impact Accident Imposes Design Level Forces on Threads (X339). Forces on threads are expected to be inward acting and would tend to jam the plug on more tightly rather than remove it. Therefore, this element was set at zero. This analysis is identical to that used for event $\times 39$.

(X340) through (X343). Not used.

Exposed Bolt Ring Fails in Inflight Ground Impact Accident (X344). The value for this element was set at $4 \times 10^{-3}$, a value identical to that used for $\times 44$. See $x 44$ for analysis. 
(X345) and (X346). Not used.

Inflight Ground Impact Accident Impact Forces Sufficient to Cause Rupture of Outer can by $2 R(\times 347)$. Information supplied by Sandia $(5)$ shows that in approximately $30 \%$ of all inflight impact accidents, forces are present of sufficient magnitude to cause the $2 R$ container to rupture the outer vessel. Using this, and following the analysis presented for event $X 47$, a value of 0.05 per container involved in an inflight impact accident was obtained.

Inflight Ground Impact Accident Puncture Probe Longer than 11 in. and Force Equal to a Drop of $300 \mathrm{in.}\left(X_{348)}\right.$. The analysis for this event is identical to that for $\times 248$. A value of $1.3 \times 10^{-4}$ per puncture probe strike of the outer drum was used.

Fire Occurs During an Inflight Ground Impact Accident (X349). Based on data from Sandia ${ }^{(2)}$ on the fire environment during civilian aircraft accidents, the occurrence rate of fire is estimated to be 0.336 fires per inflight impact accident.

(X350). Not used.

Inflight Ground Impact Accident Crush Forces Cause Lid Removal (X351). This event was included in $X 355$. The value assigned to $X 351$ is zero.

Inflight Ground Impact Accident Impact Forces Cause Lid Removal (X352). This element was included in $\times 353$. Therefore, its value here is zero.

Inflight Ground Impact Accident Impact Forces Exceed Design Strength of Outer Drum (X353). Based on data supplied by Sandia ${ }^{(6)}$ and the failure threshold of an outer container, the frequency with which a container will be exposed to forces which will cause a breach was found to be 0.753 per container involved in an inflight impact accident.

Inflight Ground Impact Accident Fire Stresses Cause Outer Drum Failure (X354). This element was given a zero value. Analysis is identical to that presented for $\times 254$. 
Inflight Ground Impact Accident Crush Forces Exceed Design Strength of Outer Drum (X355). Realizing that all accidents of this nature involve impact, and using the analysis set forth in the evaluation of X255, a value of 0.05 per container-accident was assigned to this event.

Inflight Ground Impact Accident Produces Puncture Probes (X356). Analysis by Sandia ${ }^{(4)}$ shows that puncture probes will be a part of the inflight impact accident environment $12 \%$ of the time. A value of 0.12 was assigned to this event.

Inflight Ground Impact Accident Puncture Probe Strikes Drum (X357). Based on the analysis by Sandia, (3) puncture probe will be present, will be sufficiently rigid, and will strike at an angle which can produce puncture in $1.5 \%$ of the accidents. A frequency of 0.015 per container accident was assigned to this event. See the analysis of $X 157$.

Inflight Ground Impact Accident Puncture Force Equal to Drop of 133 in. onto a 6 -in. Spike (X358). The evaluation of this event is identical to that used for event $X 158$. A rate of 0.825 per container strike was used. (X359) through (X362). Not used.

Dunnage Fails During Inflight Ground Impact Accident (X363). A value of 0.25 (the same as used for event X263) was assigned to X363. See X263 for evaluation.

(X364) through (X366). Not used.

Criticality Occurs Due to Extreme Deformation in Inflight Ground Impact Accident (X367). For reasons explained in the analysis of X67, this event was assigned a value of zero.

Impact Forces from Inflight Ground Impact Accident Sufficient to Fail $2 R(X 368)$. Using information supplied by Sandia ${ }^{(5)}$ concerning the severity of impact forces and the probabilities of hitting "hard" or "soft" surfaces, it can be shown that $9 \%$ of all containers involved in an inflight impact accident will be exposed to forces sufficient to cause their failure. The value of $x 368$ was set at 0.09 . 
Fire Stresses from Inflight Ground Impact Accident Sufficient to Fail 2R (X369). For the reasons outlined under X269, X369 was set at zero.

Inflight Ground Impact Accident Imposed Crush Force Exceeds 2R Design Strength (X370). Event $\times 370$ is similar to event $X 270$. Because of a lack of more defined information, $X 370$ was also given a value of $10^{-6}$.

Puncture Probe Strikes 2R During an Inflight Ground Impact Accident $(X 371)$. This element was assigned a value of 0.33 . See analysis of event $x 71$.

Inflight Ground Impact Puncture Force Equivalent to Drop of 170 in. onto 6-in. Spike (X372). The analysis of this event is identical to that of $X 172$. Event $X 372$ was assigned a value of 0.80 .

(X373). Not used.

Defective Weld Cannot Survive Inflight Ground Impact Accident (X374). As was done for event $\times 174$, a value of 0.05 per defective weld-accident was used for $\times 374$.

\subsection{BARRIER RELEASE SEQUENCE PROBABILITIES}

The Basic Event Probabilities in Section 9.1 provide the data necessary to calculate the frequency of any event sequence. Only event sequences which lead to a release are of interest. As explained in Section 8.3, the computer code FAULTG was used to evaluate the release sequences. Fault tree logic and event description, failure rates, and sequence length and probability cutoff values are input to FAULTG (see Figure 9.2). The code determines which sequences will actually result in releases, then eliminates those which contain more elements than the preset cutoff level (ten event cut sets are the maximum allowed), and those not surviving the probability cutoff limit. Computer runs were made using different sequence lengths and probability cutoffs. It was determined that a maximum cut set size of ten elements and a probability cutoff of $10^{-18}$ allowed all major cut sets to be identified. Redundant release sequences are eliminated automatically. 


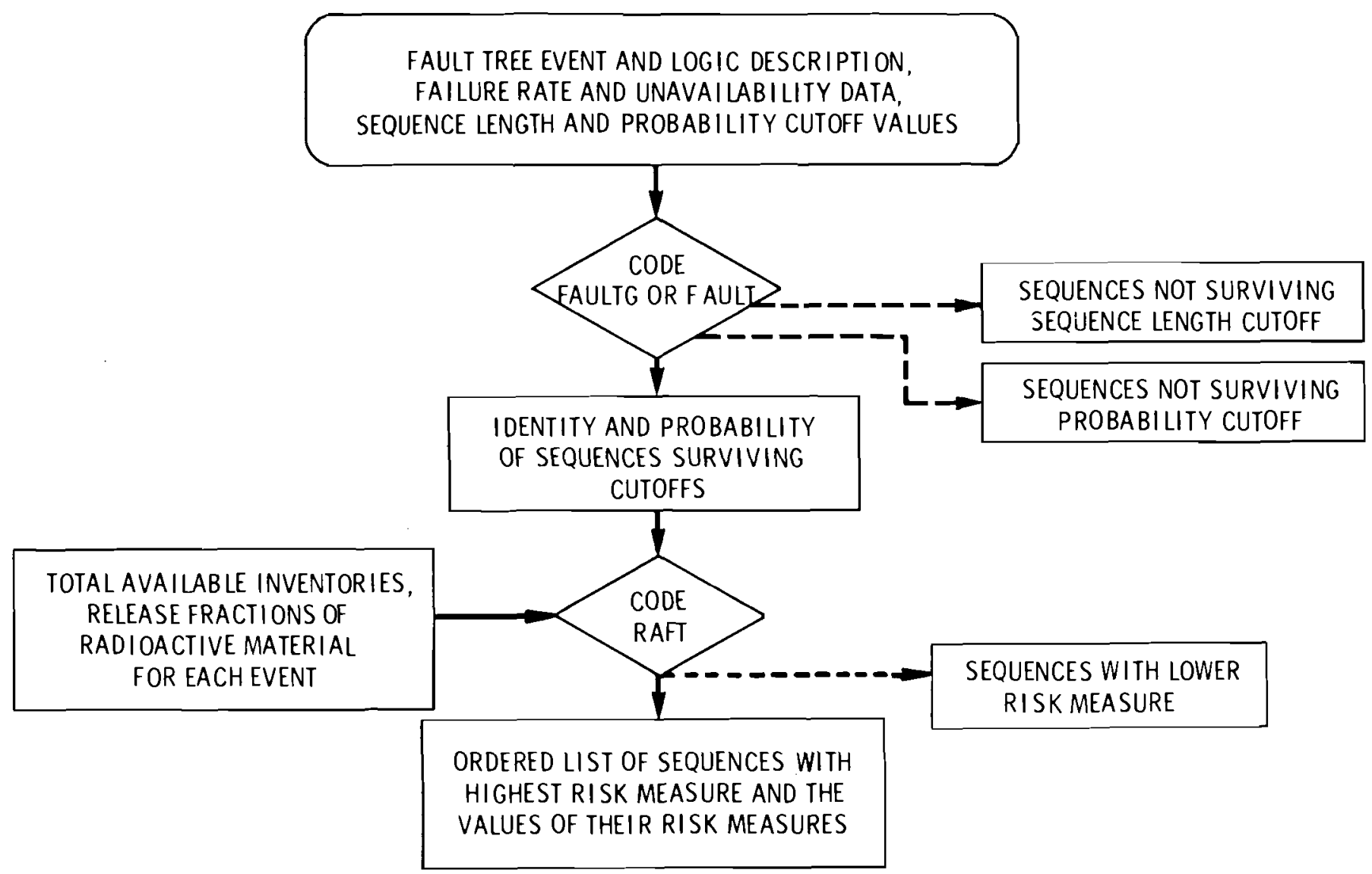

FIGURE 9.2. Screening Process Schematic (The risk sum of all discarded sequences is estimated for later addition to give the total risk in the entire fault tree.) 


\subsection{RELEASE FRACTIONS}

Due to the large number of cut sets and the fact that these sequences are system rather than barrier release sequences, the computer code RAFT (7) was employed to calculate total release fractions. The identity and probability of sequences surviving the cutoffs in FAULT, total available inventories, and release fractions of material for each event are input to the code (see figure 9.2). The result is an ordered listing of the release sequences, released amounts and the probability of the release.

Release fractions for each event were evaluated using a concept borrowed from the idea of barrier release sequences. That is, the release fraction given for a barrier is developed on the basis that it is the only barrier which contains the plutonium. Each event was examined to determine if it affected one of the three barriers. Release fractions were assigned according to the guidelines presented below for each barrier. Events not affecting a barrier were given a release fraction of one. A sensitivity study was carried out to determine the effect of the release fraction values on the overall risk.

\subsubsection{Sample Cans}

The steel can containing the dioxide powder is not considered an effective barrier. If the can is defective, all the material in the can is potentially available for release. Since there are two cans in the 6M container, the release fraction for all can failures from closure errors or defects is conservatively assumed to be 0.5 . The fraction released for railures from accident forces is assumed to be 1.0 .

\subsubsection{R Vessel}

Two types of failures of the $2 R$ vessel can be postulated. One is the loose cap. Assuming that all material is free inside the $2 R$ and the cap is loose, it is still necessary for the material to work its way past the cap threads. With the plug half unscrewed, there are assumed to be five full turns reamining threaded.* For this condition, a fractional release from the barrier of $10^{-6}$ of the total $2 \mathrm{R}$ contents was used in the analysis.

* Requirements for specification $2 \mathrm{R}$ containers are that only five threads have to be engaged when the plug is fully tightened. However, containers examined in tiris study had at least ten threads engaged when the plug was fully seated. 
The second failure mode of the $2 R$ is a failure either because the cap is completely unscrewed or because the $2 R$ is breached in an accident. If the $2 R$ is open and the container is on its side, or if the bottom weld fails in an accident, then the fraction released is assumed to be 1.0. 0therwise the fraction released is assumed to be 0.5 .

\subsubsection{Outer Drum}

The outer drum represents a less effective barrier than the $2 R$. If the drum is breached by lid removal and the drum is on its side, or if breached by impact, all material is assumed to be released from the drum. If it is punctured, the fraction released is 0.5 . If the outer drum is not extensively damaged, then the powder must work its way past the Celotex ${ }^{R}$ and out a vent hole or some other small opening in the drum. No more than a few grams of material should be released in this matter. Thus, a release fraction of $10^{-3}$ has been selected.

\subsection{SUMMARY OF RELEASE SEQUENCE EVALUATIONS}

Since a release sequence is made up of a number of basic events, the fraction released for a release sequence is obtained by multiplying the event release fractions for each selected release sequence. Release sequence probabilities must be obtained by forming a list of basic failure elements and by eliminating any duplicates before the probability multiplication is performed. Following both of these calculations, a release fraction can be paired with a release probability of all the release sequences. The release fraction is the $A F_{R_{j}}$ term and the release probability is the $P_{R_{j}}$ term in Section 3, Equation 2:

$$
R_{i}=\left(A F_{R_{i}} \times P_{R_{i}}\right) \times \underset{q}{\Sigma}\left(C_{E_{i, q}} P_{E_{q}}\right)
$$

The environmental terms $\left(C_{E_{i, q}} \times P_{E_{q}}\right)$ are developed in Section 10. 


\section{REFERENCES}

1. T. I. McSweeney, R. J. Hall et al., An Assessment of the Risk of Transporting Plutonium Oxide and Liquid Plutonium Nitrate by Truck, BNWL-1846, Battelle, Pacific Northwest Laboratories, Richland, WA August 1975.

2. R. K. Clarke, J. T. Foley, W. F. Hartman, D. W. Larson, Severities of Transportation Accidents, Volume II, Cargo Aircraft, (SLA-74-0001), Sandia Laboratories, July 1976.

3. L. L. Bonzon, and M. McWhirter, "Special Tests of Plutonium Shipping Containers", (IAEA-SR-10/22), presented at the IAEA International Seminar on the Design, Construction and Testing of Packaging for the Safe Transport of Radioactive Materials, Vienna, Austria, August 1976.

4. R. K. Clarke et al., Accident Environment Expected in Air Force C-5, C-141, and C-130 Aircraft Accidents, Sandia Laboratories, January 1976.

5. Bill Hartman, Sandia Laboratories, Private Communication.

6. Bill Hartman Testimony, ACRS Working Group Meeting on Safety Aspects of Packages for Shipping Plutonium, Chicago, IL, August 28, 1975.

7. T. H. Smith et al., A Risk-based Fault Tree Analysis Method for Identification, Preliminary Evaluation, and Screening of Potential Accidental Release Sequences in Nuclear Fuel Cycle Operations, BNWL-1959, Battelle, Pacific Northwest Laboratories, Richland, WA, January 1976. 


\subsection{EVALUATION OF ENVIRONMENTAL CONSEQUENCES}

In Section 9, release sequences were identified and evaluated by determining their expected frequency of occurrence and the associated amount of material released. A risk number could be obtained by forming the product of the expected frequency of occurrence and the amount of material released and summing over a 11 release sequences. This number does not fit a certain criterion for a risk assessment as specified in the Introduction. Namely, the results of the assessment must be expressed in a form that permits comparison to other societal risks.

This section develops the data required to compare the plutonium transportation risk assessment to other societal risks. Factors in developing this information are: Quantity Airborne, Meteorology, Demography, Individual and Population Dose, Population Health Effects and Expected Exposure Frequency.

Analyses of these factors are summarized sequentially in separate parts of this section. These factors and their relationships to other steps in the risk assessment are shown in Figure 10.1.

Results given in this section can be thought of as conversion factors required to obtain risk values which can be compared to other societal risks.

\subsection{QUANTITY AIRBORNE}

Section 9.4 shows the method used to get release sequence data and summarizes the data in terms of Barrier Release Sequences The released material considered in Section 9 is in the environment but it is not dispersed. Based on the plutonium pathway analysis calculations presented in Reference 1, the airborne pathway dominates all other pathways through the environment by about four orders of magnitude. Thus, only the airborne pathway was considered in this analysis.

This part of Section 10 will summarize the results of experiments which provide a basis for airborne dispersal estimates. Many basic experimental 


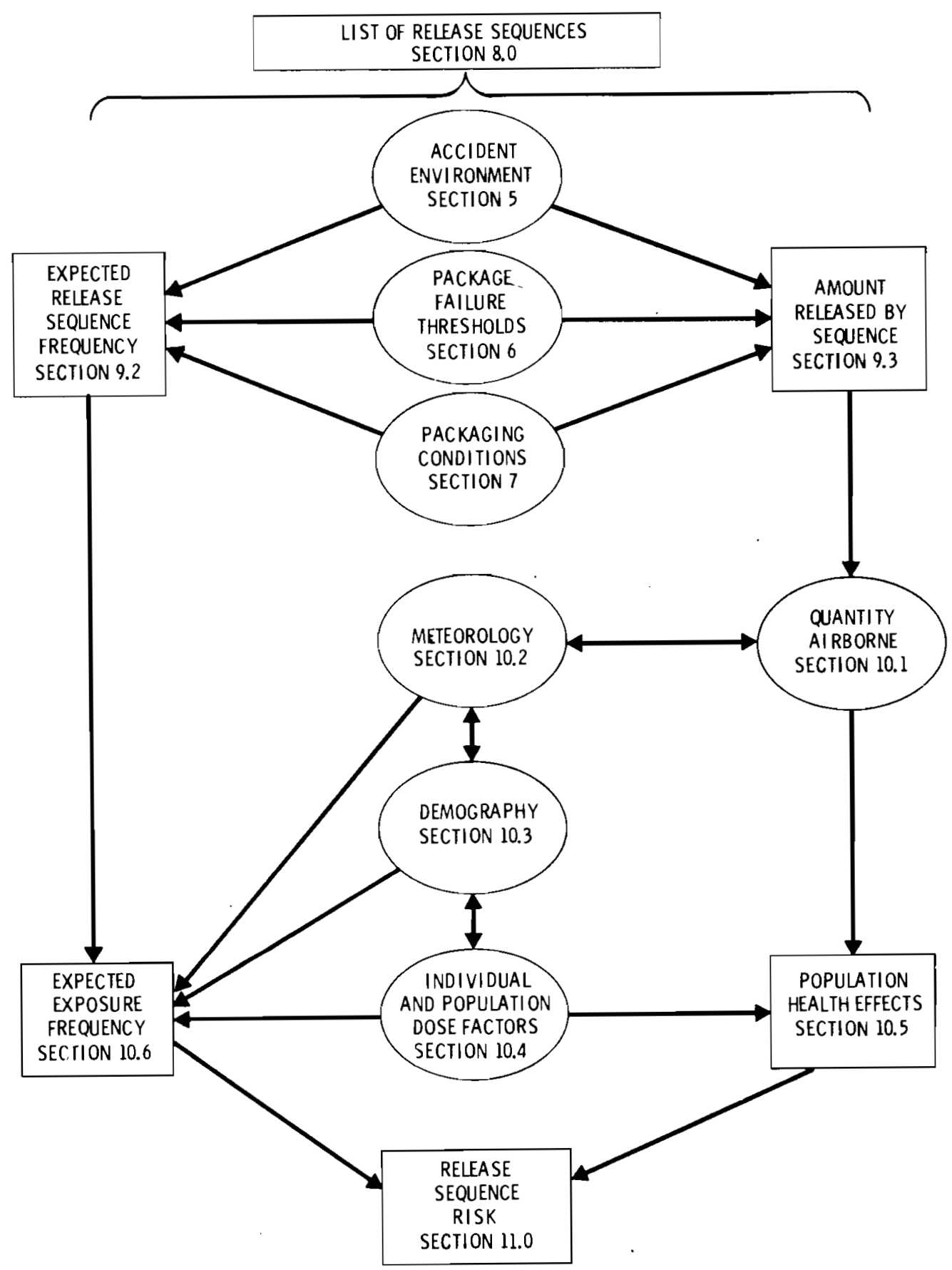

FIGURE 10.1 Release Sequence Evaluation Steps 
studies have been performed by Mishima and Schwendiman. (2-6) The pertinent results from these studies were summarized in Appendix $C$ of Reference 1 . Additional data have been obtained from the Sandia tests referenced in Section 6. These experimental studies form the basis for evaluating the amount of plutonium made airborne if accident stresses are sufficient to fail a 6M container, being carried on a cargo airplane. The dispersal evaluation reported here considers two components of the release: Quantity of Material Immediately Dispersed and Quantity Dispersed During Time Intervals Following Initial Release.

\subsubsection{Quantity of Material Immediately Dispersed}

During a high speed impact, the outer drum of the $6 \mathrm{M}$ container is an ineffective barrier and need not be considered in evaluating the release fraction. Indeed, most of Sandia's tests have been performed using just the inner container. Of the Sandia tests, referenced in Section 6, two provide the most significant data on the fraction made airborne following container failure. In one test, a $2 \mathrm{R}$ container struck a steel plate at a $6^{\circ}$ impact angle at a velocity of $399 \mathrm{ft} / \mathrm{sec}$. The impact angle was measured between the line drawn through the centerline and its projection down on to the flat steel plate. In this case, the $2 R$ was breached; a visible crack could be observed around part of the 2R's circumference at the base of the plug. However, none of the Mg0 simulant escaped. The inner steel can effectively blocked the release path. An impact at $15^{\circ}$, at a velocity of $385 \mathrm{ft} / \mathrm{sec}$ produced a breach of the $2 \mathrm{R}$ and a loss of some of the MgO simulant. The failed container bounced off the plate spinning and emitting the MgO in pinwheel fashion. In al1, $0.51 \mathrm{bs}$ of the 9.0 lbs of $\mathrm{MgO}$ was lost before the container finally came to rest some distance from the impact point. The half pound of powder lost represents about $6 \%$ of the total amount of powder in the container. If the material in the container had been $\mathrm{PuO}_{2}$, with properties like that described in Appendix $\mathrm{B}$, it can be conservatively assumed that all the released material would remain airborne once released. Based on this limited data, an airborne release fraction of $10 \%$ will be conservatively used for impacts severe enough to fail the $2 R$ vessel. 


\subsubsection{Quantity Dispersed During Time Intervals Following Initial Release}

The total amount of material made airborne is the sum of the fraction immediately airborne and any subsequent releases. Delayed releases could take on three forms. If a container failed within the cargo compartment and the fuselage remained intact, the fuselage could partially contain the release. If the material being shipped was thermally unstable and exposed to a prolonged fire, a delayed release could occur. Finally, if the plutonium was present on a combustible material; the combustion process could release the plutonium. For plutonium oxide shipments by air, the first two types of delayed releases can be easily eliminated. Accidents causing severe danage to a $6 M$ container destroy the fuselage, making it a totally ineffective barrier. The $\mathrm{PuO}_{2}$ powder is thermally stable, thus prolonged fires would not cause a release. If the Celotex ${ }^{R}$ filling in the $6 M$ container was contaminated with plutonium, the plutonium would be released in any accident severe enough to fail the outer container. Based on the flight recorder tests, ${ }^{(7)}$ all the Celotex ${ }^{R}$ would be destroyed in a 1-hour fire. During the fire, Mishima and Schwendiman ${ }^{(3)}$ estimate that $0.15 \%$ of the $\mathrm{PuO}_{2}$ and the Celotex ${ }^{\mathrm{R}}$ will be made airborne. The release rate is assumed to be linearly dependent on the fire duration and 1 imited to $0.15 \%$ of the contaminant for fires lasting for one hour or longer.

\subsection{METEOROLOGY}

The atmospheric characteristics along the transport route must be incorporated into any risk analysis where the atmosphere is an important pathway for dosage to man. The important atmospheric variables are: 1) wind direction indicates the initial direction of trave1, 2) windspeed - indicates the rate of transport, and 3) atmospheric stability - indicates the rate of dilution and plume rise potential. Certain characteristics of the release (e.g., height and temperature) are also important in the evaluation of the atmospheric pathway.

In terms of hazard, the most severe releases occur when failure occurs closest to man's habitat, i.e., upon ground impact. A release from a mid-air collision, can be modeled as an elevated release. Comparisons of consequences 
from ground level releases, show that ground level releases are much more severe. For this reason emphasis was placed on modeling ground level releases, almost to the exclusion of models for high altitude releases.

Assuming a postulated accident with a surface release and little or no release-related plume rise, the immediate and greatest impact will be in the region surrounding the location of the event. Transport and diffusion are often determined by local influences. Windspeeds and directions show considerable variation that cannot always be summarized by large geographic regions. Local influences include topography (surface roughness, channeling), heat island effects, and proximity to large bodies of water. The inclusion of such influences in the present analysis is not possible, principally because the information is not available either from a data base or from current modeling capabilities.

For estimates of long-term diffusion averages, the average persistence of winds by sectors are used. Considering wind direction persistences alone, the actual sector annual-average air concentrations can be considerably higher or lower than an average. Based on reported values from 129 weather bureau surface stations in continental U.S., the concentrations range on the order of from half to 5 times the average. The air concentrations near a particular population center can be expected to vary by the same factor depending on the direction of the population center from the selected route. Such a factor could be quite important in determining the effects of releases near large population centers. Over a sufficiently long route the effect of different wind direction persistences may tend to cancel if there is a random relationship between the prevailing wind directions and population centers. The alternative of picking a route based on known diffusion conditions to minimize risk could be beneficial; however, at the present time it is not included in the model.

The meteorological data used in this analysis are shown in Table 10.1. The values were developed from micrometeorological data collected for diffusion calculations for reactor sites. Seven sets of micrometeorological data were selected from about 26 compilations from reactor sites to account for the variation of atmospheric characteristics that could reasonably occur along 
the route. The use of a single averaged distribution allows for the typical range of windspeeds without undue weighting to any particular site.

TABLE 10.1. Average Windspeed/Stability Characteristics

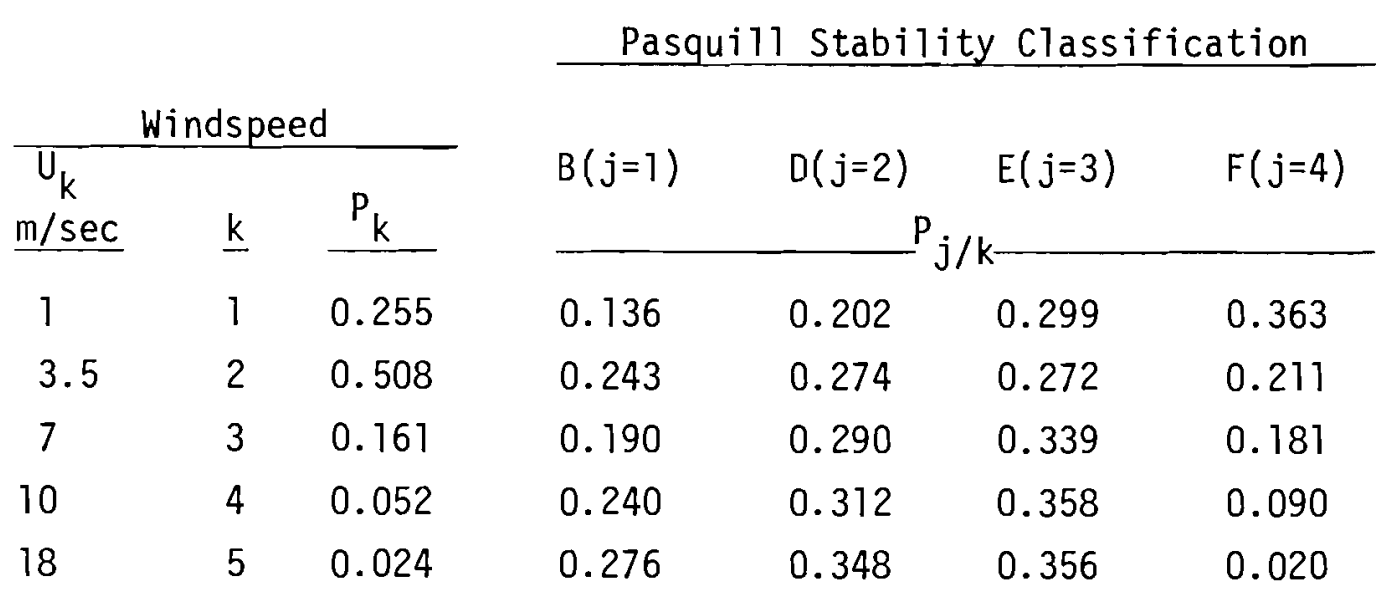

\subsection{DEMOGRAPHY}

The objective of this section is to characterize the population distribution along the plutonium shipping routes. As shown in Figure 10.1, this information is needed to determine both the expected frequency at which a given population distribution will be exposed to a release and the distribution of the resultant exposure. A comparison of the truck and air transport modes has some circumstances where the relationship between demography and the accident likelihood is simpler for air transport. In other circumstances it is more complex. Along air routes the likelihood of an accident is uniform and in addition there is never any attempt to avoid flying over a large city. This results in a relatively simple modeling of the demography described in Section 10.3.1. In the vicinity of airports the modeling is more complex. First of al1 accidents, although less severe, are more frequent. In addition, since cargo airplanes service large metropolitan areas, the approach and take-off patterns are more likely to be over urban rather than rural areas. These differences must be considered when determining the likelihood of an accident in the vicinity of an airport. Analytical details in this case are presented in Section 10.3.2. 


\subsubsection{Demography Along Shipping Routes}

The population distribution along shipping routes was characterized by dividing the continental U.S. into four zones based roughly on population density and degree of urbanization. The zones are shown in Figure 10.2. A representative state was chosen for each of the zones. Then for the purpose of the study, the population data of the selected states were used in forecasting population characteristics of their respective zones.

The population densities were grouped into three classes: Urban for densely populated urban areas, Suburban for areas of moderate population density, and Rural for the nonurbanized areas. The Suburban area data were obtained by taking the Standard Metropolitan Statistical Area (SMSA) data, which include Urban, and subtracting out the population and land area of the cities. The urban areas were then considered separately from the suburban area. In this way no segments of the population are included twice.

The initial approach was to establish a set of population data for the representative states. Census data for 1960 and 1970 were used as a data base. From this data population projections were made for the Years 1980, 1990 and 2000 using the compound interest formula to model population changes.

The fraction of each fuel reprocessor to plutonium fuel fabricator route in each of the population zones was identified. Using this, a route population density was calculated for each route for each of the time periods considered: 1980, 1990, 2000.

The techniques employed in each step of the analysis are described in more detail below.

\subsubsection{Population Zones Data}

The continental U.S. was divided into four population zones (see Figure 10.2). A representative state for each zone was chosen and data for the state taken to be representative of the entire ::one. The states chosen by zone are shown below: 


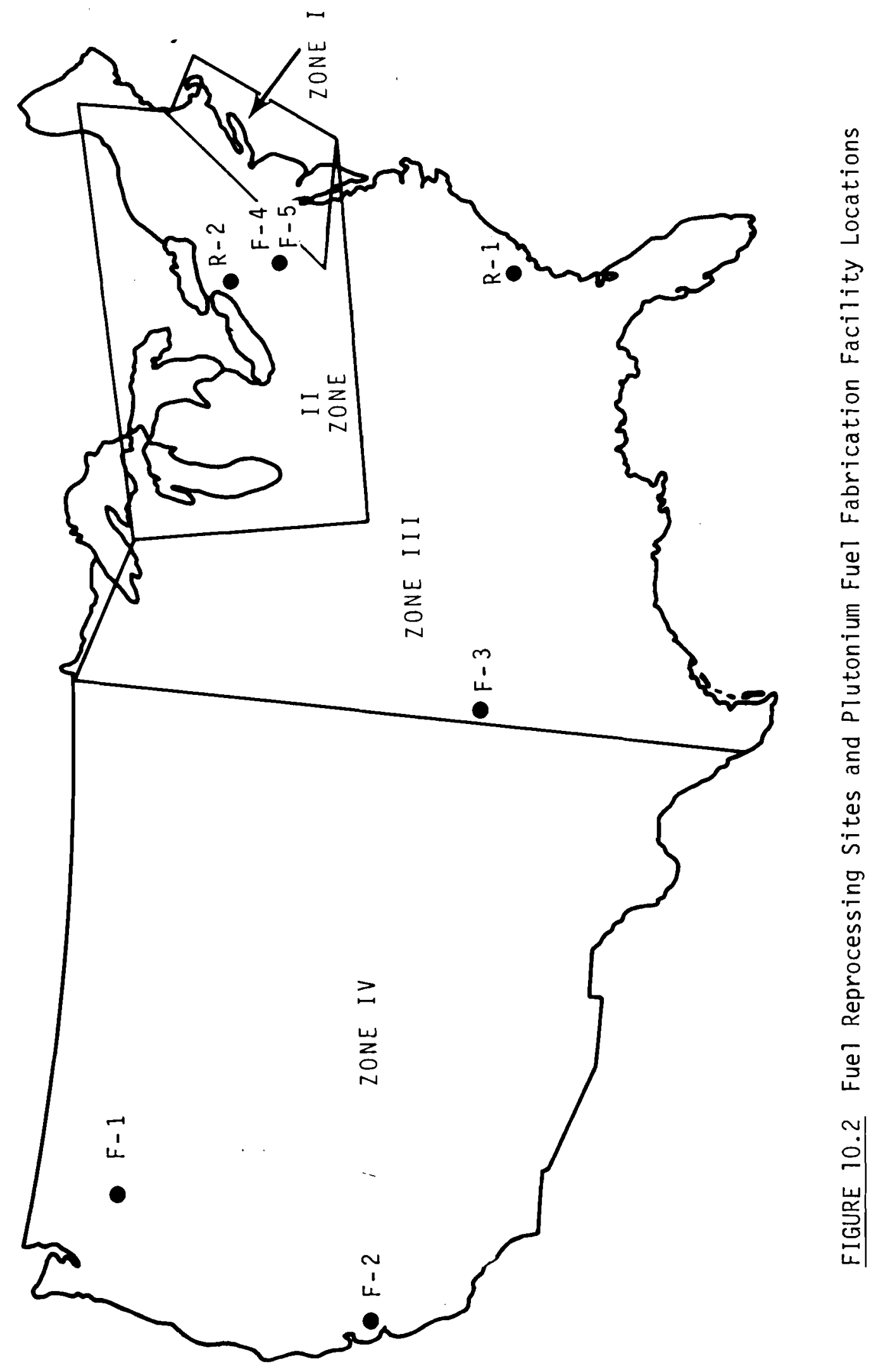

10.8 


\section{Zone}

$$
\begin{aligned}
& \text { I - High urbanization } \\
& \text { II - Densely populated } \\
& \text { III - Moderately populated } \\
& \text { IV - Low population }
\end{aligned}
$$

\section{Representative State}

New Jersey

Massachusetts

Missouri

Washington

The population characteristics for each of the representative states

\begin{tabular}{|c|c|c|c|c|}
\hline & Population & $\underset{\mathrm{mi}}{\operatorname{Land}}{ }^{2}$ & $\begin{array}{l}\text { Density } \\
\text { People/mi }\end{array}$ & $\underset{\%}{\operatorname{Land}} \mathrm{Area}$ \\
\hline State & $6,066,782$ & 7,532 & 806 & 100 \\
\hline Cities & $2,440,602$ & $226^{(a)}$ & 10,800 & 3 \\
\hline SMSA ${ }^{(b)}$ & $4,821,032$ & 4,227 & 1,147 & 56.1 \\
\hline Rural & $1,245,750$ & 3,305 & 377 & 43.9 \\
\hline
\end{tabular}
based on 1960 census figures $^{(8)}$ are shown in Tables 10.2 through 10.5, respectively.

TABLE 10.2 New Jersey Population Characteristics - 1960
(a) City of Vineland, $\mathrm{NJ}$ showed an area of $67 \mathrm{mi}^{2}$. This was corrected

\begin{tabular}{|c|c|c|c|c|}
\hline & Population & $\begin{array}{l}\text { Land Area, } \\
\mathrm{mi}^{2}\end{array}$ & $\begin{array}{l}\text { Density } \\
\text { People/mi }\end{array}$ & $\underset{\%}{\text { Land Area, }}$ \\
\hline State & $5,148,578$ & 7,828 & 657 & 100 \\
\hline Cities & $2,876,806$ & 713 & 4,035 & 9.1 \\
\hline SMSA & $4,379,477$ & 2,924 & 1,498 & 37.3 \\
\hline Rura 1 & 769,101 & 4,904 & 157 & 62.7 \\
\hline
\end{tabular} to $10 \mathrm{mi}^{2}$, which is larger than most cities of comparable population (b) Includes cities.

TABLE 10.3 Massachusetts Population Characteristics - 1960 
TABLE 10.4 Missouri Population Characteristics - 1960

\begin{tabular}{|c|c|c|c|c|}
\hline & Population & $\begin{array}{l}\text { Land Area, } \\
\mathrm{mi} 2\end{array}$ & $\begin{array}{c}\text { Density } \\
\text { People/mi } \\
\end{array}$ & $\begin{array}{l}\text { Land Area, } \\
\%\end{array}$ \\
\hline State & $4,319,813$ & 69,046 & 63 & 100 \\
\hline Cities & $1,715,093$ & 336 & 5,104 & 0.5 \\
\hline SMSA & $3,414,071$ & 7,967 & 429 & 11.5 \\
\hline Rural & 905,742 & 61,079 & 15 & 88.5 \\
\hline
\end{tabular}

TABLE 10.5 Washington Population Characteristics - 1960

\begin{tabular}{|c|c|c|c|c|}
\hline & Population & $\begin{array}{l}\text { Land Area, } \\
\mathrm{mi} 2\end{array}$ & $\begin{array}{c}\text { Density } \\
\text { People/mi }\end{array}$ & $\begin{array}{l}\text { Land Area, } \\
\quad \%\end{array}$ \\
\hline State & $2,853,214$ & 66,663 & 43 & 100 \\
\hline Cities & $1,066,336$ & 226 & 4,718 & 0.3 \\
\hline SMSA & $1,707,136$ & 7,663 & 223 & 11.5 \\
\hline Rural & $1,146,078$ & 59,000 & 19 & 88.5 \\
\hline
\end{tabular}

In Tables 10.2 through 10.5 the city data is based on cities of 25,000 population or greater and the SMSA are all the standard metropolitan statistical areas in the state. The rural population and area values are those of the total state minus those of the SMSA. It should be recognized that since the SMSA includes many major cities, the cities are included twice in the tables. This shows up in both the land area and total population counts which result in the numbers adding to greater than $100 \%$. In the analysis, the Suburban class is defined as that fraction of the SMSA not included in the City category. In this way, no segments of the population are included twice.

The next step was to obtain the same data for 1970 and then determine the population and land area change for major cities (100,000 population) from 1960 to 1970. The 1970 census data were obtained from the Statistical Abstracts of the U.S. ${ }^{(9)}$ The extrapolation to 2000 was then based on information presented in an article by J. P. Pickard. (10) Pickard stated that by the Year 2000 
the urban land area will double. He also states that $85 \%$ of the total population growth will occur in major urban areas. Using this, the total population increase is the urban increase divided by 0.85 . This leaves the rural increase at $15 \%$ of the total growth.

Based on Pickard's projections, the land areas and rural populations were calculated for the Year 2000. The data for 1980 and 1990 were filled in using the compound interest formula. The resultant population characteristics for each of the four zones in the years 1980, 1990 and 2000 are presented in Table 10.6. The composite population densities for the four zones are shown in Table 10.7.

TABLE 10.6 Projected Population Density and Land Area by Zone and Population Classes

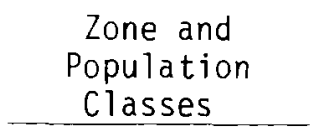

I Urban

Suburban (a)

Rura 1

II Urban

Suburban (a)

Rura 1

II Urban

Suburban (a)

Rural

IV Urban

Suburban (a)

Rura1

\begin{tabular}{lc}
1980 \\
$\begin{array}{ll}\text { Land } & \text { Density } \\
\text { Area, } \% & \text { People/mi }\end{array}$ \\
\hline
\end{tabular}

3.8

66.9

29.3

11.5

35.5

53.0

0.8

17.3

81.9

0.5

15.0

84.5
9290

822

612

3170

845

238

3980

226

17

4390

131

25

\begin{tabular}{l}
$\frac{1990}{\text { Land }}$ \\
Area, $\%$ \\
\hline
\end{tabular}

4.8

84.3

10.9

14.5

44.8

40.7

1.0

21.8

77.2

0.6

$\cdot 18.9$

80.6
8390

893

696

3130

762

350

3930

223

24

4480

144

29

\begin{tabular}{cc}
2000 \\
\hline Land & Density 2 \\
Area, \% & People/mi \\
\hline
\end{tabular}

6.0

7570

94.0

1005

18.2

2820

56.5

686

25.3

635

1.2

3890

27.5

221

71.3

29

0.8

23.7

4560

147

34

$\overline{(a) \text { (SMSA minus Cities) }}$ 
TABLE 10.7 Average Population Densities

by Zone (People/mi2)

\begin{tabular}{|c|c|c|c|}
\hline Zone & 1980 & 1990 & 2000 \\
\hline I & 1082 & 1231 & 1399 \\
\hline I I & 824 & 936 & 1061 \\
\hline I I I & 84 & 104 & 129 \\
\hline IV & 62 & 76 & 93 \\
\hline
\end{tabular}

\subsubsection{Average Size of an Urban Area}

The data in Table 10.6 show that urban areas occupy a small fraction of the land area. If a release occurs in a city, it would be incorrect to assume that the release plume is confined completely to an urban area. For that reason, it is important to determine the size of a representative urban area and thereby limit the urban area included in any dose calculation. Using the representative states for each of the four zones, the average urban land area was determined. Only urban areas having a population greater than 25,000 in the year 1960 were used in the analysis. The results of this analysis are summarized in Table 10.8 for the years of interest.

TABLE 10.8 Projected Land Area of Urban Areas in the Four Zones of the U.S.

\begin{tabular}{|c|c|c|c|c|}
\hline \multirow[b]{2}{*}{ Zone } & \multirow{2}{*}{$\begin{array}{c}\text { Number of } \\
\text { Urban Areas } \\
(\text { Pop }>25,000) \\
1960 \\
\end{array}$} & \multicolumn{3}{|c|}{$\begin{array}{l}\text { Average Urban } \\
\text { Land Area, } \mathrm{mi}^{2}\end{array}$} \\
\hline & & 1980 & 1990 & 2000 \\
\hline I & 36 & 7.92 & 9.97 & 12.56 \\
\hline I I & 35 & 25.66 & 32.34 & 41.77 \\
\hline I I I & 12 & 43.92 & 55.33 & 69.67 \\
\hline IV & 8 & 37.80 & 47.63 & 60.00 \\
\hline
\end{tabular}

(a) Only includes urban areas in representative state. 


\subsubsection{Shipping Route Mileage by Population Zones}

The second factor in the characterization of the demography is to relate the shipping routes to the population zones. Plutonium shipment routes were previously determined in Section 4. Previous parts of Section 10.3 have characterized the population distribution for the various zones of the country for the same years. This section will develop the information on the route mileage in each zone that is needed to obtain the population density along each shipping route.

A map with the population zones and the location of the fabrication and reprocessing plants is shown in Figure 10.2. The designations $F-1$ through F-5 refer to the fuel fabrication facilities listed in Table 4.2. The designations R-1 and R-2 refer to the fuel reprocessing facilities identified in Section 4.2. The distance between each reprocessor and fabricator was obtained from Rand MclNally road maps. (11) For each route the fraction of the route in each of the four zones was determined by drawing arcs of a great circle between each fuel fabricator and reprocessor and determining the fraction of the arc in each zone. This data is summarized in Table 10.9. The four columns under each reprocessor contain the fractioned route mileage in each zone to each fuel fabricator.

TABLE 10.9 Fractional Shipping Route Mileage by Population Zones (values in percentage)

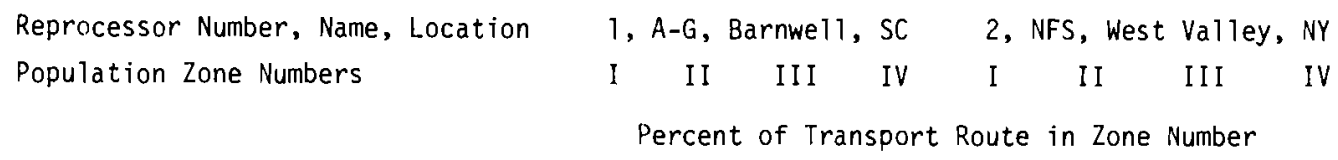


The shipping routes are now completely characterized. The mileage between any reprocessor and fabricator can be determined from Table 4.3. The fraction of the route in each zone is shown in Table 10.9, and the population distribution in each zone along the route for a particular year can be determined from the data presented in Table 10.6.

\subsubsection{Demography in the Vicinity of Large Metropolitan Airports}

The data in the previous section described the population distribution for the entire country by dividing the country into four regions and then describing the demographic characteristics of each region.

Airports with regular cargo service are adjacent to large metropolitan centers. In this analysis, it will be assumed that a11 accidents during takeoff, ascent and descent will occur in a suburban area. From knowledge of the shipping routes summarized in Table 4.3 , it is relatively straightforward to calculate the fraction of landings and takeoffs occurring in each region. The population distribution associated with the suburban population in these regions is presented in Table 10.6. Table 10.10 shows the resultant likelihood of accidents occurring in various regions.

TABLE 10.10. Distribution of Ascent, Descent, Takeoff and Landing Accidents Occurring in Selected Demographic Zones

$\begin{array}{lcc}\text { Region } & \begin{array}{c}\text { Fraiction of Accidents } \\ \text { Occurring in Region }\end{array} & \begin{array}{c}\text { Population Density (a) } \\ \text { in Accident Vicinity } \\ \text { Individuals/mi2 }\end{array} \\ \text { I } & 0 \text { (b) } & 822 \\ \text { II } & 0.5 & 845 \\ \text { III } & 0.38 & 226 \\ \text { IV } & 0.12 & 131 \\ \text { (a) Suburban population density typical for region in } 1980 \\ \text { (b) No landings or take-off occur in this region for the } \\ \text { case being studies. }\end{array}$




\subsection{INDIVIDUAL AND POPULATION DOSE FACTORS}

As shown in Figure 10.1, factors from the meteorological and demographic characteristics of the shipping route are combined with the dose conversion factors developed here to determine the population doses resulting from an accidental release of plutonium. There are two parts to the calculation, discussed in the following subsections. First, Dose Conversion Factors must be developed as a step toward the characterization of the effect of inhaled plutonium on an individual's health. Second, using the meteorological data, an Atmospheric Dispersion Model must be developed to characterize the plutonium aerosol concentration downwind from the release point.

\subsubsection{Dose Conversion Factors}

Tre dose resulting from plutonium inhalation is calculated using either of two lung models recommended by the International Commission on Radioperiod, the particle size, the isotopic composition of the released plutonium, the individual's ventilation rate, the solubility of the inhaled material in body fluids and the retention time of plutonium in body organs.

The dose resulting from plutonium inhalation is calculated using either of two lung models recommended by the International Commission on Radiological Protection (ICRP). The Initial Lung Model (ILM) recommended by ICRP differentiates soluble and insoluble inhaled material. $(12,13)$ When the inhaled material is soluble, the uptake by other organs is assumed to be essentially instantaneous. A more sophisticated Task Group Lung Model (TGLM), recently suggested by ICRP, characterizes more completely the metabolic pathways of the inhaled material. (14) The derived equations for estimating the dose to organs other than the lung are considerably more complex than those for the ILM. A computer program has been developed for calculating the dose to lung and other organs using the TGLM. (15)

A detailed discussion of the two lung models is presented in Appendix $F$ of Reference 1. Only results from the TGLM calculations were used in the dose conversion for the present analysis. 
For both lung models, the inhalation dose to an individual exposed to a passing cloud can be expressed by:

$$
D_{j}=51.1\left(\frac{f_{a} \varepsilon T\left(\lambda_{e}, t\right)}{\lambda_{e}^{m}}\right)_{j} P
$$

where:

$D_{j}$ is dose to organ of interest, $j$, delivered over time, $t$, rem

$f_{a}$ is fractional uptake, via inhalation by organ of interest

$\varepsilon$ is effective absorbed energy for organ of interest, Mev•rem/dis. rad

$P$ is quantity inhaled, $\mu C i$

$\lambda_{e}$ is effective elimination rate constant for organ $j, d^{-1}$

$t$ is time following initial intake, $d$

$m$ is mass of organ $j, g$

$T\left(\lambda_{e}, t\right)$ is function of $\lambda_{e}$ and $t$ and $i$ ts exact form is dependent upon lung model used to describe inhalation uptake.

The quantity of material inhaled is dependent upon the time-integrated air concentration as expressed by:

$$
P=b c_{a} \tau=b E
$$

where:

$b$ is human ventilation rate, $\mathrm{cm}^{3} / \mathrm{sec}$

$c_{a}$ is air concentration, $\mu \mathrm{C} i / \mathrm{cm}^{3}$

$\tau$ is duration of inhalation exposure, sec

$E$ is time-integrated air concentration, $\mu \mathrm{C} i \cdot \mathrm{sec} / \mathrm{cm}^{3}$.

The time-integrated air concentration, $E$ is obtained from the Atmospheric Dispersion Model discussed in Section 10.4.2. 
Combining Equation 10-1 with Equation 10-2 and normalizing the result to the quantity released yields:

$$
\left(\frac{D_{j}}{Q}\right)=51.1 \frac{f_{a} \varepsilon T(\lambda e, t)}{\lambda e^{m}} \quad b\left(\frac{E}{Q}\right)
$$

where $Q$ is the quantity released in curies, or

$$
\left(\frac{D}{Q}\right)=K\left(\frac{E}{Q}\right)
$$

where $K$ is the inhalation dose conversion factor for an accidental atmospheric release. Dose conversion factors for 50-year dose commitments for several plutonium isotopes and for ${ }^{241} \mathrm{Am}$ based on both the ILM and TGLM are tabulated in Table 10.11.

The conversion factors presented in Table 10.11 are values of $K$ in Equation 10-3 for the individual isotopes. In the case of the TGLM calculations, the particle size is based on an equivalent aerodynamic median diameter (AMAD) of 1 micron. Using this table, one set of conversion factors for any specified isotopic mixture can be obtained.

Table 10.12 lists the plutonium isotopic mixture, assumed to be representative of that which will be shipped in the early 1980s, which was used for the dose calculations reported in this document. Using this isotopic mixture, the conversion factors for the mixture have been calculated and summarized in Table 10.13 using the TGLM conversion factors. The set of $K$ values shown in Table 10.13 convert the amount of material inhaled, expressed in total curies of the mixture, into 50-year dose commitments to the lung and bone for both soluble and insoluble particles. The Task Group Lung Model was used in this analysis with $\mathrm{PuO}_{2}$ metabolized as translocation class $Y$ and all nitrate compounds are class $\mathrm{W}$.

The release fractions developed in Section 10.1 are presented as fractions of the total weight of plutonium in a container based on the isotopic mixture shown in Table 10.12.

$$
Q=11.4 \times A \times F_{r}
$$


Dose Conversion Factors for Inhalation of Plutonium and 241 Am Isotopes (Standard Man)(a)

\begin{tabular}{|c|c|c|c|c|}
\hline \multirow{2}{*}{ Isotope } & \multirow{2}{*}{$\begin{array}{l}\text { Organ of } \\
\text { Reference }\end{array}$} & \multirow{2}{*}{$\begin{array}{l}\text { Solubility in } \\
\text { Body Fluids(a) }\end{array}$} & \multicolumn{2}{|c|}{$\begin{array}{l}\text { Conversion Factor }(b) \\
\left.\text { (rem per } \mathrm{Ci} \mathrm{sec/m} / \mathrm{m}^{3}\right)\end{array}$} \\
\hline & & & $\mathrm{ILM}(\mathrm{c})$ & TGLM(d) \\
\hline \multirow[t]{2}{*}{${ }^{238} \mathrm{Pu}$} & Lung & $\begin{array}{l}\text { Insol }(Y) \\
\text { Sol }(W)\end{array}$ & $4.4 E+4^{(e)}$ & $\begin{array}{l}1.2 E+5 \\
1.2 E+4\end{array}$ \\
\hline & Bone & $\begin{array}{l}\text { Insol }(Y) \\
\text { Sol }(W)\end{array}$ & $\begin{array}{l}6.0 \mathrm{E}+5 \\
1.2 \mathrm{E}+6\end{array}$ & $\begin{array}{l}1.2 E+5 \\
3.2 E+5\end{array}$ \\
\hline \multirow[t]{2}{*}{${ }^{239} \mathrm{Pu}$} & Lung & $\begin{array}{l}\text { Insol }(Y) \\
\text { Sol }(W)\end{array}$ & $4.0 E+4$ & $\begin{array}{l}1.1 E+5 \\
1.1 E+4\end{array}$ \\
\hline & Bone & $\begin{array}{l}\text { Insol (Y) } \\
\text { Sol }(W)\end{array}$ & $\begin{array}{l}7.0 \mathrm{E}+5 \\
1.4 \mathrm{E}+6\end{array}$ & $\begin{array}{l}1.4 E+5 \\
3.7 E+5\end{array}$ \\
\hline \multirow[t]{2}{*}{${ }^{240} \mathrm{Pu}$} & Lung & $\begin{array}{l}\text { Insol }(Y) \\
\text { Sol }(W)\end{array}$ & $4.0 E+4$ & $\begin{array}{l}1.1 E+5 \\
1.1 E+4\end{array}$ \\
\hline & Bone & $\begin{array}{l}\text { Insol }(Y) \\
\text { Sol }(W)\end{array}$ & $\begin{array}{l}7.0 E+5 \\
1.4 E+6\end{array}$ & $\begin{array}{l}1.4 E+5 \\
3.7 E+5\end{array}$ \\
\hline \multirow[t]{2}{*}{${ }^{241} \mathrm{Pu}$} & Lung & $\begin{array}{l}\text { Insol (Y) } \\
\text { Sol }(W)\end{array}$ & $\begin{array}{l}4.0 E+1 \\
-\cdots--\end{array}$ & $\begin{array}{l}2.0 E+2 \\
3.7 E+0\end{array}$ \\
\hline & Bone & $\begin{array}{l}\text { Insol }(Y) \\
\text { Sol (W) }\end{array}$ & $\begin{array}{l}1.4 E+4 \\
2.7 E+4\end{array}$ & $\begin{array}{l}2.1 E+3 \\
6.7 E+3\end{array}$ \\
\hline \multirow[t]{2}{*}{${ }^{242} \mathrm{Pu}$} & Lung & $\begin{array}{l}\text { Insol }(Y) \\
\text { Sol }(W)\end{array}$ & $\begin{array}{l}6.4 E+5 \\
-\end{array}$ & $\begin{array}{l}1.3 E+5 \\
1.1 E+4\end{array}$ \\
\hline & Bone & $\begin{array}{l}\text { Insol }(Y) \\
\text { Sol }(W)\end{array}$ & $\begin{array}{l}6.4 \mathrm{E}+5 \\
1.3 \mathrm{E}+6\end{array}$ & $\begin{array}{l}1.3 E+5 \\
3.4 E+5\end{array}$ \\
\hline \multirow[t]{2}{*}{${ }^{241} \mathrm{Am}$} & Lung & $\begin{array}{l}\text { Insol }(Y) \\
\text { Sol }(W)\end{array}$ & $1.4 E+4$ & $\begin{array}{l}5.2 E+4 \\
1.2 E+4\end{array}$ \\
\hline & Bone & $\begin{array}{l}\text { Insol }(Y) \\
\text { Sol }(W)\end{array}$ & $\begin{array}{l}7.0 \mathrm{E}+5 \\
1.4 \mathrm{E}+6\end{array}$ & $\begin{array}{l}7.6 E+4 \\
2.0 E+5\end{array}$ \\
\hline \multirow[t]{2}{*}{$\begin{array}{l}\text { Reference } \\
\text { Mixture(f) }\end{array}$} & Lung & $\begin{array}{l}\text { Insol }(Y) \\
\text { Sol }(W)\end{array}$ & $\begin{array}{l}1.4 E+3 \\
----\end{array}$ & $\begin{array}{l}5.4 E+3 \\
4.0 E+2\end{array}$ \\
\hline & Bone & $\begin{array}{l}\text { Insol }(Y) \\
\text { Sol }(W)\end{array}$ & $\begin{array}{l}3.5 E+4 \\
6.9 E+4\end{array}$ & $\begin{array}{l}6.1 E+3 \\
1.7 E+4\end{array}$ \\
\hline
\end{tabular}

(a) Biological parameters recommended by ICRP. (13)

(b) Calculated as a 50-year dose commitment per $\mathrm{Ci} \mathrm{sec} / \mathrm{m}^{3}$ inhaled. Ventilation rate assumed to be $230 \mathrm{~cm}^{3} / \mathrm{sec}$.

(c) Initial Lung Mode1, ICRP. (25)

(d) Task Group Lung Mode1. (14) Particle Size: 1 micron (AMAD).

(e) $4.4 \mathrm{E}+4$ equivalent to $4.4 \times 10^{4}$ or 44,000 .

(f) See Table 10.12 for composition of Reference Mixture. 
where:

11.4 is the number of curies per gram in the plutonium isotopic mixture being shipped. (See Table 10.12)

$Q$ is the curies released

$A$ is the amount of plutonium in a container in grams

$F_{r}$ is the release fraction of plutonium dispersed during a release.

TABLE 10.12 Reference Mixture of Plutonium and Americium

$\begin{array}{lcc} & \begin{array}{c}\text { Composition } \\ \text { by Weight }(\%)\end{array} & \begin{array}{c}\text { Activity }(b) \\ \text { (Ci/g of Mix) }\end{array} \\ 238 \mathrm{Pu} & 1.5 & 0.26 \\ 239 \mathrm{Pu} & 58 & 0.036 \\ 240 \mathrm{Pu} & 24 & 0.054 \\ 241_{\mathrm{Pu}} & 11 & 11 \\ 242 \mathrm{Pu} & 4.9 & 1.9 \times 10^{-4} \\ 241 \mathrm{Am} & --- & 0.034\end{array}$

(a) Initial composition, after separation from $U$ and FP. Note: Sum does not equal 100 because only two significant figures are used.

(b) Activity of isotope in mixture 2 years after separation.

TABLE 10.13 Dose conversion Factors for Inhalation of Reference Plutonium Mixture (Standard Man)

\begin{tabular}{|c|c|c|}
\hline $\begin{array}{l}\text { Organ of } \\
\text { Reference }\end{array}$ & $\begin{array}{l}\text { Solubility in } \\
\text { Body Fluids }\end{array}$ & $\begin{array}{c}k^{(a)} \\
\left(\text { rem per } C^{\prime} \mathrm{sec} / \mathrm{m}^{3}\right)\end{array}$ \\
\hline Lung & $\begin{array}{l}\text { Insol }(Y) \\
\text { Sol }(W)\end{array}$ & $\begin{array}{l}5.4 \times 10^{3} \\
4.0 \times 10^{2}\end{array}$ \\
\hline Bone & $\begin{array}{l}\text { Insol (Y) } \\
\text { Sol (W) }\end{array}$ & $\begin{array}{l}6.1 \times 10^{3} \\
1.7 \times 10^{4}\end{array}$ \\
\hline
\end{tabular}

(a) Constant in Equation 4 


\subsubsection{Atmospheric Dispersion Model}

The atmospheric dispersion model calculates the ground level, time integrated air concentration at any downwind distance $x$ and crosswind distance $y$. Based on the coefficients derived in the previous section, the dose to an individual standing at point $(x, y)$ can be calculated. By integrating over the contaminated area, a population dose can then be determined.

\subsubsection{Time-Integrated, Ground Level Air Concentration}

For releases of short duration, less than a day, the time-integrated air concentration at ground level is evaluated by the bivariate normal diffusion model using Pasquill diffusion parameters. (16) In equation form:

$$
E=\frac{Q}{\pi \sigma_{y} \sigma_{z} \bar{U}_{h}} \exp \left[\left(-y^{2} / 2 \sigma_{y}^{2}\right)-\left(h^{2} / 2 \sigma_{z}^{2}\right)\right]
$$

where:

$E$ is ground level time-integrated air concentration at point $x, y, \mathrm{Ci} \cdot \mathrm{sec} / \mathrm{m}^{3}$

$x$ is downwind distance measured from point of release, $m$

$y$ is crosswind distance measured horizontally from centerline of cloud, $\mathrm{m}$

$Q$ is total release from source, curies

$\sigma_{y}$ is crosswind lateral standard deviation of cloud concentration, m

$\sigma_{z}$ is crosswind vertical standard deviation of cloud concentration, $m$

$\bar{U}_{h}$ is average windspeed at the height of release in direction of travel, $\mathrm{m} / \mathrm{sec}$

$h$ is height of release, $m$. 
The values of $\sigma_{y}$ and $\sigma_{z}$ are a function of the downwind distance $x$ and the Pasquill Stability Category existing at the time of the accident. These values are shown in Tables 10.14 and 10.15, respectively.

\section{TABLE 10.14 Values of $\sigma_{y}$ for Pasquill Stability Categories}

\begin{tabular}{|c|c|c|c|c|c|c|}
\hline \multirow{2}{*}{$\begin{array}{l}\text { Downwind } \\
\text { Distance } \\
\text { (meters) }\end{array}$} & \multicolumn{6}{|c|}{$\sigma_{y}$ for Pasquill Type } \\
\hline & A & $B$ & C & $\mathrm{D}$ & $E$ & $F$ \\
\hline 100 & 21 & 16 & 12 & 8.0 & 6.0 & 3.9 \\
\hline 250 & 54 & 40 & 28 & 20 & 14 & 9.8 \\
\hline 500 & 100 & 76 & 55 & 37 & 28 & 18 \\
\hline $1: 000$ & 200 & 150 & 110 & 72 & 52 & 36 \\
\hline 2,500 & 450 & 340 & 240 & 160 & 120 & 81 \\
\hline 5,000 & 830 & 630 & 450 & 310 & 220 & 150 \\
\hline 10,000 & 1,600 & 1,200 & 850 & 570 & 410 & 280 \\
\hline 25,000 & 3,400 & 2,600 & 1,800 & 1,200 & 880 & 610 \\
\hline 50,000 & 6,200 & 4,700 & 3,400 & 2,300 & 1,600 & 1,100 \\
\hline 100,000 & 11,000 & 8,500 & 6,300 & 4,100 & 2,800 & 2,000 \\
\hline
\end{tabular}

$\underline{\text { TABLE } 10.15}$ Values of $\sigma_{z}$ for Pasquill Stability Categories

\begin{tabular}{|c|c|c|c|c|c|c|}
\hline \multirow{2}{*}{$\begin{array}{l}\text { Downwind } \\
\text { Distance } \\
\text { (meters) }\end{array}$} & \multicolumn{6}{|c|}{$\sigma_{z}$ for Pasquill Type } \\
\hline & A & $B$ & $\mathrm{C}$ & $\mathrm{D}$ & $E$ & $F$ \\
\hline 100 & 15 & 10 & 7.8 & 4.7 & 3.0 & 1.4 \\
\hline 250 & 43 & 26 & 18 & 10 & 7.1 & 4.0 \\
\hline 500 & 140 & 57 & 34 & 19 & 13 & 7.6 \\
\hline 1,000 & 670 & 140 & 64 & 33 & 22 & 14 \\
\hline 2,500 & 2,000 & 580 & 140 & 62 & 41 & 25 \\
\hline 5,000 & 2,000 & 2,000 & 260 & 95 & 61 & 35 \\
\hline 10,000 & 2,000 & 2,000 & 440 & 140 & 84 & 47 \\
\hline 25,000 & 2,000 & 2,000 & 880 & 220 & 120 & 64 \\
\hline 50,000 & 2,000 & 2,000 & 1,400 & 320 & 140 & 79 \\
\hline 100,000 & 2,000 & 2,000 & 2,000 & 450 & 170 & 94 \\
\hline
\end{tabular}

10.21 
The dose to an individual at point $(x, y)$ can now be obtained by specifying the windspeed, height of release and the Pasquill Stability Category. For these conditions, values of $\sigma_{y}$ and $\sigma_{z}$ at the downwind distance, $x$, can be obtained from Tables 10.14 and 10.15 by interpolation. The E/Q can be calculated at $x, y$ using Equation 6 and $D / Q$ obtained using Equation 10-4 and Table 10.13.

The population dose could, in theory, be calculated by locating every individual or groups of individuals and going though the above procedure until all individuals receiving a dose have been included in the calculation. In practice, however, Equations 4 and 6 are used mainly to obtain the maximum individual dose. The population dose is more easily estimated by calculating isopleths of constant dose or time-integrated air concentration. Then the differential area between isopleths and the mean dose received by individuals residing between the two isopleths is calculated.

The isopleths could theoretically be calculated starting at the release point and moving downwind. Such a calculation could be unrealistic because no one could reside a few meters from the air accident and not be fatally injured by the debris. In the truck shipment analysis, (1) a 100-meter exclusion radius was used as a basis for all dose calculations. For air shipment accidents, use of a longer control zone would be inappropriate since a large fraction of the total dose is received close to the accident scene. Hence, a 100 meter exclusion radius was also used in this study.

The isopleth areas outside $100 \mathrm{~m}$ from the release are obtained using Equation 10-6. Rather than evaluate $E$ in Equation 6 for every $Q$ and every windspeed $U$, it is more convenient to move $Q$ and $U$ to the other side of the equation and determine isopleths of constant (UE/Q). The isopleths are determined by first selecting a value of $U E / Q$, obtaining values of $\sigma_{y}$ and $\sigma_{z}$ for each $x$ beginning at 100, and then solving Equation 10-6 using the $k^{\text {"l }}$ average windspeed (see Table 10.1) to obtain the value of $y$ for each $x$. The $x, y$ coordinates for an entire isopleth of constant UE/Q can be obtained in the same way. Then by integration, the area enclosed by any isopleth can be determined. The area between two isopleths receives a dose which is intermediate between the two boundary isopleths. 
Table 10.16 presents a summary of the isopleth calculations for a $1 \mathrm{~m} / \mathrm{sec}$ wind speed $\left(U_{k}=U_{1}\right)$, similar tables could be constructed for other windspeeds. Isopleths were calculated for UE/Q values at order of magnitude intervals from $10^{-2}$ to $10^{-10}$. Areas between adjacent isopleths were calculated and are shown as the area values for each Pasquill Stability Class. The mean value of $\overline{U E} / Q$ is set at 2.5 times the value of UE/Q at the outer isopleth. The $n$ subscript refers to the isopleth number and the $j$ subscript denotes the stability class. A value of $j=1$ refers to $B$ stability and $j=2$ refers to $D$ stability, etc. The windspeed index, $k$, is one in the table. In Table 10.16 some of the values of $A_{n, j, l}$ are zero. These zeros are present because the calculations indicate that for those stabilities the isopleth areas lie entirely within the $100 \mathrm{~m}$ evacuation distance.

TABLE 10.16 Land Areas Within Isopleths of a Release Plume and More Than $100 \mathrm{~m}$ from the Release Point $\left(U_{k}=U_{1}=1 \mathrm{~m} / \mathrm{sec}\right)$

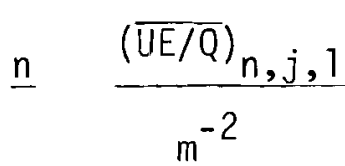

$1 \quad 2.5 \times 10^{-2}$

$2 \quad 2.5 \times 10^{-3}$

$32.5 \times 10^{-4}$

$42.5 \times 10^{-5}$

$52.5 \times 10^{-6}$

$6 \quad 2.5 \times 10^{-7}$

$7 \quad 2.5 \times 10^{-8}$

$8 \quad 2.5 \times 10^{-9}$

$9 \quad 2.5 \times 10^{-10}$

Pasquill Stability Classification

\begin{tabular}{|c|c|c|c|}
\hline $\bar{B}$ & D & $E$ & $F$ \\
\hline & $A_{n, j, 1}\left(\right.$ Area $\left.m^{2}\right)$ & & \\
\hline 0 & 0 & 0 & $4.4 \times 10^{3}$ \\
\hline 0 & $1.6 \times 10^{4}$ & $2.2 \times 10^{4}$ & $2.6 \times 10^{4}$ \\
\hline $4.1 \times 10^{4}$ & $1.4 \times 10^{5}$ & $3.8 \times 10^{5}$ & $8.0 \times 10^{5}$ \\
\hline $1.8 \times 10^{5}$ & $3.0 \times 10^{6}$ & $3.8 \times 10^{6}$ & $2.2 \times 10^{7}$ \\
\hline $1.4 \times 10^{6}$ & $7.1 \times 10^{7}$ & $1.9 \times 10^{8}$ & $2.3 \times 10^{8}$ \\
\hline $3.3 \times 10^{6}$ & $4.8 \times 10^{8}$ & $3.1 \times 10^{8}$ & $1.5 \times 10^{8}$ \\
\hline $2.8 \times 10^{6}$ & $2.9 \times 10^{8}$ & $1.7 \times 10^{8}$ & $1.1 \times 10^{8}$ \\
\hline $1.3 \times 10^{7}$ & $2.1 \times 10^{8}$ & $1.3 \times 10^{8}$ & $8.8 \times 10^{7}$ \\
\hline $6.0 \times 10^{6}$ & $1.8 \times 10^{8}$ & $1.1 \times 10^{8}$ & $7.7 \times 10^{7}$ \\
\hline
\end{tabular}

Accidents frequently attract large numbers of onlookers. The dose received by these individuals was calculated using the model developed in the truck analyses. (1) In the truck shipment analyses, 411 individuals evacuated from the 100-meter exclusion area were given the centerline dose at 100 meters. This was felt to more than compensate for the dose received 
by onlookers. The same assumption is made in the evaluation of air accident releases. Based on this assumption, Table 10.17 shows the area within $100 \mathrm{~m}$ which would be in an isopleth for the various stability conditions. Also shown are the values of UE/Q at the centerline $100 \mathrm{~m}$ downwind from the release point. These areas, when multiplied by the population density associated with the accident location, are used to represent the dose received by onlookers.

\section{TABLE 10.17 Land Area Contaminated Within $100 \mathrm{~m}$ of Accident Scene and Centerline Value of UE/Q at $100 \mathrm{~m}$ Versus Pasquill Stability Classification}

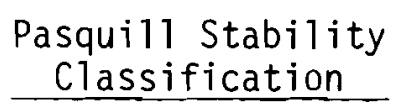

B

D

E

$F$

$\mathrm{UE} / \mathrm{Q} \mathrm{m}^{-2}$

$2.0 \times 10^{-3}$

$8.6 \times 10^{-3}$

$1.9 \times 10^{-2}$

$5.7 \times 10^{-2}$
Area $\mathrm{m}^{2}$

$5.9 \times 10^{3}$

$3.3 \times 10^{3}$

$2.5 \times 10^{3}$

$1.9 \times 10^{3}$

\subsection{POPULATION HEALTH EFFECTS}

The health effects of plutonium are discussed in several survey articles. Bair and Thompson (17) and Bair, Richmond and Wachholz (18) summarize the major findings of over 30 years of research with plutonium. These findings indicate that exposure of humans to large quantities of plutonium ( $\mu \mathrm{Ci}$ range) may ultimately result in undesirable health effects; however, none have been observed to date. The few individuals who have been so exposed consist of occupational workers at nuclear facilities, and after more than 25 years of these exposures there have been no observable deleterious effects. Such findings give little guidance in estimating the health effects which may result from the exposure of large populations to small quantities of plutonium. The effects of ionizing radiation on large populations are the only applicable data source available. The number of deaths in the U.S. population which might result from continual exposure to ionizing radiation at a rate of $0.1 \mathrm{rem} / \mathrm{yr}$ has been estimated by an 
advisory committee of the National Academy of Science. (19) Two risk models were used to estimate the number of excess deaths due to radiation-induced cancer. The results for each model are reported here as Tables 10.18 and 10.19. Details of the models can be found in the NAS-BEIR committee report.

TABLE 10.18. Estimated Numbers of Deaths per Year in the U.S. Population Attributable to Continual Exposure at a Rate of $0.1 \mathrm{rem} / \mathrm{yr}$ from Leukemia and from A11 Other Malignancies Combined(19)

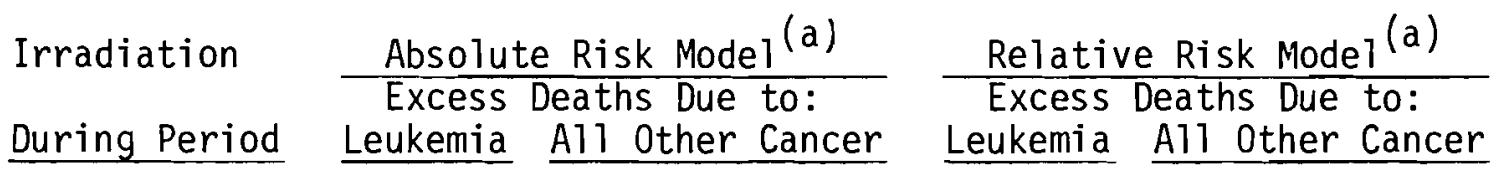

$\begin{array}{lrrrr}\text { In Utero } & 75 & 75(\mathrm{~b}) & 56 & 56(\mathrm{~b}) \\ 0-9 \text { years } & 164 & 73^{(\mathrm{b})} & 93 & 715^{(\mathrm{b})} \\ & & 122^{(\mathrm{c})} & & 5,869^{(\mathrm{c})} \\ 10+\text { years } & 277 & 1,062^{(\mathrm{b})} & 589 & 1,665^{(\mathrm{b})} \\ & & 1,288^{(\mathrm{c})} & & 2,415^{(\mathrm{c})} \\ \text { Subtota1 } & 516 & 1,210^{(\mathrm{b})} & 738 & 2,436^{(\mathrm{b})} \\ & & 1,485^{(\mathrm{c})} & & 8,340^{(\mathrm{c})}\end{array}$

TOTAL

$$
\begin{array}{ll}
1,726^{(b)}=0.6 \% \text { increase } & 3,174(b)=1.0 \% \text { increase } \\
2,001^{(c)}=0.6 \% \text { increase } & 9,078(c)=2.9 \% \text { increase }
\end{array}
$$

(a) The figures shown are based on the following assumptions:

- 1967 U.S. vital statistics can be used for age specific rates from leukemia and a11 other cancer and for U.S. population.

- Values for the duration (b or $c$ ) of the latent period (the length of time after irradiation before any excess of cancer deaths occur), duration of risk ("plateau region"), and magnitude of average increase in annual mortality for each group are as shown in Table 10.19.

(b) Thirty year duration of plateau (see Table 10.19).

(c) Lifetime duration of plateau (see Table 10.19).

A range of risk estimators for the present study was determined as follows. The excess deaths due to "all other cancers" for all ages were assumed to range from the lower subtotal value of the "Absolute Risk Model" to the upper subtotal value of the "Relative Risk Model." As shown in 
Table 10.18, the resulting range is from 1210 to 8340 excess deaths per year due to all cancers other than leukemia. Based on a U.S. population of $200 \mathrm{million}$ people and a dose rate of $0.1 \mathrm{rem} / \mathrm{yr}$, the range can be expressed as $6 \times 10^{-5}$ to $4 \times 10^{-4}$ in units of deaths per man-rem.

The frequency of cancer death by type of cancer was estimated from Table 10.19 to be:

\begin{tabular}{|c|c|}
\hline Type of Cancer & Frequency \\
\hline $\begin{array}{l}\text { Breast } \\
\text { Lung } \\
\text { GI including stomach } \\
\text { Bone } \\
\text { A11 other cancer }\end{array}$ & $\begin{array}{l}0.30 \\
0.26 \\
0.20 \\
0.04 \\
0.20 \\
\end{array}$ \\
\hline Total & 1.00 \\
\hline
\end{tabular}

TABLE 10.19 Assumed Values Used in Calculating Estimates of Risk Shown in Table 10.18

\begin{tabular}{|c|c|c|c|c|c|}
\hline \multirow[b]{2}{*}{$\begin{array}{l}\text { Age at } \\
\text { Irradiation }\end{array}$} & \multirow[b]{2}{*}{$\begin{array}{l}\text { Type of } \\
\text { Cancer }\end{array}$} & \multirow[b]{2}{*}{$\begin{array}{l}\text { Duration } \\
\text { of Latent } \\
\text { Period } \\
\text { (years) } \\
\end{array}$} & \multirow[b]{2}{*}{$\begin{array}{l}\text { Duration } \\
\text { of Plateauu } \\
\text { Region(a) } \\
\text { (years) } \\
\end{array}$} & \multicolumn{2}{|c|}{ Risk Estimate } \\
\hline & & & & $\begin{array}{c}\text { Absolute } \\
\text { Risk (b) } \\
\text { (deaths } / 10^{6} / \\
\text { yr/rem) } \\
\end{array}$ & $\begin{array}{l}\text { Relative } \\
\text { Risk } \\
\text { (\% incr. in } \\
\text { deaths/rem) } \\
\end{array}$ \\
\hline \multirow[t]{2}{*}{ In Utero } & \multirow{2}{*}{$\begin{array}{l}\text { Leukemia } \\
\text { A11 Other } \\
\text { Cancer }\end{array}$} & 0 & 10 & 25 & 50 \\
\hline & & 0 & 10 & 25 & 50 \\
\hline \multirow[t]{2}{*}{$0-9$ years } & \multirow{2}{*}{$\begin{array}{l}\text { Leukemia } \\
\text { A11 Other } \\
\text { Cancer }\end{array}$} & 2 & 25 & 2.0 & 5.0 \\
\hline & & 15 & Life & 1.0 & 2.0 \\
\hline \multirow[t]{2}{*}{$10+$ years } & \multirow{2}{*}{$\begin{array}{l}\text { Leukemia } \\
\text { A11 Other } \\
\text { Cancer }\end{array}$} & 2 & 25 & 1.0 & 2.0 \\
\hline & & 15 & Life & 5.0 & 0.2 \\
\hline
\end{tabular}

\footnotetext{
(a) Plateau region is the interval following latent period during which risk remains elevated.

(b) The absolute risk for those aged 10 or more at the time of irradiation for all cancer excluding leukemia can be broken down into the respective sites as follows:
} 


\begin{tabular}{lc} 
Type of Cancer & Deaths $/ 10^{6} / \mathrm{yr} / \mathrm{rem}$ \\
\cline { 1 - 1 } Breast & 1.5 \\
Lung & 1.3 \\
GI incl. Stomach & 1.0 \\
Bone & 0.2 \\
A11 Other Cancer & $\underline{1.0}$ \\
Total & 5.0
\end{tabular}

These frequencies of occurrence were then applied to the range of excess deaths previously derived to estimate the range of excess deaths which might occur from plutonium releases postulated in this study. The resulting risk estimators are shown in Table 10.20.

\section{TABLE 10.20 Cancer Risk Estimates for Plutonium in Man}

\begin{tabular}{|c|c|c|}
\hline \multirow{2}{*}{$\begin{array}{l}\text { Organ of } \\
\text { Reference }\end{array}$} & \multicolumn{2}{|c|}{$\begin{array}{c}\text { Estimated Excess Cancer Deaths } \\
\text { Per } 106 \text { man-rem(a) }\end{array}$} \\
\hline & Range of values & Value Used(b) \\
\hline & $16-110$ & 40 \\
\hline & $2-17$ & 6 \\
\hline
\end{tabular}

\footnotetext{
(a) Derived from the BEIR Report

(b) Geometric Mean
}

It is noted that the risk estimators listed in Table 10.20 are based on observed health effects produced at high dose levels, primarily by low linear energy transfer (LET) radiations and a hypothesis of linearity between effect and dose. It is probable that these estimators are significantly dependent on the energy transfer (LET) of the ionizing radiation and upon the dose levels actually encountered. ${ }^{(20)}$ Determination of these probable dependencies is not within the scope of this study and the dependencies have not yet been determined by others. Therefore, they have been ignored in this analysis.

Conversion of population doses in man-rem to estimated possible excess cancer deaths was based on the factors presented in Table 10.20. These conversion factors enable a comparison to be made of plutonium shipment risk estimates with other societal risks. 


\subsection{ESTIMATED EXPOSURE FREQUENCY}

As shown in Figure 10.1, the risk calculation proceeds along two parallel and interrelated paths. One path characterizes the consequences of an accidental release, and the other path determines the frequency of occurrence for each event in the consequence analysis.

As briefly discussed in Section 3, risk is expressed by the equation:

$$
R_{i}=\left(A F_{R_{i}} \times P_{R_{i} /}\right) \times \sum_{q}\left(C_{E_{i, q}} \times P_{E_{q}}\right)
$$

where $q$ represents a number of indices as indicated below.

The terms inside the first set of parentheses represent the product of the amount of material present in a shipment times the fraction of that material which is lost to the environment in the $i^{\text {th }}$ release sequence times the expected frequency of occurrence of the release sequence. This part of the analysis is shown as the top half of Figure 10.1 and all the information needed to evaluate these terms was developed in Section 9. The last two terms represent the consequences of a unit release and the expected frequency of encountering a given set of environmental conditions. These parts of the analysis are shown in the bottom part of Figure 10.1. The primary purpose of previous parts of this section has been to determine the factors required to evaluate the consequences of a release. Simultaneous $1 y$, the information required to determine the expected frequency that a given environmental consequence wi11 be encountered has been presented. This part of Section 10 will show the development of the frequency of occurrence term.

The analysis presented in this section treated the windspeed, weather stability class and population class as distributed variables. The expected frequency of encountering a given set of environmental conditions can be expressed as:

$$
P_{E_{j, k, l, m}}=P_{j / k} P_{k} P_{l / m} P_{m}
$$


where:

$j$ is the atmospheric stability classification index

$k$ is the windspeed index

$\ell$ is the population density index in zone $m$ of the U.S.

$\mathrm{m}$ is the zone index for the shipping routes.

The notation $j / k$ indicates that the expected frequency of encountering the $j^{\text {th }}$ stability class is a function of the windspeed existing at the time of release. In like manner the expected frequency of encountering the $e^{\text {th }}$ population density is dependent on the expected frequency that a shipment will pass through zone $\mathrm{m}$.

The values for the "p" in Equation 10-8 are obtained from the following tables in this section:

$$
\begin{aligned}
& P_{k} \text { - Table } 10.1 \text {, column } 3 \\
& P_{j / k} \text { - Table } 10.1 \text {, columns } 4-7 \\
& P_{\ell / m} \text { - Table } 10.6 \\
& P_{m} \text { - Table } 10.9 \text { or } 10.10 \text { depending on accident class being } \\
& \quad \text { evaluated ( } i \text { subscript) }
\end{aligned}
$$

By specifying a value for $j, k, l$, and $m$, one can obtain the expected frequency that an environmental condition will be experienced during a shipment. Associated with that frequency is a corresponding value for the environmental consequences. The relationship is best summarized by the following equation for the environmental term in the risk equation:

$$
{ }_{q}\left(C_{E_{i, q}} \times P_{E_{q}}\right)=
$$

$$
\sum_{j, k, \ell, m, n} 11.4 k_{1, j} K_{2} A_{n, j, k}(\overline{E / Q})_{n, j, k} N_{\ell / m} P_{j / k} P_{k} P_{\ell / m} P_{m}
$$


where:

11.4 is the factor to convert grams released to curies (Table 10.12)

$k_{1, j}$ converts curies received to organ dose (Table 10.13)

$K_{2}$ converts organ dose to health effects (Table 10.20)

$A_{n, j, k}$ is the area between two isopleths $n$ and $n-1$ (Tables 10.16 and 10.17)

$(\bar{E} / \bar{Q})_{n, j, k}$ is the time integrated air concentration received in $A_{n . i . k}$ per curie released

$\overline{E / Q}=\overline{\mathrm{UE} / Q}$ (Tables 10.16 and 10.17) divided by $\bar{U}$ (Table 10.6).

$\mathrm{N}_{\ell / \mathrm{m}}$ is the population density in the release plume (Table 10.6).

Ihe subscripts and the values for $P$ in Equation 10-9 have been defined following Equation 10-8. The product $\left({ }^{C} E_{i, q} \times P_{E_{q}}\right)$ has units of population health effects per gram of material released. If several organs receive a dose as a result of a release, then the product $k_{1, i} k_{2}$ for each organ receiving a dose must be summed to get the overall effect to the human body.

Equation 10-9 summarizes the information presented in this section. In Section 11, these results will be used in conjunction with the release sequences developed in Section 9 to obtain the risk of shipping plutonium oxide in the $6 \mathrm{M}$ by air in the United States. 


\section{REFERENCES}

1. T. I. McSweeney, R. J. Hall et al., An Assessment of the Risk of Transporting Plutonium Oxide and Liquid Plutonium Nitrate by Truck, BNWL-1846, Battelle, Pacific Northwest Laboratories, Richland, WA, August 1975.

2. J. Mishima, L. C. Schwendiman and C. A. Radasch, Plutonium Release Studies, III, Release from Heated Plutonium Bearing Powders, BNWL-786, Batte11e, Pacific Northwest Laboratories, Rich1and, WA, JuTy 1968.

3. J. Mishima and L. C. Schwendiman, Some Experimental Measurements of Airborne Uranium (Representing Plutonium) in Transportation Accidents, BNWL-1732, Battel1e, Pacific Northwest Laboratories, Richland, WA, March 1973.

4. J. Mishima and L. C. Schwendiman, Fractional Airborne Release of Uranium (Representing Plutonium) During the Burning of Contaminated Waste, BNWL-1730, Battelle, Pacific Northwest Laboratories, Richland, WA, Apri1 1973.

5. J. Mishima and L. C. Schwendiman, The Amount and Characteristics of Plutonium Made Airborne Under Thermal Stress, BNWL-SA-3379, Batte11e, Pacific Northwest Laboratories, Richland, WA, October 20, 1970.

6. J. Mishima, L. C. Schwendiman and C. A. Radasch, Plutonium Release Studies. IV. Fractional Release from Heating Plutonium Nitrate Solutions in a Flowing Airstream, BNWL-931, Battelle, Pacific Northwest Laboratories, Richland, WA, November 1968.

7. M. McWhirter, R. 0. Brooks, J. M. Stomp and L. A. Dillingham Final Report on Special Tests of Plutonium 0xide Shipping Containers to FAA Flight Recorder Survivability Standards SAND 75-0446, Sandia Laboratories, A1buquerque, NM, September 1975.

8. County and City Data Book 1967, U.S. Dept. of Commerce, 1968.

9. Statistical Abstracts of the U.S. 1970, Census Division, U.S. Dept. of Commerce, Washington, D.C., 1971.

10. J. P. Pickard, Urban Land and New Trends in Land Development, Dept. of Housing and Urban Development, January 1970.

11. Rand McNally Standard Highway Mileage Guide No. 10, Household Goods Carrier's Bureau, Arlington, VA, 1973.

12. Report of Committee II on Permissible Dose for In ernal Radiation, ICRP Publication 2, Pergamon Press, 1959.

13. Recommendations of the International Commission on Radiological Protection, ICRP Publication 6, Pergamon Press, 1962. 
14. The Metabolism of Compounds of Plutonium and Other Actinides, A Report prepared by a Task Group of Committee 2 of the Internationa 1 Commission on Radiological Protection, ICRP Publication 19, Pergamon Press, May 1972.

15. J. Houston, D. L. Strenge, and E. C. Watson, DACRIN Computer Program for Calculations of Organ Dose from Acute or Chronic Radionuclide Inhalation, BNWL-B-389, Battelle, Pacific Northwest Laboratories, Richland, WA, December 1974.

16. David H. Slade, Ed., Meteorology and Atomic Energy, 1968, TID 24190, Office of Information Services, U.S. Atomic Energy Commission, Washington, D.C., 1968.

17. W. J. Bair and R. C. Thompson, "Plutonium: Biomedical Research," Science, vol. 183, p. 715, February 22, 1974.

18. W. J. Bair, C. R. Richmond, and B. W. Wachholz, A Radiobiological Assessment of The Spatial Distribution of Radiation Dose from Inhaled Plutonium, WASH-1320, U.S. Atomic Energy Commission, Washington, D.C., September 1974.

19. The Effects on Populations of Exposure to Low Levels of Ionizing Radiation, Report of the Advisory Committee on the Biological Effects of Ionizing Radiations, National Academy of Science, November 1972.

20. National Council on Radiation Protection and Measurements, Review of the Current State of Radiation Protection Philosophy, NCRP Report No. 43, Washington, D.C., January 15, 1975. 


\subsection{THE RISK OF SHIPPING PLUTONIUM DIOXIDE BY AIR}

The risk of plutonium dioxide transport by cargo aircraft between fuel cycle facilities within the continental United States is calculated in this section. The analysis is performed for a reference year, sometime in the early 1980s. In that year there exists a requirement to ship 18 MT of plutonium in support of the Light water Reactor Fuel Cycle. An identical evaluation criterion was used in the earlier plutonium truck transport evaluation.

To provide a meaningful comparison between truck and air transport, every effort was made to make the evaluation criterion the same. The flows between facilities are the same, the shipment size is identical and the containers are the same. In previous analysis all the plutonium was shipped by truck. In this analysis, the plutonium is taken to the nearest airport with scheduled cargo air transport service; air transported to the cargo airport closest to the fuel fabrication facility, and transported to the facility by truck.

A meaningful comparison between truck and air transport requires that the truck segments of the air transport mode be included in the analysis. A complete description of the truck transport segments can be found in the truck risk report $(1)$ and will not be repeated here. In this section, the air segment risks will be described in detail. The truck segment risks will then be presented and added to the air segment to obtain the overall risk of shipping plutonium dioxide by air.

Following the evaluation procedure summarized in Section 3 , the first step is to completely describe the air transport system. This information is presented in Section 11.1. The data presented in Sections 9 and 10 are used to evaluate the risk of air shipments in Section 11.2. Major contributors to the risk and the sensitivity of the assessment to pertinent parameters are shown in Section 11.3. Because of its particular importance, the risk arising from many containers failing in a single accidert is shown. Section 11.4 provides comparison of the overal1 air transport and truck transport risks. 


\subsection{SYSTEM DESCRIPTION}

Two cases were analyzed. The first case evaluates the risk of shipping 1 MT of plutonium dioxide powder in 6M containers a distance of 1,500 miles using cargo aircraft. The second case evaluates the annual U.S. risk from plutonium transport at a shipping level projected to occur in the early 1980s.

11.1.1 System Description for Shipping One Metric Ton of Plutonium Dioxide $\underline{1,500 \text { Miles by Air }}$

It is assumed that there is a requirement to ship 1 metric ton of plutonium dioxide in 6M containers 1,500 miles by cargo aircraft across the United States. The number of shipments required to transport 1 metric ton of plutonium in dioxide form has been based on shipping regulations, container capacities, transport indices for criticality safety, weight limitations and the physical dimensions of the cargo aircraft. These results and the expected accident frequency per metric ton shipped are shown in Table 11.1.

The isotopic composition of the plutonium used in this study is given in Table 10.12. The composition represents the average expected from LWR fuel in the early 1980s. Based on 30 watt per container heat generation limit, the mass of $\mathrm{PuO}_{2}$ permitted in a $6 \mathrm{M}$ is $2.9 \mathrm{~kg}\left(11.4\right.$ watts $/ \mathrm{kg}$ of $\mathrm{PuO}_{2}$ for these isotopics). With this limit, 390 containers are required to hold 1 metric ton of plutonium. Based on dose rate calculations by Brackenbush, Brown and Faust, ${ }^{(3)}$ and assuming that some neutron shielding could be placed around the array of containers, 39 containers can be transported in one shipment. This means that each shipment would contain $100 \mathrm{~kg}$ of plutonium and 10 shipments would be required to transport 1 metric ton of plutonium.

11.1.2 System Description for Evaluating the Risk of Plutonium Transport in the United States in the Early 1980s

A major portion of the description for the comparison case can be used in the system description for the U.S. annual risk evaluation for the early 1980s. Two additional pieces of information are required. First, the total quantity shipped annually must be specified. Second, a composite 
TABLE 11.1. Shipping Characteristics for 6M Assumed for Analysis (Based on the Shipment of 1 Metric Ton of $\mathrm{Pu}$ )

\author{
$\mathrm{PuO}_{2}$ Form \\ in 6M Container
}

Amount $\mathrm{Pu} /$ Container, $\mathrm{kg}$

2.55

Containers/MT of $\mathrm{Pu}$

Containers/Shipment

Shipments/MT of Pu

10

Distance/Shipment, mi

$1,500^{(b)}$

Shipment Distance, mi

15,000

Accident Probability, \#/mi

$1.0 \times 10^{-8(c)}$

Accident Frequency, \#/MT of $\mathrm{Pu}$

$1.5 \times 10^{-4}$
(a) Based on $2.9 \mathrm{~kg}$ of $\mathrm{PuO}_{2}$ per container of projected $\mathrm{Pu}$ isotopics in the early 1980s. (Assumed to comply with 30 watts heat generation, $10 \mathrm{mrem} / \mathrm{hr}$ at $6 \mathrm{ft}$, and tota 1 weight limits. Additional neutron shielding could increase the number of containers per shipment.)
(b) Assumed average distance between reprocessing plant and (c) Reference 2 .

shipping route, representative of plutonium transportation throughout the contiguous United States, must be constructed.

As stated in Section 4.1, it is assumed that in the early 1980s the nuclear power industry will have grown to include 100 operating power reactors. It is further assumed that an industry this size will ship 18 metric tons of plutonium annually.

The composite route can be obtained from information developed in Section 4. In 1980 the reprocessing load is assumed to be met by the Barnwell and West Valley Plants, with Barnwell handling $67 \%$ of the load. Using this factor and the distribution of plutonium fuel fabricators 1 isted in Section 4.4 , the relative region mileage of a composite shipment route in the United States can be developed. The composite route is shown in Table 11.2. 
TABLE 11.2. Characteristics of a Composite U.S. Route

for Plutonium Transport in the Early 1980s

\begin{tabular}{|c|c|c|c|c|c|}
\hline \multirow[t]{2}{*}{$\begin{array}{c}\text { Zone } \\
\text { Number }\end{array}$} & \multirow[t]{2}{*}{$\begin{array}{r}\text { Geographical } \\
\text { Description } \\
\end{array}$} & \multicolumn{2}{|c|}{$\begin{array}{c}\text { Average Route } \\
\text { Length in Zone } \\
\text { (weighted by a1 } 1 \text { routes) } \\
\text { Miles }\end{array}$} & $\begin{array}{l}\text { Fraction of } \\
\text { Total Mi leage } \\
\text { Transversing } \\
\text { the Zone } \\
\end{array}$ & \multirow{2}{*}{$\frac{\text { Truck \& Air }}{\underline{\text { Air }}}$} \\
\hline & & Truck & $\underline{\text { Air }}$ & Truck & \\
\hline I & $\begin{array}{l}\text { North Atlantic } \\
\text { Seaboard }\end{array}$ & 0 & 0 & 0 & 0 \\
\hline I I & $\begin{array}{l}\text { Great Lake } \\
\text { States }\end{array}$ & 21 & 251 & 0.105 & 0.205 \\
\hline I I I & $\begin{array}{l}\text { North Central } \\
\& \text { Southeast }\end{array}$ & 130 & 438 & 0.663 & 0.357 \\
\hline IV & West & 45 & 536 & 0.232 & 0.438 \\
\hline Total & Entire U.S. & 196 & 1225 & 1.000 & 1.000 \\
\hline
\end{tabular}

\subsection{RISK EVALUATIONS FOR PLUTONIUM DIOXIDE SHIPMENTS BY CARGO AIRCRAFT}

The risk calculated for plutonium shipment is presented in this section. Section 11.2.1 presents a detailed development of the risk equation and a discussion of measures of risk. The risk of shipping 1 MT of plutonium dioxide powder in $6 \mathrm{M}$ containers a distance of 1500 miles in a cargo aircraft is given in Section 11.2.2. The annual risk in the nearly 1980s from air transport of plutonium dioxide is given in Section 11.2.3.

\subsubsection{The Risk Equation}

As described in Section 3, the total risk is defined as:

$$
R=\sum_{i} R_{j}
$$

where

$$
R_{i}=\left(A F_{R_{i}} \times P_{R_{i}}\right) \times \sum_{q}\left(C_{E_{i, q}} \times P_{E_{q}}\right)
$$


The subscript " $i$ " referes to the $i^{\text {th }}$ release sequence. In Section 10 , a general equation was developed for the terms in the second set of parenthesis in Equation 11-2. Substituting this expression into Equation 11-2 results in the following equation.

$$
R_{i}=\left(A F_{R_{i}} \times P_{R_{j}}\right) \sum_{j, k, \ell, m, n} 11.4 K_{1, i} K_{2} A_{n, j, k}(\overline{E / Q})_{n, j, k} N_{\ell / m} P_{j / k} P_{k} P_{\ell / m} P_{m}
$$

The total risk of shipping one container then becomes

$$
\begin{aligned}
R= & \sum_{i, j, k, \ell, m, n}\left[11.4 k_{1, i} K_{2} A F_{R_{i}} A_{n, j, k}(\overline{E / Q})_{n, j, k} N_{\ell / m}\right] \times \\
& {\left[P_{R_{i}} P_{j / k} P_{k} P_{\ell / m} P_{m}\right] . }
\end{aligned}
$$

Equation 11-4 has been arranged so that the frequency of occurrence terms are separated from the consequence terms. As described in Section 10, each container is analyzed individually. Thus the risk of shipping $\mathrm{N}_{\mathrm{C}}$ containers is given by the following equation:

$$
\begin{aligned}
R_{T}= & \sum_{i, j, k, \ell, m, n}\left[11.4 k_{1, i} K_{2} A F_{R_{i}} A_{n, j, k}(\overline{E / Q})_{n, j, k} N_{\ell / m}\right] x \\
& {\left[N_{c} P_{R_{i}} P_{j / k} P_{k} P_{\ell / m} P_{m}\right] . }
\end{aligned}
$$

The $\mathrm{N}_{\mathrm{c}}$ term is included in the frequency of occurrence term. By putting $N_{C}$ in this part of Equation 11-4, the consequences of an accident are made proportional to the amount of material in one container and the frequency of release increases with the number of containers shipped in any year.

In Equation 11-5 the frequencies of occurrence and the consequences of all accidents are summed to obtain a single annual risk number. This number can be though of as the expected frequency of occurrence of a fatality attributable to plutonium transport. As discussed in Section 1 , 
the risk spectrum must also be considered because it differentiates between an event which occurs once a year and results in one fatality and an event which occurs once in a thousand years but results in 1000 fatalities. To distinguish between these two events which have the same risk but different severities, curves are constructed which plot accident severity versus the expected frequency of accidents with greater severity. The two events described above have discrete contributions to the graph. Thus for the risk of two operations to be truly comparable, they must have both the same risk and the same risk spectrum.

Both the risk and the risk spectrum can be obtained from the terms in Equation 11-5. The number of fatalities from an accident release sequence is expressed by the term inside the first set of brackets in Equation 11-5. The frequency of the consequence (i.e., number of fatalities) is obtained by calculating the terms within the second set of brackets. These two terms can be thought of as pairs of numbers. The risk spectrum curves can be obtained choosing a value of $N$, the number of fatalities, and then scanning the paired sets of numbers for any first terms which exceed $N$. The summation of all second terms which have a first term greater than or equal to $\mathrm{N}$ is the expected frequency of occurrence of accidents which result in $\mathbb{N}$ or more fatalities. This is one point on the risk spectrum curve. This operation is continued until points on the risk spectrum curve are calculated for selected values of $N$ down to one facility.

\subsubsection{The Risk of Shipping Plutonium Dioxide 1500 Miles by Cargo Aircraft}

Based on the data shown in Table 11.1, accidents are expected to occur at a rate of $1.0 \times 10^{-8} /$ shipment mile, i.e., once in $10^{8}$ shipment miles. For a shipping distance of 1500 miles, the expected frequency at which plutonium shipments wi11 be involved in an accident is 1 in 66,667 shipments.

The frequency of a release has been estimated using the data presented in Section 9. For the oxide shipment in the 6M container, one release can be expected for every $5.4 \times 10^{6}$ containers shipped. Since $396 \mathrm{M}$ containers 
are transported per shipment and accidents are expected at a rate of once per 66,667 shipments, then one accident in two can be expected to release some oxide powder.

The risk specturm curves for shipping 1 metric ton of plutonium dioxide across the United States is shown in Figure 11.1. Also shown in the figure are the risk spectra for meteorites, chlorine shipments, the shipment of plutonium dioxide and plutonium nitrate by truck, the total of all natural disasters and the total of all man-caused disasters. These latter curves were taken from the draft version of WASH 1400. (4) From the results shown in the figure, one in two accidents where a $6 \mathrm{M}$ containing oxide powder fails will result in one or more fatalities attributable to the release.

Combining the above occurrence frequencies, the likelihood of one or more fatalities from plutonium release during a 1500 mile shipment of plutonium dioxide powder in 6M containers is about 1 in 300,000

Although not shown in the spectrum curves, the calculations show that the highest number of fatalities occurred under very stable atmospheric conditions (Pasquil1 F Stability) and at 1 meter per second windspeeds. The curves shown in Figure 11.1 do not consider evacuation of people from the release plume. However, it should be noted that at low windspeeds, there is some time available to evacuate people before the release plume reaches their location. For example, if the average windspeed is $1 \mathrm{~m} / \mathrm{sec}$, approximately 16 minutes is available before the release plume travels $1 \mathrm{~km}$. Over 2.5 hours is available $10 \mathrm{~km}$ downwind. Although 16 minutes does not allow time to evacuate individuals, two and a half hours would appear to represent a time interval during which some evacuation might be possible. In this respect, the results presented here represent a conservative upper limit.

Sensitivity analyses presented in Section 11.3 will further analyze the risk spectrum curves and identify the more important contributors to the risk. 


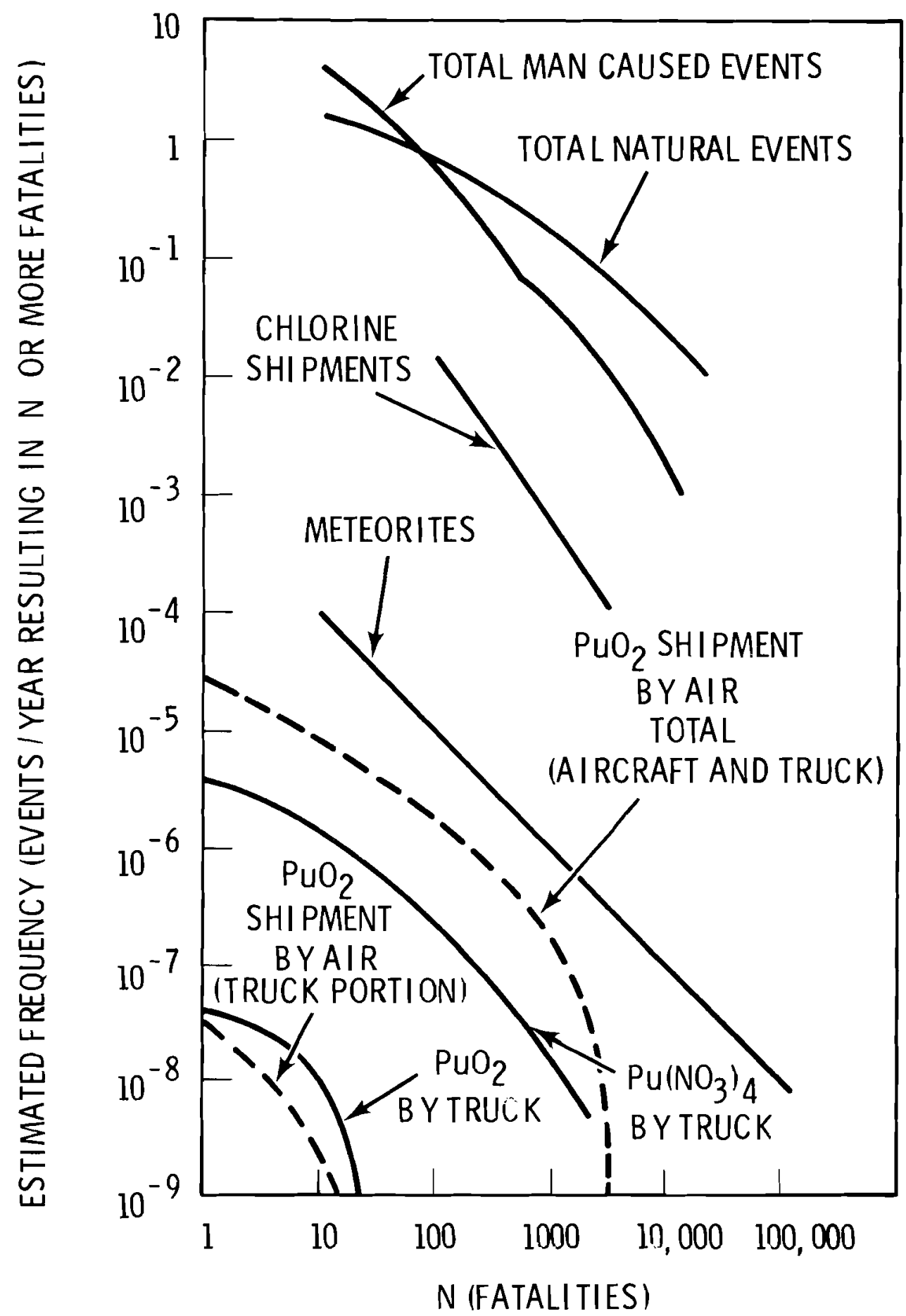

FIGURE 11.1. Risk Spectrum for Shipping One Metric Ton of Plutonium 1500 Miles Across the U.S. 
11.2.3 The Risk of Shipping Plutonium Dioxide by Cargo Aircraft in the Early 1980s

The annual risk to the U.S. from plutonium dioxide powder shipment in 6M containers in the early 1980s is reported in this section. Figure 11.2 shows the risk spectrum for the dioxide shipments. Also shown in Figure 11.2 are the risk spectra for plutonium dioxide and nitrate by truck meteorites, chlorine shipments, the total of all natural disasters and the total of all man-caused events. It can be seen that the air transport risk of plutonium dioxide is comparable to the liquid nitrate truck shipment risk spectrum and both are comparable to the risk spectrum for meteorites. Since the risks from chlorine shipments and other man-caused events pose a significantly greater hazard, the conclusion would be that many commonly accepted risks pose a hazard which is greater than that from plutonium shipments.

Discussions of the uncertainties in the results and the sensitivity of these curves to pertinent parameters in the analysis are presented in Section 11.3.

\subsection{RISK CALCULATIONAL UNCERTAINTIES}

There are two major uncertainties in this analysis. First, the analysis was performed by looking at container failures as individual events. This worked well for evaluating truck transport failures. Section 11.3.1 evaluates the likelihood of many containers failing in an accident. The second major uncertainty involves the sensitivity of the risk spectrum curves to parameters which may be highly uncertain. For example, Sandia found that the puncture environment was very difficult to quantify. If the risk curves are being controlled by puncture, then it is important to recognize that fact since the analysis can be no more certain than the input data. The risk sensitivity evaluations presented in Section 11.3.2 identify the important parameters which contribute to the risk.

\subsubsection{Analysis of Multiple Container Failures}

Based on the information presented in Section 6 , the $6 \mathrm{M}$ containers cannot survive impacts with unyielding surfaces if the impact velocity is greater 


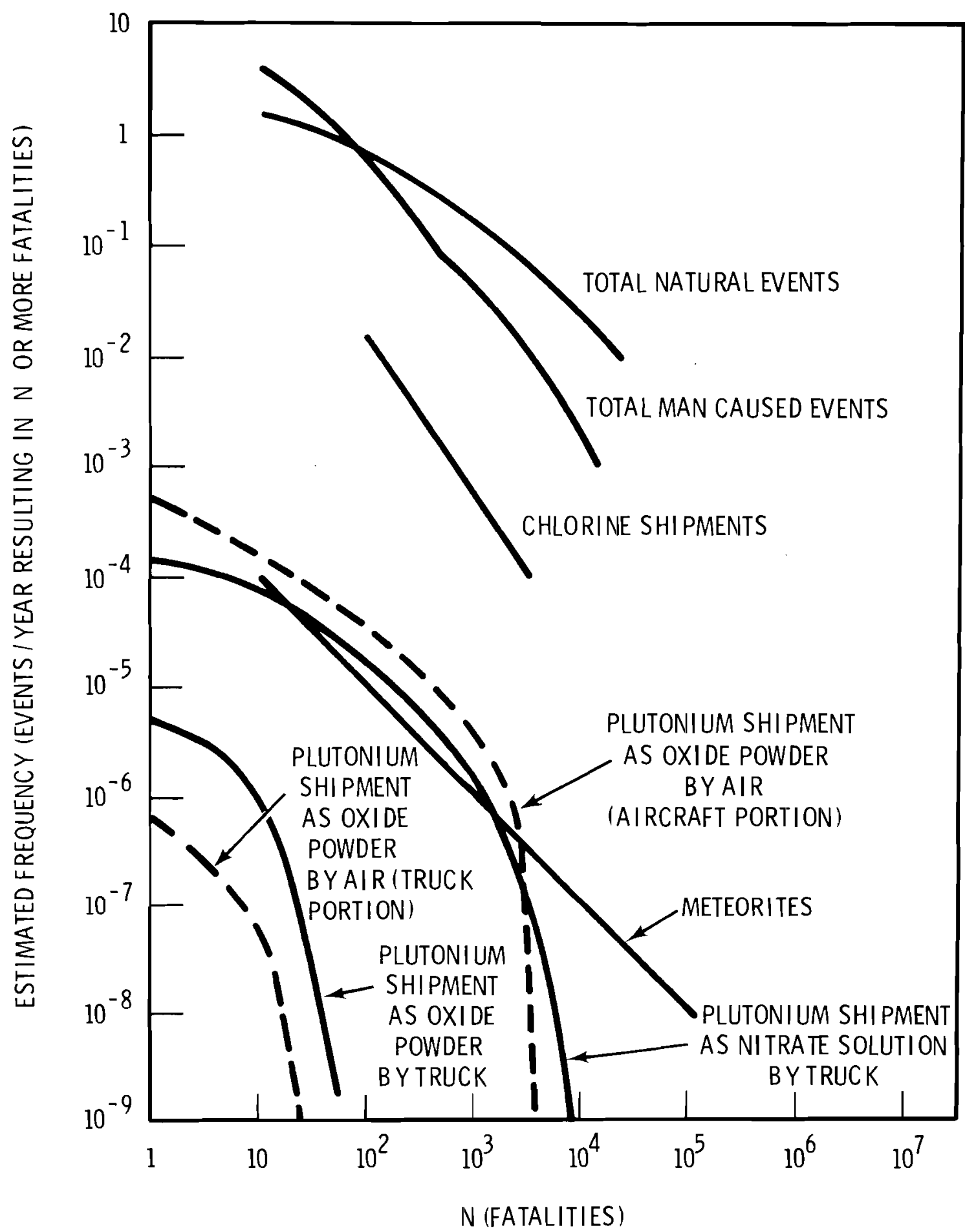

FIGURE 11.2. Risk Spectrum for Plutonium Shipments in the Early 1980s for the Entire U.S. (Single Container Analysis) 
than $400 \mathrm{ft} / \mathrm{sec}$. Impacts at higher velocities are possible as a result of inflight accidents (see Figure 5.2). Thus, it is possible that all 39 containers could fail in a single accident if the packages strike rock-like surfaces.

Thus the single container analysis does not yield a good approximation to the risk spectrum for the impact release sequence from an inflight accident. Since on a single container basis, this sequence was found to contribute approximately $80 \%$ to the overall risk spectrum, a special evaluation was made. This sequence was mathematically removed from the risk spectrum, treated separately, and then added back into the risk curve. The analysis used the accident rate for shipments instead of the single container rate. The shipment accident rate is 39 times smaller than the container rate, because 39 containers are involved in a single accident. Simultaneously, the release fraction for the multiple container release sequence was multiplied by 39 since all containers are assumed to fail. Figure 11.3 shows the result of this release sequence manipulation to include the effect of multiple container failures. It should be noted that the ordinate of the graph shown in Figure 11.3 extends down only to a frequency of $10^{-9}$. At lower frequencies, the curves cross and the multiple container failure risk spectrum is above the single container spectrum. The area under both curves is the same since the total risk does not depend on the data manipulation method used. Again, it should be noted that this release sequence tends to dominate the risk spectrum curve.

Because there is a significant difference between the single and multiple container risk spectrum curves for this release sequence, subsequent sections will use the single container curves adjusted for release sequences which can induce multiple container failures. In this way, the simplicity of the single container analysis of package closure errors is effectively combined with the very severe accident environment generated in a high-speed ground impact accident. If this modified method were to be used in a 1-metric ton, 1500-mile analysis, (see Sectior 11.2.2.) the effect would be to reduce the multiple container curve by a factor of approximately 18 . 


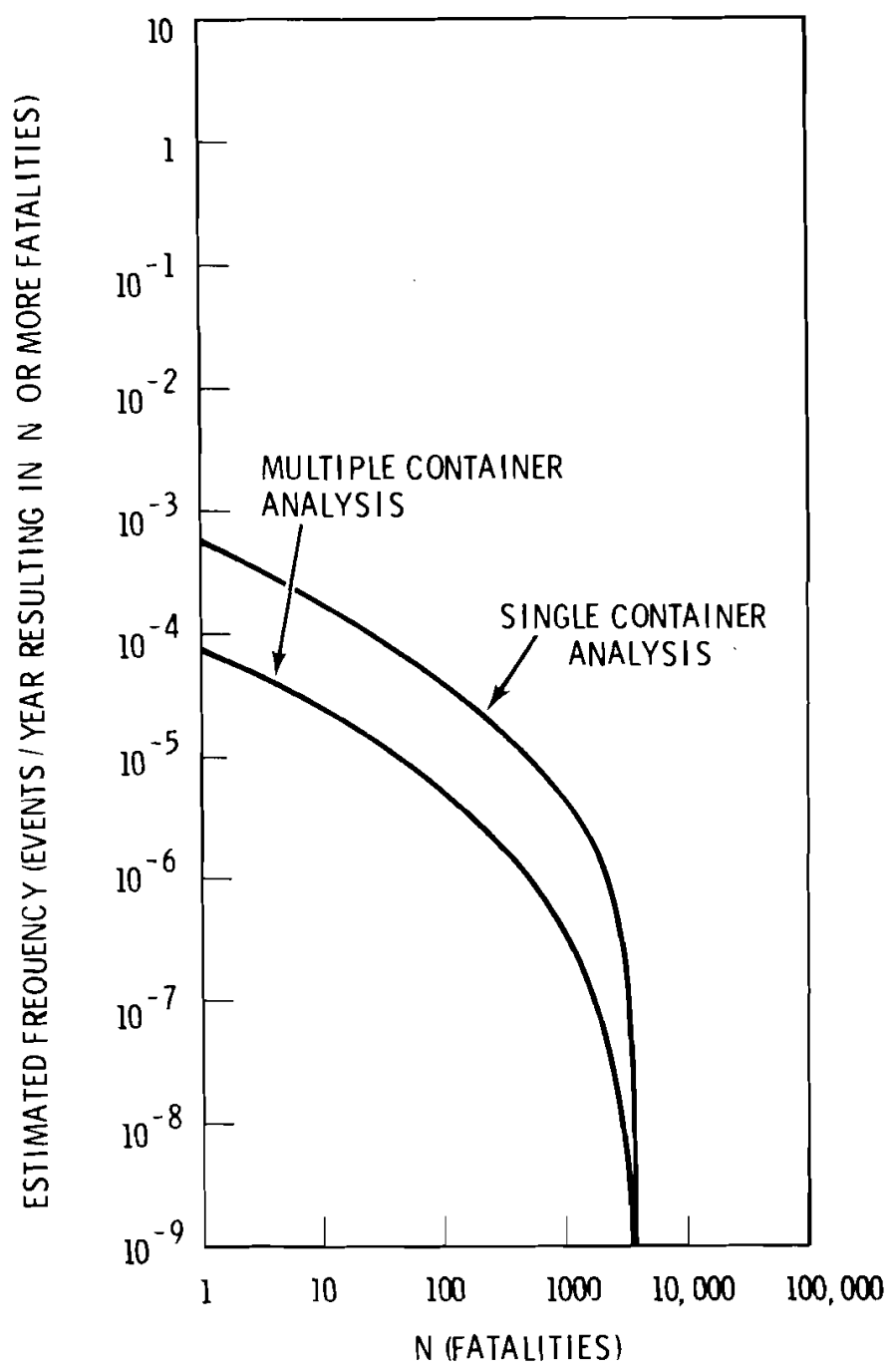

FIGURE 11.3. Risk Spectrum Evaluation of Single and Multiple Container Failure from Impact Forces Imposed on the $6 \mathrm{M}$ in the Accident Environment. Note: Multiple container curve drops more slowly below $10^{-11}$ Events/year.

\subsection{RISK SENSITIVITY EVALUATIONS}

Prior to discussion of the sensitivity of the risk evaluation to the values of certain system parameters, it is important to point out a fundamental sensitivity of the risk evaluation; i.e., the calculated risk is a function of the shipping assumptions. The present risk assessment is made for the system described in Section 11.1. Shorter shipment distances, the use of different shipping containers, etc., would result in a different risk. In general, reevaluation would be required to determine the risk 
under these changed conditions. However, for some simple changes in shipment conditions, determination that the risk would be less than, or greater than, that calculated for the systems considered in this analysis could be made without recalculation.

Risk sensitivity evaluations permit analysis of the importance of the various factors which contribute to the risk. They can be used: 1) to identify and quantify the effects of the major contributors to the risk, and 2) to identify ways to improve the certainty in the risk evaluation.

Most sensitivity studies are performed by repeating the risk calculation with a changed value for the parameter of interest. In general, the dependence of the risk on a particular parameter is complex. In some cases, however, a parameter enters simply and directly into the risk equation and the sensitivity can be determined directly.

The results of risk sensitivity studies for the oxide shipment analysis are given in Table 11.3. The effect on the risk spectrum of the more important cases are also shown in Figure 11.4. It is seen that packaging deficiencies and puncture of the $2 \mathrm{R}$ container do not contribute significantly to the risk of plutonium dioxide powder air shipment in $6 \mathrm{M}$ containers. The three curves have been presented as one because the differences are too small to be shown graphically. All sensitivity studies were donw on the basis of a single container evaluation.

TABLE 11.3. Risk Sensitivity Cases for Dioxide Shipments in the U.S. in the Early 1980s

\begin{tabular}{|c|c|c|}
\hline Sensitivity Case & $\begin{array}{l}\text { Risk Level } \\
\text { (Estimated Annual Frequency } \\
\text { of Occurrence of One } \\
\text { or More Fatalities) }\end{array}$ & $\begin{array}{c}\text { Risk Level } \\
\text { Relative } \\
\text { to } \\
\text { Base Case }\end{array}$ \\
\hline Base Case ${ }^{(a)}$ (single container) & $4.98 \times 10^{-4}$ & --- \\
\hline Zero Packaging Condition Deficiencies & $4.93 \times 10^{-4}$ & 0.99 \\
\hline Zero Puncture of $2 \mathrm{R}$ Container & $4.84 \times 10^{-4}$ & 0.97 \\
\hline Release Fractions $=1.0$ & $8.81 \times 10^{-4}$ & 1.77 \\
\hline $44 \mathrm{ft} / \mathrm{sec}$ impact failure threshold & $4.74 \times 10^{-3}$ & 9.52 \\
\hline $350 \mathrm{ft} / \mathrm{sec}$ impact failure threshold & $1.00 \times 10^{-4}$ & 0.20 \\
\hline
\end{tabular}




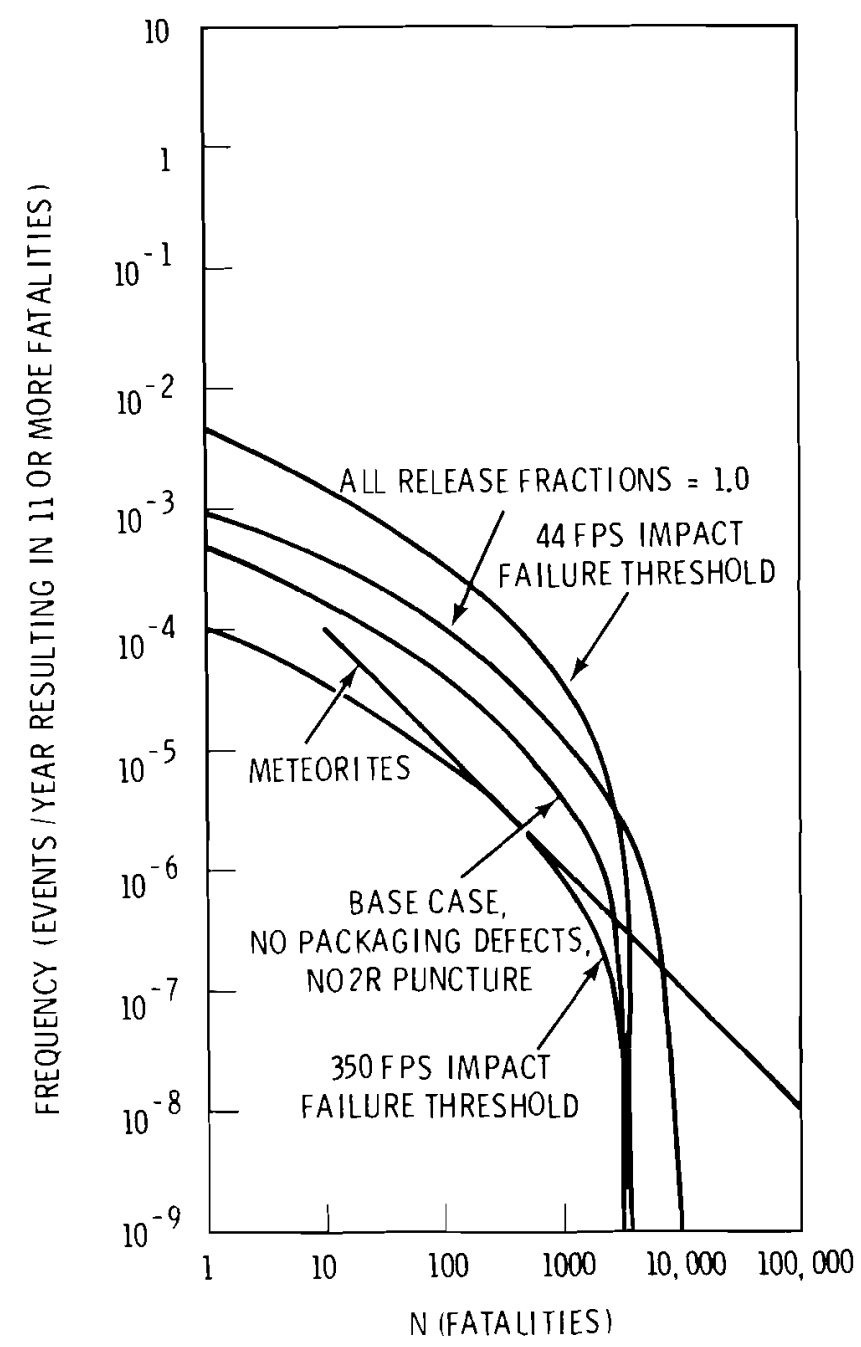

FIGURE 11.4. Sensitivity of the Risk Spectrum Curves to Several Parameters for Plutonium Dioxide Shipments in the 6M Container

As an upper limit example, a run was made which assumed that any release sequence releases the entire content of a container (i.e., the fraction released $=1$ ). The results indicate that this increases the risk about a factor of 1.77 .

A fourth sensitivity study was carried out to determine the effects of container impact failure thresholds on the risk. One case, using a failure threshold equivalent to the drop test limits which all Type B containers must pass (30 ft. drop height with impact velocity of approximately $44 \mathrm{ft} / \mathrm{sec}$ ) was 
used as a lower bound. A second case, assuming a $350 \mathrm{ft} / \mathrm{sec}$ impact velocity was evaluated to determine the effects of a higher failure threshold.

These sensitivity studies have identified areas in which further studies could result in increased knowledge of events and processes pertinent to the assessment.

\subsection{COMPARISON OF PLUTONIUM SHIPMENT RISKS FOR TRUCK AND CARGO AIRCRAFT}

As discussed in the introduction to Section 11, the total risk of shipping plutonium by air must include both the ground and air transport segments. The previous sections have presented results for the air transport segments. Figure 11.5 shows the risk spectrum for the ground and air segments and also adds the two together to get an overal1 risk spectrum for shipping plutonium by air. It can be seen that the ground transport segment adds very little to the overal1 risk. (In fact, it adds so little that the change cannot be represented graphically.)

Figure 11.6 compares the overall air transport shipment risk spectrum with the previously reported shipment risks spectrums for plutonium oxide and nitrate by truck, chlorine shipments, meteorites and the total of all man-caused and natural events.

It can be seen that although shipping $\mathrm{PuO}_{2}$ by air is more hazardous than truck transport of $\mathrm{PuO}_{2}$, it is less hazardous than plutonium nitrate shipments by truck. All three pose a risk which is much lower than chlorine shipments and many other natural or man-cause risks. 

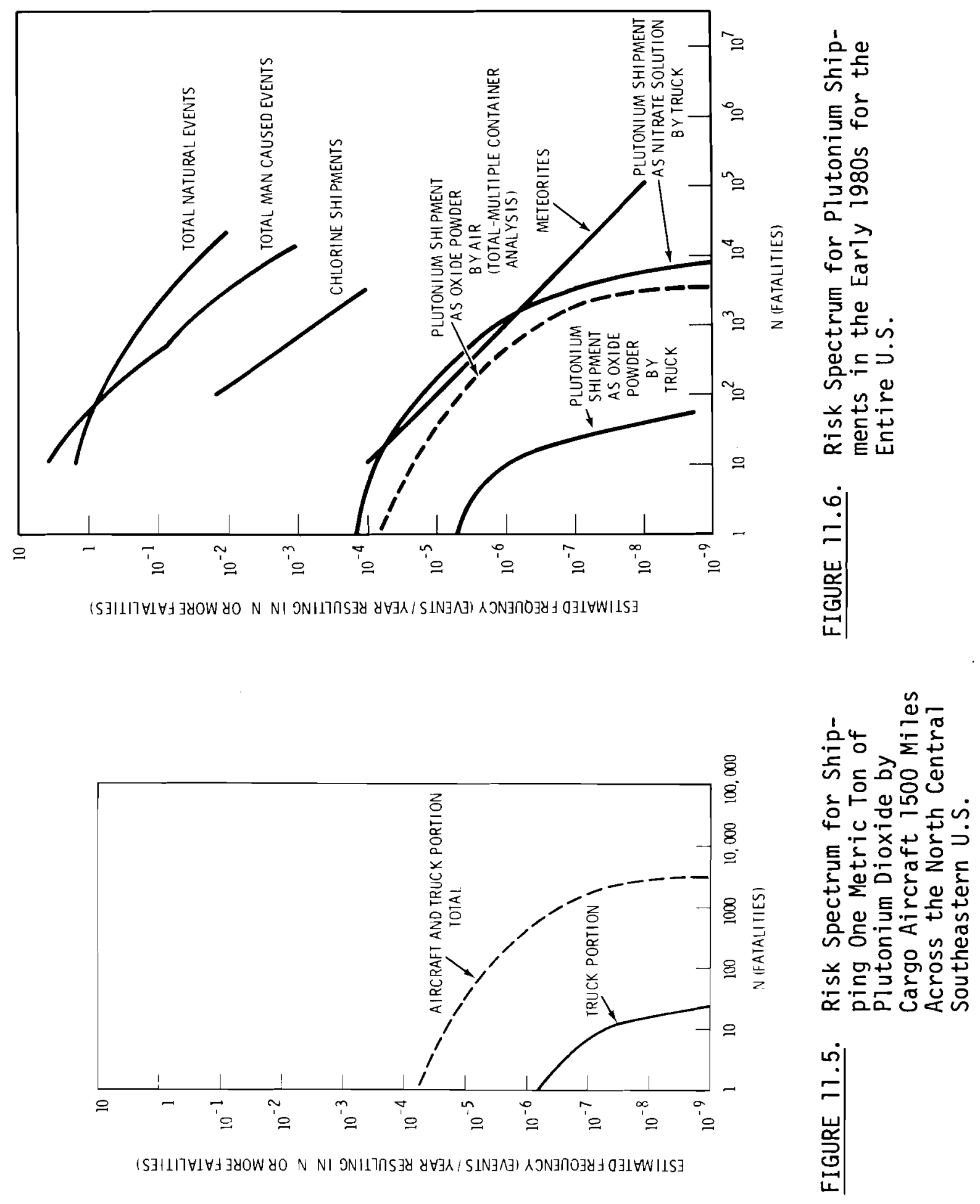


\section{REFERENCES}

1. T. I. McSweeney, R. J. Hall et al., An Assessment of the Risk of Transporting Plutonium 0xide and Liquid Plutonium Nitrate by Truck, BNWL-1846, Batte17e, Pacific Northwest Laboratories, Richland, WA, August 1975.

2. R. K. Clarke, T. J. Foley, W. F. Hartman and D. W. Larson, Severities of Transport Accidents, Vol. II I - Cargo Aircraft, SLA-75-0001, Sandia Laboratories, Albuquerque, NM, September 1975.

3. L. W. Brackenbush, C. L. Brown and L. G. Faust, Future Considerations in the Shipment of Plutonium, BNWL-1847, Battelle, Pacific Northwest Laboratories, Richland, WA, October 1974.

4. Reactor Safety Study-An Assessment of Accident Risks in U.S. Commercial Nuclear Power Plants (Draft), WASH 1400, U.S. Atomic Energy Commission, Washington, D.C., August 1974. 


\section{APPENDIX A}

\section{DESCRIPTION OF 6M PACKAGE USED TO SHIP $\mathrm{PUO}_{2}$}

The 6M designation represents a class of containers which have been approved for radioactive material transport. The general set of design criteria are found in 49CFR 178.104. The outer drum must conform to Spec. 6C and $17 \mathrm{C}$ as defined under paragraph 178.99 and 178.115 , respectively. The inner container design must meet or exceed the $2 \mathrm{R}$ specification present in paragraph 178.34 .

The outer container of the 6M can vary from a 10 to 110 gal capacity. The foliowing description is based on the 15-gal size. This size 6M was used throughout the report and is shown in Figure A.1. Much of the information shown below was taken from Reference 1 . Other information has been obtained from actual container measurements.

Authorized Contents:

Up to $4.5 \mathrm{~kg}$ of plutonium metal, alloy or compound or up to $13.5 \mathrm{~kg}$ or uranium 235 metal or alloy. Additional details and restrictions are provided in 49CFR 173.396.

Interior and Exterior Dimensions:

Interior 5.25 in. ID $x 10.5$ in. deep inside; Drum - 15.57 in. diam. $x$ 21.25 in. high outside with $18 \mathrm{ga}$. wall.

Description of Contairer:

The outer container is a 15-gal DOT Spec. 17C drum. The inner container is a 5 -in. Sch. 80 steel pipe with a threaded plug. The bottom end is closed by welded 1/2-in. thick steel cap. The dioxide powder is contained in two sealed No. 8 steel cans which are placed inside the inner container. The inner container is lined with padding to minimize damage to the steel cans during a shipment. 


\section{M CONTAINER}

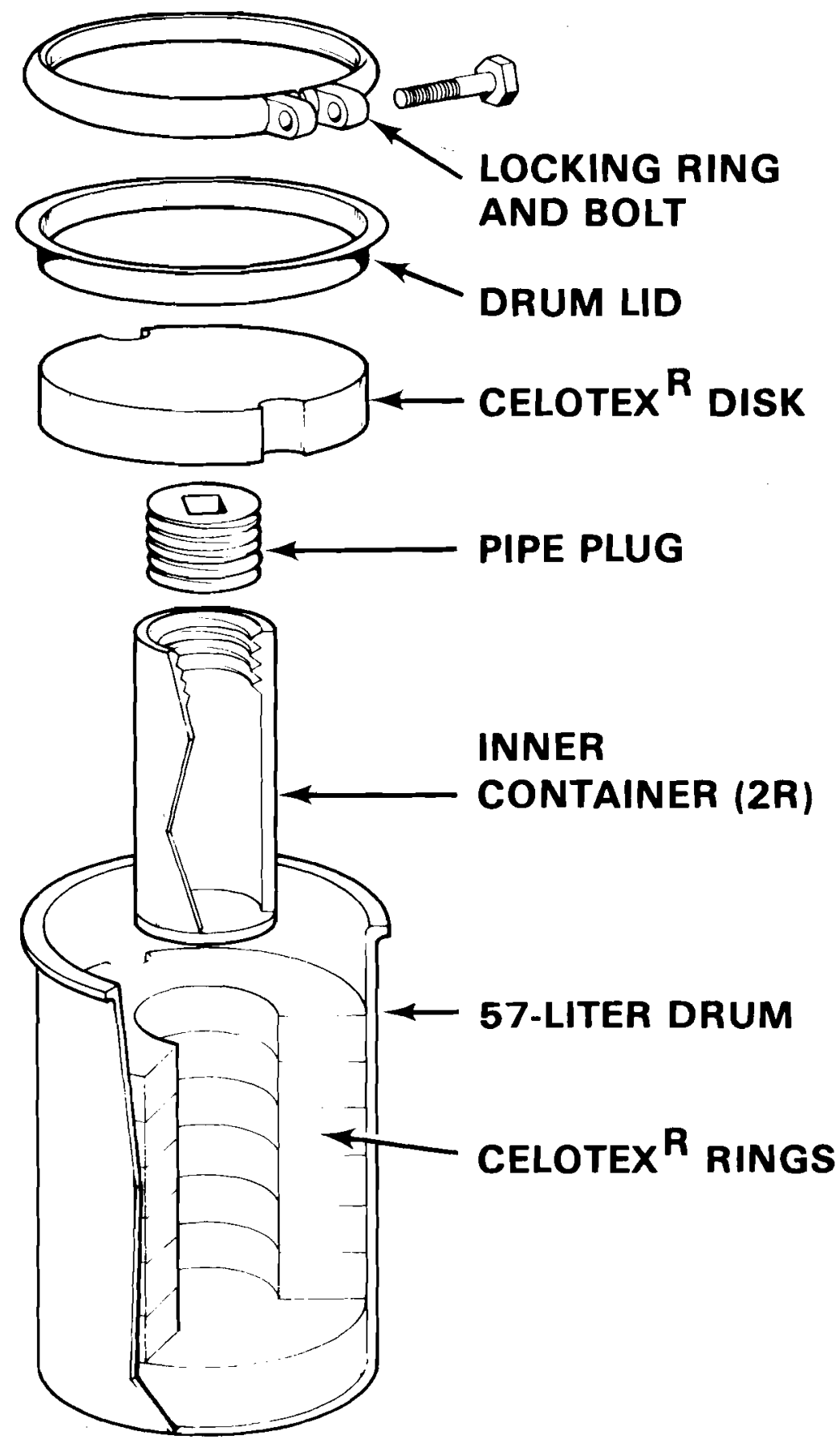

AND BOLT

DRUM LID CELOTEX $^{\mathrm{R}}$ DISK

PIPE PLUG

INNER

CONTAINER (2R)

FIGURE A.1 6M Container 
Type and Thickness of Insulation:

The inner container is insulated by Celotex ${ }^{R}$ Industrial Board with a minimum thickness of 3 in.

Shielding:

No additional shielding beyond that by structural material provided; may be added within the containment vessel when required.

Heat Removal Capacity:

Normal licensed limit of 10 watts. Special permits have been issued for designs which allow for up to 50 watts. The 10-watt 1 imit results in a containment vessel temperature limit of $155^{\circ} \mathrm{F}$ for a $70^{\circ} \mathrm{F}$ ambient temperature. There are special handling requirements for shipping materials that generate more than 10 watts.

Authorized Modes of Transport:

Vessel, cargo or passenger-carrying aircraft, motor vehicle, rail freight, and rail express.

\section{REFERENCE}

1. Division of Waste Management and Transportation, Directory of Packagings for Transportation of Radioactive Materials, WASH-1279, United States Atomic Energy Commission, Washington, DC, 1973. 
APPENDIX B

\section{PHYSICAL AND CHEMICAL PROPERTIES OF PLUTONIUM DIOXIDE}

This appendix presents a brief summary of the $\mathrm{PuO}_{2}$ properties pertinent to the present study. The truck shipment risk report $(1)$ and the references sited in this appendix can be consulted for further details.

Plutonium dioxide may be prepared in many ways. It is normally a buff powder, but its color and particle size is a function of the method of preparation. Its desirable properties include high melting point, irradiation stability, compatibility with metals, and ease of preparation. A listing of some of the physical characteristics of plutonium dioxide is given in Table B. 1 .

TABLE B.1. Selected Surnmary of $\mathrm{PuO}_{2}$ Properties (3)

$\begin{array}{ll}\text { Theoretical Density }\left(\mathrm{g} / \mathrm{cm}^{3}\right) & 11.45 \\ \text { Melting Point } & 2400 \pm 30^{\circ} \mathrm{C} \\ \text { Coefficient of Linear Thermal Expansion } & 10.9 \times 10^{-6} \\ \quad\left({ }^{\circ} \mathrm{C}^{-1} \text {, Range } 25^{\circ} \text { to } 1000^{\circ} \mathrm{C}\right) & \\ \text { Thermal Conductivity } & 0.023 \text { at } 1000^{\circ} \mathrm{C} \\ \quad\left(W / \mathrm{cm}-{ }^{\circ} \mathrm{C}, \text { at } 95 \% \mathrm{TD}\right) & \\ \text { Resistance to Thermal Shock } & \text { Fairly Good }\end{array}$

Plutonium dioxide is practically insoluble in water and dilute acids, but is difficultly soluble in some concentrated acids. The best solvents are 12 to 16 normal (N) $\mathrm{HNO}_{3}$ with 0.01 to $0.1 \underline{\mathrm{N}} \mathrm{HF}, 5$ to $6 \underline{\mathrm{N}} \mathrm{HI}$, and $9 \underline{\mathrm{N}} \mathrm{HBr}$. Increasing acidity generally increases the rate of dissolution. The dioxide calcined at temperatures below $275^{\circ} \mathrm{C}$ is soluble in hydrochloric acid. Concentrated sulfuric acid will dissolve dioxide calcined at temperatures up to $600^{\circ} \mathrm{C}$. (5) Refluxing is necessary in all cases, and dissolution is very slow, generally requiring at least several hours to dissolve small samples. (4) 
If exposed to humid air, calcined plutonium dioxide powder will adsorb moisture. The powder eventually saturates about 1 to $2 \mathrm{wt} \%$ water.

Study of the size of plutonium dioxide particles reveals that it is an extremely fine powder. Some distributions of particle size are shown in Figure B.1. (6) Many of the particles are small enough to become airborne and be inhaled. (7)

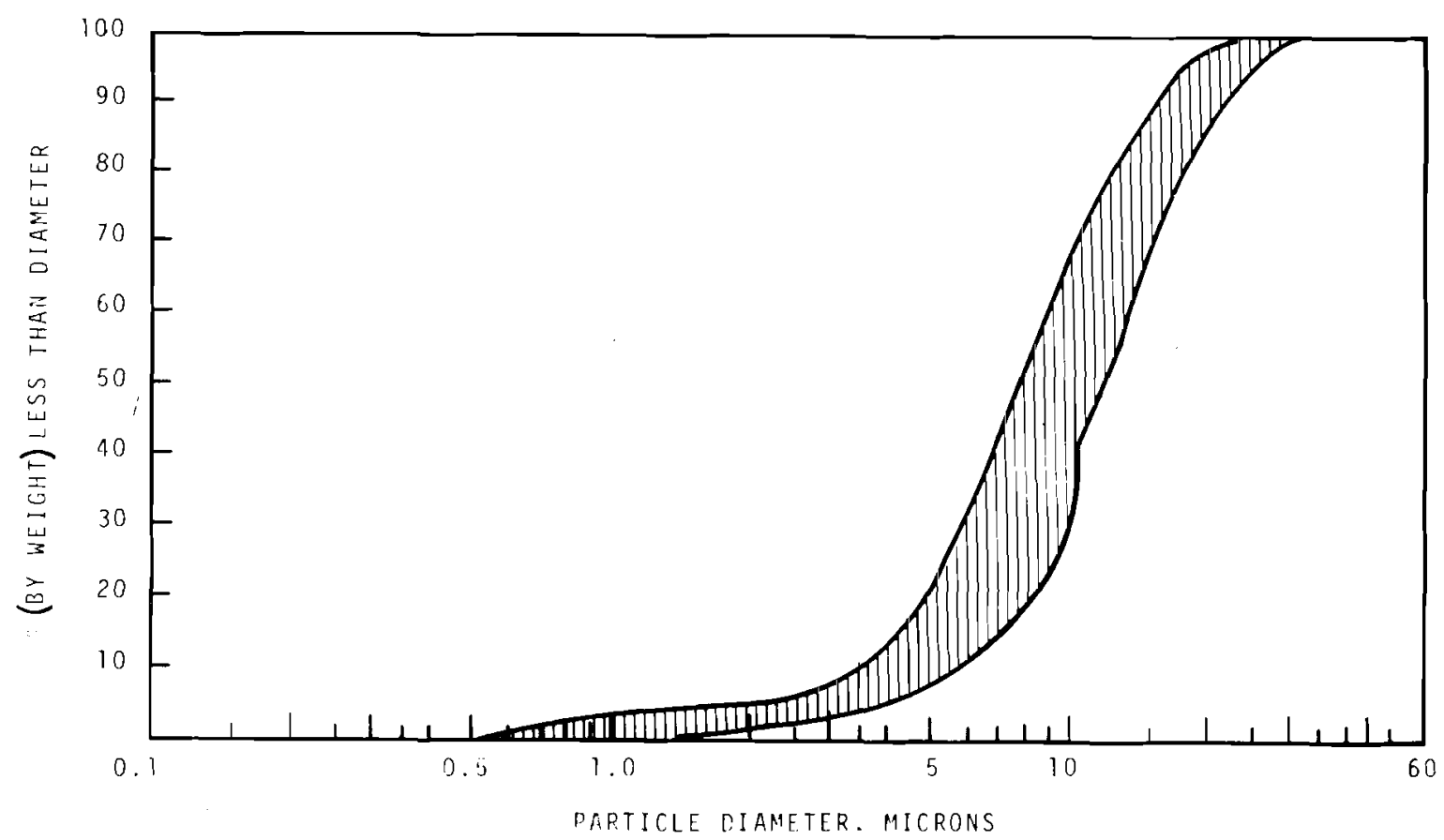

FIGURE B.1 Plutonium Dioxide Particle Size Distribution Formed by Calcination of Plutonium 0xalate( 6 )

REFERENCES

1. T. I. McSweeney, R. J. Hall et al., An Assessment of the Risk of Transporting Plutonium Oxide and Liquid Plutonium Nitrate by Truck, BNWL-1846, Battelle, Pacific Northwest Laboratories, Richland, WA, August 1975.

2. B. R. Fish, G. W. Keilholtz, W. S. Snyder and S. D. Swisher, Calculation of Doses Due to Accidentally Released Plutonium from an LMFBR, ORNL-NSIC-74, November 1972. 
3. B. F. Rubin, Comp., Summary of $(U, P u) 0_{2}$ Properties and Fabrication Methods, GEAP-13582, November 1970.

4. J. D. Moseley and R. 0. Wing, Properties of Plutonium Dioxide, RFP-503, August 1965.

5. 0. J. Wick, Ed., Plutonium Handbook, A Guide to the Technology, Gordon and Breach, 1967.

6. C. S. Caldwe11, "Relationship Between Process Variables and Final Properties of $\mathrm{UO}_{2}, \mathrm{UO}_{2}-\mathrm{PuO}_{2}$, and $\mathrm{PuO}_{2}$," Meeting on Characterization of Uranium Dioxide Held at Oak Ridge National Laboratory, December 12-13, 1961, TID-7637, pp. 249-271.

7. J. Mishima, L. C. Schwendiman and C. A. Radash, Plutonium Release Studies III. Release from Heated Plutonium Bearing Powders, BNWL-786, Battelle, Pacific Northwest Laboratories, Richland, WA, Ju1y 1968. 
APPENDIX C

\section{MECHANICAL ANALYSIS OF THE 6M CONTAINER}

The 6M container will withstand, without failure, the hypothetical accident conditions specified in 10CFR71. These hypothetical, conditions involve: (1) a free drop onto a flat essentially unyielding surface from a height of $30 \mathrm{ft}$, (2) a free drop through $40 \mathrm{in}$. onto the top end of a 6-in. diameter cylindrical mild steel bar, (3) exposure to a thermal radiation environment of $1475^{\circ} \mathrm{F}$ for $30 \mathrm{~min}$, and (4) immersion in $3 \mathrm{ft}$ of water for $8 \mathrm{hr}$. The qualification tests demonstrate that the container can withstand the simulated accident conditions, but yield no information regarding failure points. Tests that exceed the qualification tests for a 1 imited range of container orientations and other test parameters have been performed by Sandia Laboratories and others. $(1,2,3,4,5)$ The analytical results presented herein have been compared with the test data available and found to be in general agreement.

Several analytical approaches are available to determine failure thresholds of the 6M container, including: (1) force-displacement methods outlined in the Cask Designer's Guide, ${ }^{(6)}$ (2) finite element analysis using computer codes, and (3) mass-spring models. The use of the more precise, but expensive, computer analysis methods was considered inappropriate for the purposes of the present study. The general analytical approach used in this appendix is the force-displacement method based on linearelastic structural behavior. This approach is considered sufficiently accurate as to not control the risk assessment uncertainties.

This appendix presents the mechanical analyses used in the determination of the failure drop heights shown in Table 6.1, Section 6 of this report. Failure of the outer container by impact or crush forces is assumed to occur when the perimeter of the lid in the deformed state becomes smaller than the undeformed inside circumference of the clamp ring. The analysis is based on elastic deformation of the outer container and should 
be conservative because significant energy would be dissipated in localized buckling or plastic deformation. However, local buckling or oblique angles of impact could lead to other undefined mechanisms of failure.

6M Container Analysis

Case 1: Determine the drop height which results in rupture of the outer container (side drop).

Specification of 6M Container:

Weight $(\operatorname{tota} 1)=1601 \mathrm{~b}$

$O D=15.57$ in. $x 21.25$ in. high (15-gal size)

She11 thickness - 0.0478 in. (18 GA)

Pressure Vessel:

$I D=5-1 / 4$ in. $x 10-1 / 2$ in. high

Wall thickness $=1 / 4$ in.

Dynamic Flow Stress:

$$
\begin{aligned}
& \text { She11: } \sigma_{S}=50,000 \mathrm{psi}{ }^{(6)} \\
& \text { Celotex: } \sigma_{C}=100 \mathrm{psi} \text { (assumed). }
\end{aligned}
$$

It was assumed that the $6 \mathrm{M}$ container was dropped on an unyielding surface. All the energy due to impact would be absorbed by the container. The deformation of the shell versus drop height was calculated using an equation from the "Cask Designer's Guide."

$$
H=\frac{t_{s} R L \sigma_{s}}{w}\left\{\left[F_{1}(\theta)\right]\left[\frac{R}{t_{s}}\left(\sigma_{v} / \sigma_{s}\right)+2(R / L)\left(t_{e} / t_{s}\right)\right]+F_{2}(\theta)\right\}
$$

where:

$$
\begin{aligned}
F_{1}(\theta) & =\theta-\frac{1}{2} \sin 2 \theta \\
F_{2}(\theta) & =\sin \theta(2-\cos \theta)-\theta \\
W & =\text { weight of she11, 1bs }
\end{aligned}
$$




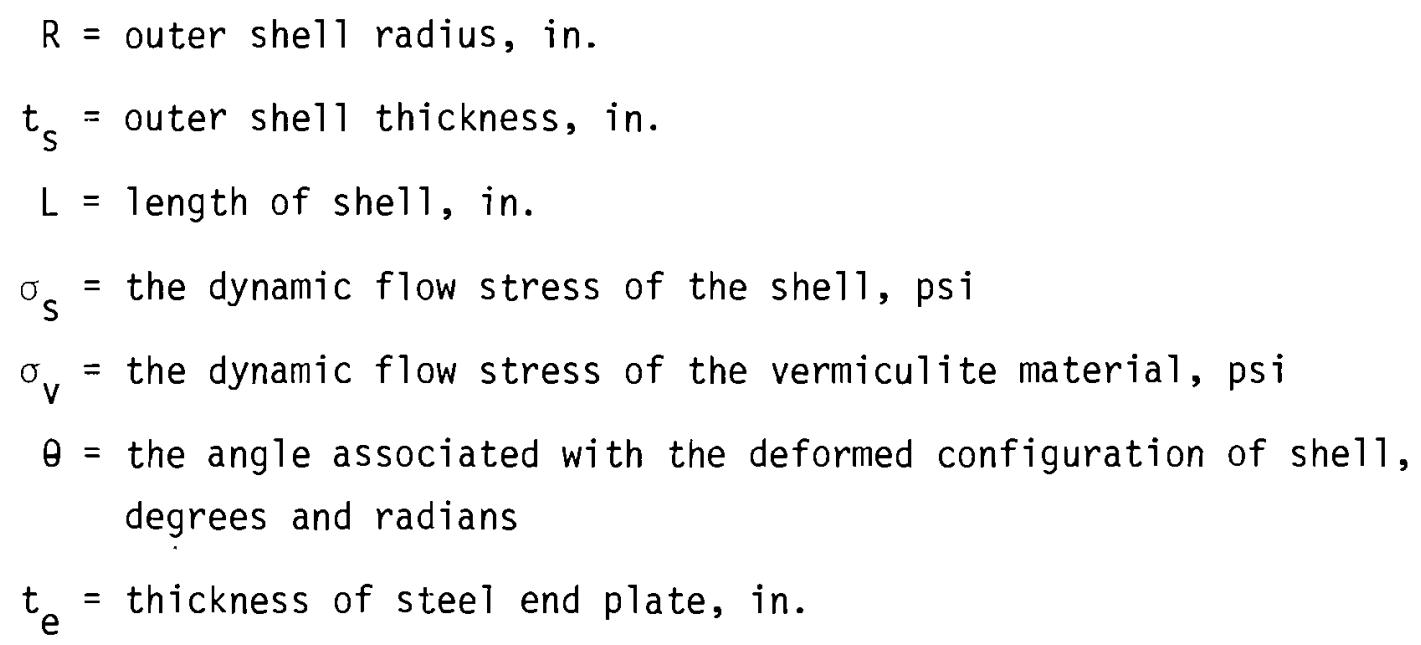

The equation above was originally developed for steel-encased solid lead cylinders. An approximation of deformation in a steel-encased cylinder filled with Celotex ${ }^{R}$ was obtained by assuming a value for dynamic flow stress for Celotex ${ }^{R}$ (100 psi) and substituting for the properties of lead in the equation. The assumed value for dynamic flow stress needs experimental verification.

The deformation of the outer container versus drop height is shown in Figure C.1. The drop height required to pop off the lid of the outer container was found to be $194 \mathrm{ft}$. Again this was based on the assumption that the lid would come off when the perimeter of the lid in the deformed state is smaller than the undeformed inside circumference of the clamp ring. This drop height corresponds to a force of 95,000 $1 \mathrm{~b}$ using the relationship in Equation 1 of Section 6 .

Case 2: Determine the drop height'which would cause rupture of the inner container

It was assumed that the inner $2 R$ vessel would not deform until the outer she11 contacted the inner vessel. The drop height to cause this contact was found to be approximately $260 \mathrm{ft}$. (7)

The deformation versus drop height for an inner vessel is shown in Figure C.2. The point at which rupture would occur due to deformation cannot be defined. The solution may only be found by a physical test. The data used in determining deformation using equation $\mathrm{C}-1$ are: 


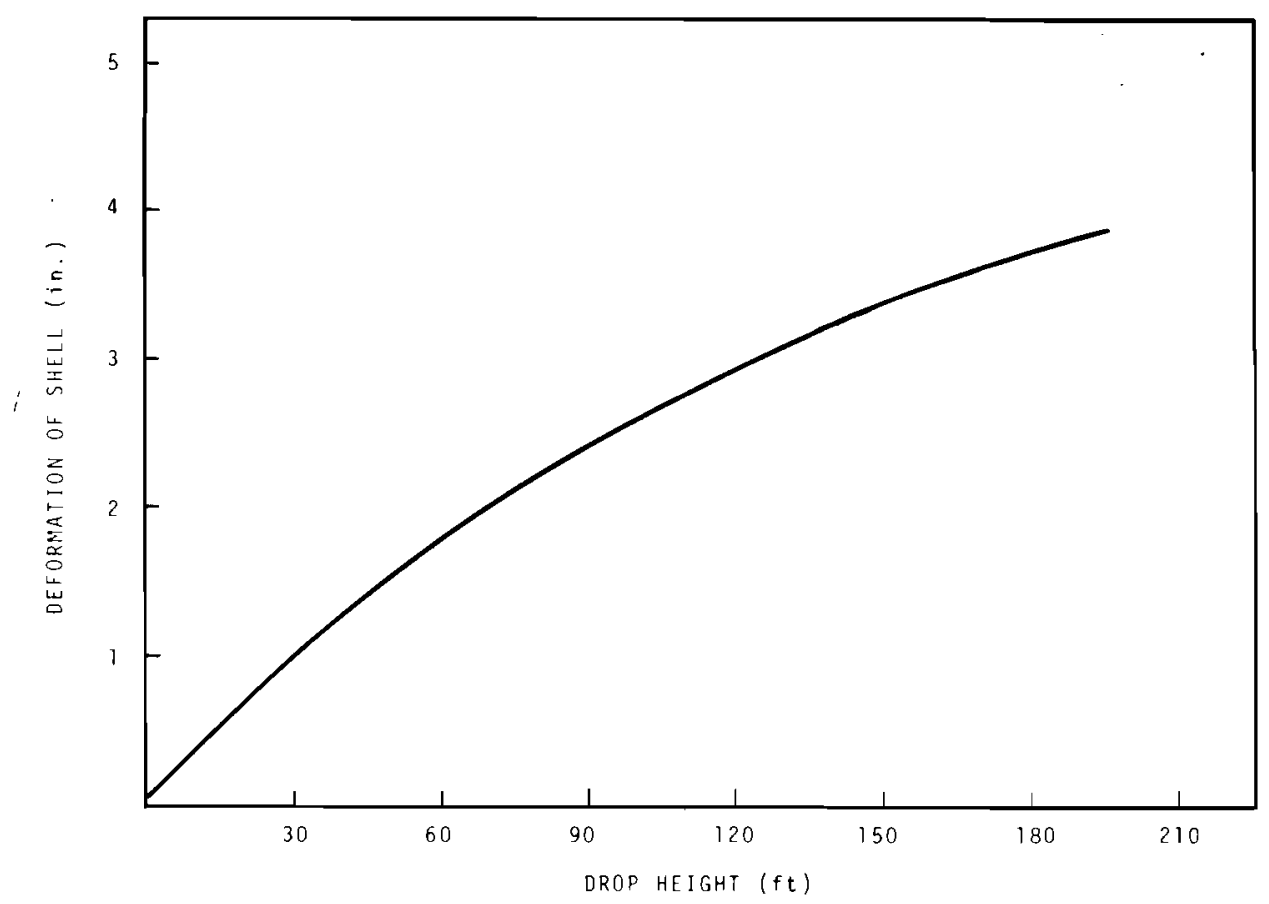

FIGURE C.1. Shell Deformation from Impact Versus Drop Height for the 6M Container

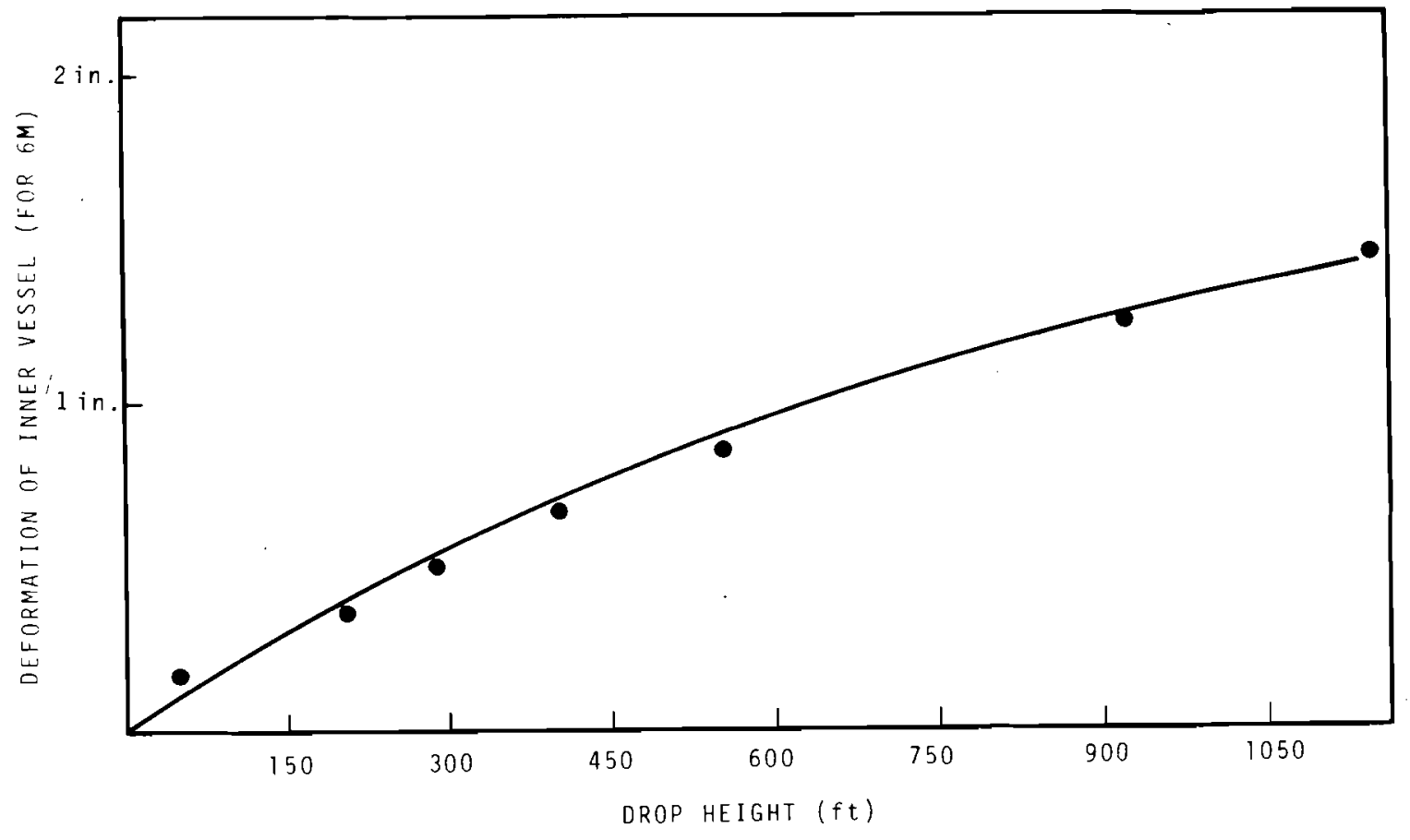

FIGURE C.2 Deformation of Inner Vessel from Impact as a Function of Drop Height - 6M Container

C. 4 


$$
\begin{aligned}
& t_{e}=\text { Thickness of steel end plate }=1 / 2 \mathrm{in} . \\
& t_{e s}=\text { Thickness of screwed end plug }=1.31 \mathrm{in} . \\
& \sigma_{s}=\text { The dynamic flow stress in steel }=50,000 \mathrm{ps} i \\
& t_{s}=\text { The outer shell thickness }=0.25 \mathrm{in} . \\
& R=\text { The outer shell radius }=2.875 \mathrm{in} . \\
& L=\text { The length of shell }=10.5 \mathrm{in} .
\end{aligned}
$$

It was also assumed that the contents of the inner pressure vessel were compressible.

Additional calculations regarding the puncture of the $6 \mathrm{M}$ container in a side drop onto a 6-in. diam pin were made in Reference 7 using the equation: (8)

where:

$$
H=\frac{39(S) t^{1.4}}{\bar{W}^{(a)}}
$$

$$
\begin{aligned}
& H=\text { drop height, in. } \\
& S=\text { ultimate tensile stress of container, psi } \\
& t=\text { thickness of container, in. } \\
& \bar{W}=\text { weight of container, } 1 \mathrm{~b} .
\end{aligned}
$$

The drop height required to puncture the outer container was found to be $133 \mathrm{in}$. The inner container will fail due to bending at a drop height of $37 \mathrm{in}$. The total drop height required to rupture both the outer and inner containers is $170 \mathrm{in.}$. It is interesting to note that in a controlled drop test carried out by Sandia, (1) a $6 \mathrm{M}$ container was side dropped onto a 6-in. diam pin from a height of 119 in. without puncturing the outer container. The results of this test tend to verify these calculations.

\section{(a) For containers less than $30 \mathrm{in}$. diameter (e.g. the $L-10$ container) $\bar{W}$ in Equation $\mathrm{C}-2$ should be increased by a factor of 1.3. (8) \\ REFERENCES}

1. L. F. Stravasnik, Special Tests for Plutonium Shipping Containers 6M, SP5795, and L-10, AEC R\&D Report TID-4500, Sandia Report SC-DR-72 0587, September 1972. 
2. M. C. Jurgensen, The Vermiculite Shipping Package: Drop Tests on the Closure, ORNL-TM-1312, Vol. 15, January 1975.

3. 0. A. Kelly and C.W. C. Stoddart, "Highway Vehicle Impact Studies: Tests and Mathematical Analyses of Vehicle, Package and Tiedown Systems Capable of Carrying Radioactive Materials," ORNL-NSIC-61, Nuclear Safety Information System, Oak Ridge National Laboratory, Oak Ridge, TN, 1970.

4. J. V. Otts, Special Closure for Radioactive Shipping Container, SAND75-0517, Draft of November 1975.

5. M. McWhirter et a1., Final Report on Special Tests of Plutonium Oxide Shipping Containers to FAA Flight Recorder Standards, SAND75-0446, September 1975.

6. L. B. Shappert, A Guide for the Design, Fabrication, and Operation of Shipping Casks for Nuclear Applications, ORNL-NSIC-68, February 1970.

7. T. I. McSweeney, R. J. Hall et al., An Assessment of the Risk of Transporting Plutonium Oxide and Liguid Plutonium Nitrate by Truck, BNWL-1846, Batte1le, Pacific Northwest Laboratories, Richland, WA, August 1975.

8. H. A. Nelms, Structural Analysis of Shipping Casks, Vol. 3, Effects of Jacket Physical Properties and Curvature on Puncture Resistance, ORNL-TM-1312, Vol. 3, June 1968. 


\section{Distribution}

No. of

Copies

\section{OFFSITE}
A. A. Churm
ERDA Chicago Patent Group
Chicago Operations Office
9800 South Cass Avenue
Argonne, IL 60439

160

ERDA Technical Information Center

K. A. Trickett

ERDA Division of Reactor Development and Demonstration

USERDA Headquarters

Germantown, MD 20014

25 W. Brobst

ERDA Division of Environmental Control Technology

Transportation Branch

USERDA Headquarters

Washington, DC 20545

J. Counts

ERDA Division of Environmenta1

Control Technology

Transportation Branch

USERDA Headquarters

Washington, DC 20545

M. Chais

ERDA Division of Environmental Control Technology

Transportation Branch

USERDA Headquarters

Washington, DC 20545

W. S. Holman

ERDA Division of Environmenta 1 Control Technology

Transportation Branch

USERDA Headquarters

Washington, DC 20545
No. of

Copies

J. A. Sisler

ERDA Division of Environmental

Control Technology

Tranportation Branch

USERDA Headquarters

Washington, DC 20545

R. M. Moser

ERDA Chicago Operations Office 9800 South Cass Avenue

Argonne, IL 60439

W. G. O'Quinn

ERDA Savannah River Operations Office

P.0. Box A

Aiken, SC 29801

N. Stetson

ERDA Savannah River Operations Office

P.0. Box A

Aiken, SC 29801

L. L. Turner

ERDA Savannah River Operations Office

P.0. Box A

Aiken, SC 29801

D. Davis

ERDA Albuquerque Operations Office P.0. Box 5400

Albuquerque, NM 87115

J. A. Lamb

ERDA Oak Ridge Operations

Office

P.0. Box E

Oak Ridge, TN 37830

J. J. Schreiber

ERDA 0ak Ridge 0perations

Office

P.0. Box E

Oak Ridge, TN 37830 
No. of

Copies

J. C. Sherwin

Environmental and Safety Division ERDA - San Francisco Operations Office

1333 Broadway

0akland, CA 94612

J. H. Blaes

ERDA - Idaho Operations office

550 Second Street

Idaho Falls, ID 83401

A. T. Neumann

ERDA - Nevada Operations

Office

P. 0. Box 14100

Las Vegas, NV 89114

R. C. Dove

University of California

Los Alamos Scientific Laboratory

P. 0. Box 1663

Los Alamos, NM 87545

T. K. Keenan

University of California

Los Alamos Scientific Laboratory

P. 0. Box 1663

Los Alamos, NM 87545

T. A. Butler

University of California

Los Alamos Scientific Laboratory

P. 0. Box 1663

Los Alamos, NM 87545

W. C. Bright

ERDA Abuquerque Operations Office

Rocky Flats Area Office

P. 0. Box 928

Golden, CO 80401

L. Benner

Nationa 1 Transportation

Safety Board

Washington, DC 20594
No. of

Copies

A. L. Schmieg

National Transportation

Safety Board

Washington, DC 20594

J. Power

Westinghouse Electric Corp.

P.0. Box 355

Pittsburgh, PA 15230

P. J. Eicker

Sandia Laboratories, Livermore

Livermore, CA 94550

J. W. Langhaar

E. I. Dupont de Nemours \&

Company

Savannah River Plant

Aiken, SC 29801

J. Curtis

Department of Transportation

Materials Transportation Bureau

2100 Second St. S.W.

Washington, DC 20590

A. Grella

Department of Transportation

Materials Transportation Bureau

2100 Second St. S.W.

Washington, DC 20590

H. Thompson

Department of Transportation

Materials Transportation Bureau

2100 Second St. S.W.

Washington, DC 20590

W. Rowe

Environmental Protection Agency

401 M. Street

Washington, DC 20460

A. J. Nertney

Aerojet Nuclear Company

550 2nd St.

Idaho Falls, ID 83401 
No. of

Copies

R. G. Bradley

ERDA Division of Nuclear Fuel

Cycle and Production

USERDA Headquarters

Germantown, MD 20014

C. Starr

Electrical Power Research Inst.

P. 0. Box 10412

Palo Alto, CA 94304

C. Comar

Electrical Power Research Inst.

P.0. Box 10412

Palo Alto, CA 94304

E. Zebrowski

Electrical Power Research Inst.

P.0. Box 10412

Palo Al to, CA 94304

R. Williams

Electrical Power Research Inst.

P. 0. Box 10412

Palo Alto, CA 94304

Combustion Engineering, Inc .

Windsor, CT 06095

J. Desmond

Babcock \& Wilcox, Co.

P.0. Box 1260

Lynchburg, VA 24505

C. Woods

Babcock \& Wilcox Co.

P.0. Box 1260

Lynchburg, VA 24505

Prof. Norman C. Rasmussen

Massachusetts Institute of

Technology

Cambridge, MA 02139

L. Bonzon

Sandia Laboratories

P. 0. Box 5800

Albuquerque, NM 87115
No. of

Copies

J. K. Cole

Sandia Laboratories

P. 0. Box 5800

A7buquerque, NM 87115

J. T. Foley

Sandia Laboratories

P. 0. Box 5800

Albuquerque, NM 87115

J. Freedman

Sandia Laboratories

P. 0. Box 5800

Albuquerque, NM 87115

W. F. Hartmann

Sandia Laboratories

P. 0. Box 5800

Albuquerque, NM 87115

R. M. Jefferson

Sandia Laboratories

P. 0. Box 5800

Albuquerque, NM 97115

R. Luna

Sandia Laboratories

P. 0. Box 5800

A1buquerque, NM 87115

T. G. Priddy

Sandia Laboratories

P. 0. Box 5800

A1buquerque, NM 87115

A. W. Snyder

Sandia Laboratories

P. 0. Box 5800

A1buquerque, NM 87115

R. Yoshimura

Sandia Laboratories

P. 0. Box 5800

A1buquerque, NM 87115

R. F. Barker

Nuclear Regulatory Commission

Washington, DC 20555 
No. of

Copies

C. B. Bartlett

Nuclear Regulatory Commission

Washington, DC 20555

S. H. Hanauer

Nuclear Regulatory Commission

Washington, DC 20555

S. Levine

Nuclear Regulatory Commission

Washington, DC 20555

R. B. Minogue

Nuclear Regulatory Commission

Washington, DC 20555

C. McDonald

Nuclear Regulatory Commission

Washington, DC 20555

W. E. Vesely

Nuclear Regulatory Commission

Washington, DC 20555

\section{Wa 11}

Nuclear Regulatory Commission

Washington, DC 20555

M. J. Steindler

Argonne National Laboratory

9700 South Cass Avenue

Argonne, IL 60439

S. J. Basham

Battelle Memorial Insititute

Columbus Operations

505 King Avenue

Columbus, $\mathrm{OH} 43201$

E. C. Lusk

Battelle Memorial Institute

Columbus Operations

505 King Avenue

Columbus, $\mathrm{OH} 43201$
No. of

Copies

E. E. Rice

Battelle Memorial Institute

Columbus Operations

505 King Avenue

Columbus, $\mathrm{OH} 43201$

R. A. Robinson

Battelle Memorial Institute

Columbus Operations

505 King Avenue

Columbus, $\mathrm{OH} 43201$

Atomics International

8900 DeSoto Avenue

Conoga Park, CA 91304

A. L. Kaplan

General Electric Co.

Nuclear Fuel Division

P. 0. Box 780

Wilmington, NC 28401

G. Lapier

Babcock \& Wilcox Co.

Apol10, PA 15613

D. Pence

General Atomic

P. 0. Box 92138

San Diego, CA 92138

R. D. Seagren

Union Carbide Corporation

Oak Ridge National Laboratories

P. 0. Box $X$

Oak Ridge, TN 37830

L. Shappert

Union Carbide Corporation

Oak Ridge Nationa1 Laboratories P. 0. Box $X$

Oak Ridge, TN 37830

J. Duckworth

Nuclear Fuel Service, Inc.

P. 0. Box 124

West Valley, NY 14171 
No. of

Copies

G. L Stukenbroeker

$\mathrm{N}$ L Industries, Inc.

Nuclear Transportation Dept.

919 Market St., Suite 1701

Wilmington, DE 19801

H. G. Shealy

Bureau of Radiological Health

South Carolina Department of

Health and Environmental

Control

Columbia, SC 29405

J. S. Corbett

ChemNuclear Systems, Inc.

P. 0. Box 1866

Bellevue, WA 98009

J. A. Hebert

Battelle Seattle Research

Center

P.0. Box 5395

Seattle, WA 98105

P. T. Tuite

Hittman Nuclear and Development Corporation

9190 Red Branch Rd.

Columbia, MD 21045

D. A. Edling

Mound Laboratories

P. 0. Box 32

Miamisburg, OH 45342

J. W. Doty

Mound Laboratories

P. 0. Box 32

Miamisburg, $\mathrm{OH} 45342$

D. Okrent

Department of Engineering and Applied Science

University of California

Los Angeles, CA 90024
No. of

Copies

2 L. Forrest

California Energy Resources

Conservation and Development Commission

1111 Howe Avenue

Sacramento, CA 95825

M. Gordon

Atomic Industrial Forum

7101 Wisconsin Ave.

Washington, DC 20014

A. L. Babb

Department of Nuclear Engineering

Benson Hall

University of Washington

Seattle, WA 98195

W. S. Fellows

Southern Interstate Nuclear Board

7 Dunwoody Park, Suite 104

Atlanta, GA 30341

D. G. Maxwell

N. L. Industries

Nuclear Division

111 Broadway

New York, NY 10006

W. R. Teer

Transnuclear Inc.

One N. Broadway

White Plains, NY 10601

S. Hartwig

Battelle Institute, e.v.

Am Romerhof 35

600 Frankfurt Main 90

GERMANY

M. Stammler

Battelle Institute, e.v.

Am Romerhof 35

600 Frankfurt Main 90

GERMANY 
No. of

Copies

R. S. Lowrie

Union Carbide Corporation

Office of Waste Isolation

P. 0. Box $Y$

Oak Ridge, TN 37830

D. Turner

Union Carbide Corporation

Office of Waste Isolation

P. 0. Box Y

Oak Ridge, TN 37830

S. C. Cohn

Teknekron

4701 Sangamore Rd.

Washington, DC 20016

I. N. Lafontaine

Belgonucleaire

Rue de Champ de Mars 25

B-1050 Bruxelles

BELGIUM

K. R. Shultz

Atomic Energy Control Board

P.0.B. 1046

Ottawa KIP $5 S 9$

CANADA

W. R. Taylor

Atomic Energy of Canada Ltd. Chalk River Laboratories

Chalk River, Ontario KOJIJo

CANADA

Y. Sousselier

CEA/CEN

B.P. No. 6

F-92260 Fontenay-aux-Roses

FRANCE

\section{H. Hubner}

Bundesansta1t für Materialprufung

Unter den Eichen 87

D-1000 Berlin 45 (West)

GERMANY, FED. REPUBLIC
No. of

Copies

B. Schulz-Forberg

Bundesanstalt für Materialprufung

Unter den Eichen 87

D-1000 Berlin 45 (West)

GERMANY, FED. REPUBLIC

R. G. Deshpande

Isotope Division

Bhabha Atomic Research Centre Trombay, Bombay 400085

INDIA

\section{S. Aoki}

Research Laboratory for Nuclear Reactors

Tokyo Institue of Technology

Ookayama, Meguroku, Tokyo 152 JAPAN

G. D. Bel1

United Kingdom Atomic Energy Authority

Safety and Reliability

Directorate

Warrington WA3 4NE

UNITED KINGDOM

A. Onedera

Hitachi Shipbuilding and Engineering Co., Ltd.

5-4 Sakurajima, Kitano-cho

Konohana-ku, Osaka-shi

JAPAN

K. I keda

Science and Technology Agency

2-2-1 Kasumigaseki,

Chi yoda-ku, Tokyo

JAPAN

M. Tom 1 inson

White Shell Nuclear Research

Establishment

Pinewa, Manitoba ROE ILO

CANADA 
No. of

Copies

S. A. Mayman

Fuel Recycle Waste

Management Program

Whiteshel1 Nuclear Research

Establishment

Pinewa, Manitoba ROE ILO

CANADA

Dr. F. Girardi

Euratom

21020 Centro Euratomdi

Ispra (Varesse)

ITALY

Ake Hultgren

$A B$ Atomenergi, Studsvik

Fack

S-611 o1 Nyköping 1

SWEDEN

B. Gustafson

C/o Ake Hultgren

$A B$ Atomenergi, Studsvik

Fack

S-611 ol Nyköping 1

SWEDEN

Dr. Schmidt-Kuester

Beim Bundesminister für

Forschung and Technologie

Stresemannstrasse 2

5300 Bonn

GERMANY

W. J. Shelley

Kerr-McGee Corporation

Oklahoma City, OK

R. W. Peterson

Allied General Nuclear Services

P. 0. Box 847

Barnwel1, SC 29812

A. Carson

Genera1 Electric Company

175 Curtner Avenue

San Jose, CA 95125
No. of

Copies

R. A. Koynenburg

University of California

Lawrence Livermore Laboratories

P. 0. Box 808

Livermore, CA 94551

W. E. Pollock

Oregon Department of Energy

Salem, OR 97301

K. Woods

Oregon Department of Energy

Salem, OR 97301

W. M. Rogers

Western Interstate Nuclear Board

1300 Carr

Denver, CO 80226

G. P. Jones

University of Southern

California

University Park

Los Angeles, CA 90007

L. L. Philipson

University of Southern

Cal ifornia

University Park

Los Angeles, CA 90007

C. V. Hodges

Holmes \& Narver

400 E. Orangethrope Ave.

Anaheim, CA 92801

E. A. Straker

Science Applications, Inc.

P. 0. Box 2351

La Jolla, CA 92038

R. C. Erdman

Science Applications, Inc.

2680 Hanover St.

Palo Alto, CA 94304 
No. of

Copies

G. Waymire

Exxon Nuclear Company, Inc.

P. 0. Box 3990

MS 8A-68

Seattle, WA 98124

\section{ONSITE}

1 ERDA Richland Operations Office Programs Division

H. E. Ranson

6 ERDA Richland Operations Office

T. A. Bauman

W. A. Burns

R. B. Goranson

P. E. Lamont

J. M. Peterson

D. J. Squires

3 Atlantic Richfield Hanford Company

W. G. Bevan

W. M. Harty

D. D. Woodrich

3 United Nuclear Industries, Inc.

J. A. Adams

P. A. Crosett $i$

T. E. Dabrowski

2 Washington Public Power Supply System

G. F. Bailey

J. B. Vetrano
No. of

Copies

2 Exxon Nuclear Company, Inc.

R. Nilsen

R. K. Robinson

Hanford Engineering Development Laboratory

A. W. DeMerschman

Battelle-Northwest

W. B. Andrews

W. J. Bair

C. L. Brown

S. H. Bush

N. E. Carter

J. G. DeSteese

H. K. Elder

R. J. Hall

H. Harty

S. W. Heaber 1 in

H. L. Henry

J. F. Johnson (25)

W. S. Kelley

S. N. Liu

T. I. McSweeney

J. Mishima

E. S. Murphy

P. L. Peterson

R. E. Rhoads

E. C. Watson

R. D. Widrig

L. D. Williams

W. K. Winegardner

Technical Information (3)

Technical Publications 